RELAÇĀO ENTRE A TEMPERATURA RADIANTE DO DOSSEL VEGETATIVO E CONDIÇÕES AMBIENTAIS E SUA APLICAÇÃO NA DETECÇÃO DE ESTRESSE HÍDRICO DA CULTURA

DO TRIGO (Triticum mestivum L.)

\author{
SERGIO DAL FABBRO \\ Engenheiro Agrônomo
}

Dissertação apresentada à Escola Superior de Agricultura "Luiz de Queiroz", da Universidade de São Paulo, para a obtenção do título de Mestre em Agronomia, Área Concentração : Agrometeorologia

PIRACICABA

Estado de São Paulo - Brasil

Fevereiro de 1995 
Ficha catalogratica preparada fola becado de livgos da

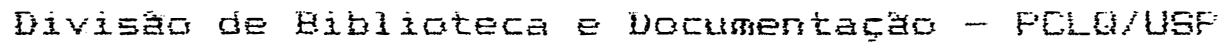

Faboro, Sergio bai

Fiss Feiaça entre a temperatura do dossel veqetativo

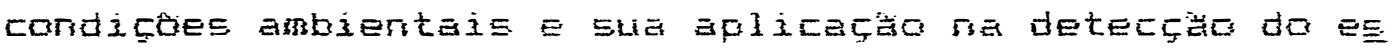
tresse hidrico da cultura do trigo fTriticum aestivu L.). Firacicabas 1995.

i2zF.

Dis5. (Mestre) - ESALE

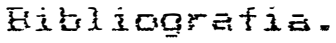

1. Heteorolagia agricala 2 . Felaça temperatura-meio ambiente 3. Sensoriamenta remato A. Trigo - Efeito da temberatura 5 . Trigo - Efeito do estresse hidrice 3. Escola Superior de Agricultura luiz de dueifor. Fi racicata 
RELAÇÃO ENTRE A TEMPERATURA RADIANTE DO DOSSEL VEGETATIVO E CONDIÇÕES AMBIENTAIS E SUA APLICAÇÃO NA DETECÇÃO DE ESTRESSE HÍDRICO DA CULTURA DO TRIGO (Triticum aestivum L.)

\author{
SERGIO DAL FABBRO
}

Orientador : Prof. Dr. Luiz Roberto Angelocci

Dissertação apresentada à Escola Superior de Agricultura "Luiz de Queiroz", da Universidade de São Paulo, para a obtenção do título de Mestre em Agronomia, Área Concentração : Agrometeorologia

PIRACICABA

Estado de São Paulo - Brasil

Fevereiro de 1995 
RELAÇÃO ENTRE A TEMPERATURA RADIANTE DO DOSSEL VEGETATIVO E CONDIÇÕES AMBIENTAIS E SUA APLICAÇÃO NA DETECÇÃO DE ESTRESSE HÍDRICO DA CULTURA DO TRIGO (Triticum aestivum $L$.)

SERGIO DAL FABBRO

Aprovada em : 05.04.1995

Comissão Julgadora :

Prof. Dr. Luiz Roberto Angelocci ESALQ/USP

Prof. Dr. Romísio B. André FCAVJ/UNESP

Prof. Dr. Marcos Folegatti ESALQ/USP

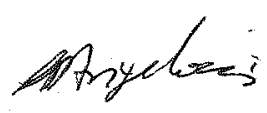

Prof. Dr. Luiz Roberto Angelocci Orientador 


\section{AGRADECIMENTOS}

Ao Prof. Dr. Luiz Roberto Angelocci, pela orientação, amizade e dedicação exemplar com a qual sempre conduz sua carreira de professor universitário e pesquisador científico.

Ao Prof. Dr. Romísio André, pelas sugestões apresentadas e pela prestatividade, amizade pessoal e preocupação constante com o aprimoramento dos trabalhos com os quais se envolve.

Ao Prof. Dr. Marcos Folegatti, pelas sugestões apresentadas e pela qualidade de suas considerações à respeito dos temas que envolvem o presente trabalho.

À ESALQ-USP, principalmente ao Departamento de Física e Meteorologia, pelo acolhimento amistoso e profissional, e pela qualidade na condução do curso de pós-graduação e de sua produção acadêmica.

À todos os funcionários do Depto. de Física e Meteorologia, pela prestatividade e amizade dedicadas ao longo do curso de pós-graduação.

Ao CEPAGRI-UNICAMP, na pessoa do Sr. Prof. Dr. Hilton José da Costa, pelo apoio concedido na implantação do projeto de pesquisa que culminou com o presente trabalho. 
Ao CPQBA-UNICAMP, pelo apoio na instalação e condução do ensaio.

Aos colegas Marcus Liedgens e Paulo Centelhas (IAC) pela amizade e companheirismo demonstrados ao longo do curso de pós-graduação.

Aos pais Maria e Amaury, que tudo fizeram pela formação de seus filhos. 
SUMÁRIO

Página

LISTA DE FIGURAS

RESUMO

xiv

SUMMARY

xvi

1. INTRODUÇÃO

2. REVISÃO DE LITERATURA 3

2.1. Temperatura da Superfície 3

2.2. Temperatura da Superfície, Condições Ambientais e Fisiológicas 11

2.2.1. Balanço de Energia 11

2.2.2. Expressão Analítica de Ts - Ta 15

2.2.3. Índice de Estresse Hídrico e Aplicações 20

3. MATERIAIS E MÉTODOS 28

3.1. MATERIAIS 28

3.1.1. Localização do Ensaio, Solo e Clima 28

3.1.2. Caracterização do Cultivar Utilizado 29

3.1.3. Instalação e Condução do Ensaio 29

3.1.4. Levantamento dos Dados Coletados 31

3.1.4.1. Radiômetro Líquido 31 
3.1.4.2. Piranômetro 31

3.1.4.3. Termômetro de Infravermelho 31

3.1.4.4. Anemômetros 32

3.1.4.5. Conjunto Psicrométrico 32

3.1.4.6. Aquisição de Dados 33

3.1.4.7. Tensiometria 33

3.2. MÉTODOS 34

3.2.1. Tensiometria e Irrigação 34

3.2.2. Caracterização dos Tratamentos 35

3.2.3. Levantamento dos Dados 36

3.2.4. Tratamento dos Dados Coletados 37

3.2.4.1. Temperatura do Dossel 37

3.2.4.2. Umidade do Ar e Déficit de Pressão de Vapor 38

3.2.4.3. Caracterização do Estado Atmosférico 39

3.2.4.4. Parâmetros Aerodinâmicos $\quad 40$

3.2.4.5. Resistência da Cobertura 42

3.2.4.6. Índice de Estresse Hídrico 43

3.2.4.7. Relações Empíricas 44

4. RESULTADOS E DISCUSSÃO 46

4.1. Caracterização dos Tratamentos 46

4.2. Temperatura da Superfície 49

4.3. Condições Micrometeorológicas $\quad 50$

4.3.1. Resistência da Cobertura 50 
4.3.2. Balanço de Energia 62

4.3.3. Índices de Estresse Hídrico 68

$\begin{array}{lr}\text { 4.3.3.1. Relações Empíricas } & 68\end{array}$

$\begin{array}{ll}\text { 5. CONCLUSÕES } & 81\end{array}$

6. REFERÊNCIAS BIBLIOGRÁFICAS $\quad 84$

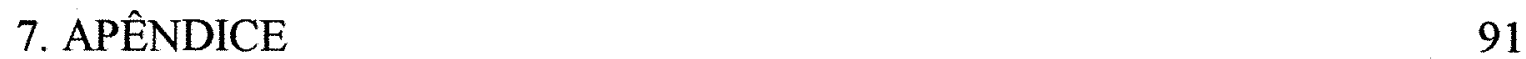


LISTA DE FIGURAS

Página

Figura 1 - Representação hipotética de uma "Linha Básica"

Figura 2 - Variação Horária da Temperatura da Superficie para o Tratamento Irrigado e o Não Irrigado nos dias 27/07 e 29/07 em Trigo

Figura 3 - Variação Horária da Temperatura da Superfície para o Tratamento Irrigado e o Não Irrigado nos dias 06/08 e 07/08 em Trigo

Figura 4 - Variação Horária da Temperatura da Superfície para o Tratamento Irrigado e o Não Irrigado nos dias 11/08 e 13/08 em Trigo

Figura 5 - Variação Horária da Temperatura da Superfície para o Tratamento Irrigado e o Não Irrigado nos dias 18/08 e 22/08 em Trigo

Figura 6 - Comportamento horário da resistência da cobertura (rc) e da resistência aerodinâmica (ra)

Figura 7 - Comportamento horário da resistência da cobertura 
Figura 8 - Comportamento horário da resistência da cobertura (rc) e da resistência aerodinâmica (ra)

Figura 9 - Comportamento horário da resistência da cobertura (rc) e da resistência aerodinâmica (ra)

Figura 10 - Fluxos horários de Saldo de Radiação (Q*), Calor Latente (Qe) e Calor Sensível (Qh)

Figura 11 - Fluxos horários de Saldo de Radiação $\left(Q^{*}\right)$, Calor Latente (Qe) e Calor Sensível (Qh)

Figura 12 - Fluxos horários de Saldo de Radiação (Q*), Calor Latente $(\mathrm{Qe})$ e Calor Sensível $(\mathrm{Qh})$

Figura 13 - Fluxos horários de Saldo de Radiação $\left(Q^{*}\right)$, Calor Latente $(\mathrm{Qe})$ e Calor Sensível (Qh)

Figura 14 - Relação observada entre Ts - Ta e es*(T) - ea para condições de boa disponibilidade hídrica (tratamento irrigado)

Figura 15 - Valores horários do CWSI obtidos no Tratamento Não Irrigado através das duas formas de cálculo, 
Figura 16 - Valores horários do CWSI obtidos no Tratamento Não Irrigado através das duas formas de cálculo, nos dias 11/08 e 18/08

Figura 17 - Valores horários do CWSI obtidos no Tratamento Não Irrigado através das duas formas de cálculo, no dia $22 / 08$

Figura 18 - Evolução dos valores do CWSI a partir do primeiro dia de amostragem

Figura 19 - Evolução dos valores do CWSI a partir do primeiro dia de amostragem

Figura 20 - Evolução dos valores do CWSI a partir do primeiro dia de amostragem

Figura 21 - Comportamento do CSWI em relação à resistência da cobertura e da razão rc/ra 
Tabela 2 - Valores Horários da Resistência da Cobertura ( $\mathrm{s} / \mathrm{m})$ nos vários dias de observação, nos tratamentos irrigado e não irrigado em Trigo.

Tabela 3 - Valores diários da Evapotranspiração de Referência (Eto), Evapotranspiração Máxima (ETM), Precipitações, Irrigações, do Potencial da Água do Solo, no Tratamento Irrigado.

Tabela 4 - Valores diários da Evapotranspiração de Referência (Eto), Evapotranspiração Máxima (ETM), Precipitações, Irrigações, do Potencial da Água do Solo, no Tratamento Não Irrigado.

Tabela 5 - Valores das Temperaturas Horárias do Dossel $\left({ }^{\circ} \mathrm{C}\right)$ no dia $27 / 07$

Tabela 6 - Valores das Temperaturas dos Bulbos Úmido e Sêco $\left({ }^{\circ} \mathrm{C}\right)$, Pressões Parciais (ea) e de Saturação do Vapor $(\mathrm{es}(\mathrm{T}))$ - kPa, da Radiação Líquida $\left(\mathrm{Q}^{*}\right)$ e 
das Velocidades do Vento (V)-m/s, obtidos no dia 27/07 - Lado Irrigado

Tabela 7 - Valores Horários dos Parâmetros : Ri, u*, ra, rc, Qh,

Qe e CWSI, obtidos no dia 27/07 - Tratamento Irrigado

Tabela 8 - Valores das Temperaturas Horárias do Dossel $\left({ }^{\circ} \mathrm{C}\right)$ no dia $29 / 07$

Tabela 9 - Valores das Temperaturas dos Bulbos Úmido e Sêco $\left({ }^{\circ} \mathrm{C}\right)$, Pressões Parciais (ea) e de Saturação do Vapor (es(T)) - kPa, da Radiação Líquida $\left(\mathrm{Q}^{*}\right)$ e das Velocidades do Vento (V)-m/s, obtidos no dia 29/07 - Lado Não Irrigado

Tabela 10 - Valores Horários dos Parâmetros : Ri, u*, ra, rc, Qe, LE e CWSI, obtidos no dia 27/07 - Tratamento não Irrigado

Tabela 11 - Valores das Temperaturas Horárias do Dossel $\left({ }^{\circ} \mathrm{C}\right)$ no dia $06 / 08$

Tabela 12 - Valores das Temperaturas dos Bulbos Úmido e Sêco $\left({ }^{\circ} \mathrm{C}\right)$, Pressões Parciais (ea) e de Saturação do Vapor $(\mathrm{es}(\mathrm{T}))$ - kPa, da Radiação Líquida $\left(\mathrm{Q}^{*}\right)$ e 
das Velocidades do Vento (V)-m/s, obtidos no dia 06/08 - Lado Irrigado

Tabela 13 - Valores Horários dos Parâmetros : Ri, u*, ra, rc, Qh, Qe e CWSI, obtidos no dia 06/08 - Tratamento Irrigado

Tabela 14 - Valores das Temperaturas Horárias do Dossel $\left({ }^{\circ} \mathrm{C}\right)$ no dia $07 / 08$

Tabela 15 - Valores das Temperaturas dos Bulbos Úmido e Sêco $\left({ }^{\circ} \mathrm{C}\right)$, Pressões Parciais (ea) e de Saturação do Vapor (es(T)) - kPa, da Radiação Líquida $\left(Q^{*}\right)$ e das Velocidades do Vento (V)-m/s, obtidos no dia 07/08 - Lado Não Irrigado

Tabela 16 - Valores Horários dos Parâmetros : Ri, u*, ra, rc, Qh, Qe e CWSI, obtidos no dia 07/08 - Tratamento não Irrigado

Tabela 17 -Valores das Temperaturas Horárias do Dossel $\left({ }^{\circ} \mathrm{C}\right)$ no dia $11 / 08$

Tabela 18 - Valores das Temperaturas dos Bulbos Úmido e Sêco $\left({ }^{\circ} \mathrm{C}\right)$, Pressões Parciais (ea) e de Saturação do Vapor (es(T)) - kPa, da Radiação Líquida $\left(\mathrm{Q}^{*}\right)$ e 
das Velocidades do Vento (V)-m/s, obtidos no dia 11/08 - Lado Não Irrigado

Tabela 19 - Valores Horários dos Parâmetros : Ri, u*, ra, rc, Qe, Qe e CWSI, obtidos no dia 11/08 - Tratamento não Irrigado

Tabela 20 -Valores das Temperaturas Horárias do Dossel $\left({ }^{\circ} \mathrm{C}\right)$ no dia $13 / 08$

Tabela 21 - Valores das Temperaturas dos Bulbos Úmido e Sêco $\left({ }^{\circ} \mathrm{C}\right)$, Pressões Parciais (ea) e de Saturação do Vapor $(\mathrm{es}(\mathrm{T}))$ - kPa, da Radiação Líquida $\left(\mathrm{Q}^{*}\right)$ e das Velocidades do Vento (V)-m/s, obtidos no dia 13/08 - Lado Irrigado

Tabela 22 - Valores Horários dos Parâmetros : Ri, u*, ra, rc, Qh, Qe e CWSI, obtidos no dia 13/08 - Tratamento Irrigado.

Tabela 23 -Valores das Temperaturas Horárias do Dossel $\left({ }^{\circ} \mathrm{C}\right)$ no dia $18 / 08$

Tabela 24 - Valores das Temperaturas dos Bulbos Úmido e Sêco $\left({ }^{\circ} \mathrm{C}\right)$, Pressões Parciais (ea) e de Saturação do Vapor (es(T)) - kPa, da Radiação Líquida $\left(Q^{*}\right)$ e 
xiii.

das Velocidades do Vento (V)-m/s, obtidos no dia 18/08 - Lado Não Irrigado

Tabela 25 - Valores Horários dos Parâmetros : Ri, u*, ra, rc, Qh, Qe e CWSI, obtidos no dia 18/08 - Tratamento não Irrigado.

Tabela 26 -Valores das Temperaturas Horárias do Dossel $\left({ }^{\circ} \mathrm{C}\right)$ no dia $22 / 08$

Tabela 27 - Valores das Temperaturas dos Bulbos Úmido e Sêco $\left({ }^{\circ} \mathrm{C}\right)$, Pressões Parciais (ea) e de Saturação do Vapor $(\mathrm{es}(\mathrm{T}))$ - kPa, da Radiação Líquida $\left(\mathrm{Q}^{*}\right)$ e das Velocidades do Vento (V)-m/s, obtidos no dia 22/08 - Lado Não Irrigado

Tabela 28 - Valores Horários dos Parâmetros : Ri, u*, ra, rc, Qh, Qe e CWSI, obtidos no dia 22/08 - Tratamento Não Irrigado.

Tabela 29 - Valores referentes à diferença $(\mathrm{Ts}-\mathrm{Ta})$ e es*(T) - ea que originaram a equação de regressão para a obtenção do CWSI 


\title{
RELAÇÃO ENTRE A TEMPERATURA RADIANTE DO DOSSEL VEGETATIVO E CONDIÇÕES AMBIENTAIS E SUA APLICAÇÃO NA DETECÇÃO DE ESTRESSE HÍDRICO DA CULTURA DO TRIGO ( Triticum aestivum $L$ )
}

\author{
Autor : Sergio Dal Fabbro \\ Orientador : Prof. Dr. Luiz Roberto Angelocci
}

\section{RESUMO}

O presente trabalho tem por finalidade estudar as relações existentes entre a temperatura radiante do dossel vegetativo da cultura do trigo (Triticum aestivum L.), sob condições distintas de disponibilidade hídrica do solo, e condições microclimáticas. Procurou-se analisar, através de sua determinação, índices propostos na literatura que quantificam o grau de estresse hídrico ao qual a cultura esteve sujeita.

Para tanto foi imposto à cultura duas situações distintas de disponibilidade hídrica : uma com total disponibilidade, sem nenhuma restrição; e outra, onde paulatinamente acentuou-se a deficiência hídrica.

Sob estas condições foram determinadas as distinções ocorridas nos seguintes parâmetros : temperatura do dossel, resistência aerodinâmica, resistência da cobertura, fluxos de calor sensível e latente. Foi determinado um 
índice proposto na literatura, o CWSI, por duas formas distintas : considerando todos os parâmetros do balanço de energia e considerando a reta de regressão determinada que define a relação entre o déficit de pressão de vapor e a diferença entre a temperatura do dossel e a temperatura do ar.

Os resultados indicaram que a temperatura da superfície obtida no tratamento não irrigado foi, na grande maioria dos dias e horas amostradas, superior à obtida no tratamento irrigado.

A resistência da cobertura pôde ser satisfatoriamente determinada, respondendo à condições diversas de disponibilidade hídrica.

Obteve-se boa correlação entre o déficit de pressão de vapor e a diferença entre a temperatura da superficie e a temperatura do ar.

Os fluxos de calor sensível e latente não refletiram o estado hídrico da cultura, no tratamento não irrigado, onde observou-se discrepâncias entre os seus valores.

Os índices estudados relacionaram-se tanto com a resistência da cobertura quanto com a razão entre a resistência da cobertura e a resistência aerodinâmica. Contudo, não expressaram o grau de severidade de estresse hídrico ao qual foi submetido a cultura. 


\title{
RELATIONSHIP BETWEEN CANOPY TEMPERATURE ENVIRONMENTAL CONDITIONS AND WATER STRESS DETETION OF WHEAT ( Triticum aestivum L)
}

\author{
Author : Sergio Dal Fabbro \\ Adviser : Prof. Dr. Luiz Roberto Angelocci
}

\section{SUMMARY}

The aim of this work is to study the relations between the canopy temperature of wheat (Triticum aestivum L.) and environmental conditions. Index that quantify the degree of the water stress were studied and analysed.

Due to this purpose the wheat culture was submitted to two different situations of water availability : one with full availability and other with progressive lack of water.

In those conditions the following parameters were analysed : canopy temperature, aerodinamic resistance, canopy resistance, latent and sensible flux. One index proposed by the literature was determined by two ways : first regarding all of the parameters of heat balance and second taking in consideration the relation between the vapour pressure deficit and the diference of canopy and air temperature. 
From this analysis it may be infered that the temperature of the surface not irrigated was always greater than that irrigated.

The canopy resistance could be well determined according to different conditions of water availability.

It was observed good correlation between vapour pressure deficit and the diference between canopy and air temperature.

It was also observed that latent and sensible heat were not associated with the diferent situation of hidric disposal.

The indexes studied were related with canopy resistance. Therefore they didn't correspond with the level of water stress. 


\section{INTRODUÇÃO}

O cultivo de trigo (Triticum aestivum L.) no Brasil se dá tradicionalmente nos períodos compreendidos entre as estações outono-inverno, ocasião em que se registra, no Estado de São Paulo, baixos índices pluviométricos, por razões macroclimáticas. É esperada pouca disponibilidade hídrica para a cultura nesta época cultivada, por períodos as vezes extensos e coincidentes com os de alta demanda por parte da cultura.

Ainda que cultivares de trigo disponíveis ao agricultor sejam, até certo ponto, pouco afetados por restrições hídricas, tanto no seu desenvolvimento quanto na produção propriamente dita, a prática da irrigação para esta cultura tem sua importância comprovada, principalmente para cultivares desenvolvidos ao seu uso.

Quando se pensa em condições hídricas das culturas, suplementação de água por irrigação em períodos de carência hídrica, ciclo da água na natureza, enfim, na dinâmica da água no continum solo-planta-atmosfera, várias são as metodologias existentes para se determinar tanto sua disponibilidade ou escassez, quanto o seu movimento. Pode-se agrupa-las em categorias : baseadas na análise da condição hídrica do solo e no estudo do movimento da água no mesmo; baseadas no estudo da demanda atmosférica à nível macro e microclimático; 
caracterização do status hídrico da planta através da análise de parâmetros que se referem a esta; ou ainda pela combinação destes métodos entre si.

Nas últimas duas décadas a caracterização das condições hídricas via sensoreamento remoto termal tem tomado grande impulso. Com o desenvolvimento de termômetros de infra-vermelho cada vez mais práticos e precisos, tem-se tornado possível o estudo, à nível de campo, da temperatura radiante do dossel vegetativo e, consequentemente, sua relação com suas condições hídricas.

O conhecimento das relações existentes entre a resposta detectada pelo sensor de infravermelho e o alvo sensoreado, bem como sua quantificação, passa pelo entendimento das influências de parâmetros microclimáticos, de modo a se melhor estabelecer uma relação unívoca entre a resposta térmica emissiva da cultura e suas relações hídricas.

O objetivo deste trabalho é de :

1. Estudar as relações entre a temperatura radiante do dossel vegetativo da cultura do trigo e condições microclimáticas, sob distintas situações de disponibilidade hídrica à cultura do trigo;

2. Estudar o comportamento dos seguintes índices propostos na literatura : CWSI proposto por JACKSON (1982) e CWSI proposto por IDSO et al. (1981). 


\section{REVISÃO DE LITERATURA}

\section{1 - Temperatura da Superfície}

Uma cobertura vegetal pode ser entendida como um sistema exposto à interações diversas com a radiação solar. $\mathrm{O}$ fluxo radiante que atinge a superfície dos elementos que compoem o dossel vegetativo sofre uma série de processos de partição. Parte desta energia é refletida pelo dossel, outra absorvida pelas diversas porções do extrato da vegetação e parte pode, ainda, ser transmitida através destas, atingindo camadas inferiores.

Tais interações, aliadas às perdas de energia pela emissão de calor na forma de ondas longas, são determinantes da porção que efetivamente é utilizada nos processos de aquecimento e evaporação junto à superfície. A energia líquida, restante da energia solar após estas interações é, assim, repartida entre os processos evaporativos (calor latente), de aquecimento do ar (calor sensível), e, ainda, aquecimento do solo.

O resultado final destes processos de transferência de energia determinará a temperatura da planta. As alterações ocorrentes nos parâmetros do balanço de energia, portanto, serão determinantes da temperatura da superfície 
vegetada, visto que estas alterações são consequência da dinâmica de trocas de energia entre a superfície e a camada de ar junto a ela.

A temperatura da superficie pode ser considerada, portanto, como uma resposta às várias influências que determinam a dinâmica das trocas de energia entre a vegetação e $o$ ar adjacente.

Sendo uma resposta à trocas de energia, a temperatura da superfície de um dossel vegetativo pode ser expressa em termos da radiação por ela emitida. Segundo a lei de Stefan-Boltzman, a densidade de fluxo emitido por um corpo qualquer é proporcional à quarta potência da temperatura absoluta de sua superfície :

$\mathbf{R}=\varepsilon \cdot \sigma \cdot \mathbf{T}^{4}$

onde $\mathbf{R}=$ densidade de fluxo emitido; $\sigma=$ constante de Stefan-Boltzman; $\varepsilon=$ emissividade da superfície, $\mathbf{T}=$ temperatura absoluta da superfície do corpo. Conhecendo-se a densidade de fluxo emitido pela superficie do corpo pode-se, portanto, determinar-se a sua temperatura.

Tais medidas tornaram-se possíveis com o desenvolvimento de termômetros de infravermelho, que detectam a energia eletromagnética emitida pelo alvo sensoreado, relacionando-a à sua temperatura, em estudos que datam do início da década de 1960 (JACKSON, 1982). Anteriormente, a determinação da temperatura das folhas componentes do dossel era feita exclusivamente por termômetros comuns, que entram em contacto com o tecido foliar e que, além da folha, também interagem com o meio. Os resultados de tais estudos, se revermos 
vários experimentos, são de dificil análise comparativa com ensaios mais recentes, os quais utilizam a radiometria infravermelha, devido a ausência de informações sobre as condições de medida (SOARES, 1987).

Quando se obtém dados provenientes de medições da temperatura da superfície através de radiometria infravermelha, está se contabilizando uma série de fluxos de energia radiante de diversas partes da planta e do solo, quando este se encontra mesmo parcialmente exposto (BOISSARD et al., 1990). Sob este aspecto, pode-se entender que a temperatura da superfície é representada como uma média no tempo e espaço, associada à radiação correspondente à região do infravermelho termal do espectro eletromagnético, detectada pelo aparelho, sob um determinado ângulo de visada (SOARES, 1987).

É importante se fazer uma análise dos fatores que influenciam a deteç̧ão propriamente dita da temperatura radiante da superfície, de modo que se possa obter, com um máximo de veracidade possível, uma caracterização real de seu valor.

A emissão de energia radiante dos corpos comumente expostos, à superficie terrestre, revelam que, por causa da gama de variação de suas temperaturas, esta ocorre dentro da faixa espectral de 8,0 à $14,0 \mu \mathrm{m}$ (EPIPHANIO, 1983). Sabe-se que a absorção de radiação pelo ar nestes comprimentos de onda é relevante, o que se torna uma preocupação no que diz respeito à distância dos sensores ao alvo. LORENZ (1968) argumenta que, para uma distância inferior a 154 metros, tal influência é negligenciável. Esta pode ser apreciável para medidas à nível de aeronaves ou espaçonaves, implicando em correções devido à absorção.

Os fatores que influenciam o comportamento dinâmico da temperatura da superfície podem ser divididos, ainda que atuem de modo 
interativo uns aos outros, em fatores ambientais, externos ao dossel, e fatores fisiológicos relativos ao comportamento das plantas (BOISSARD et al., 1990). Dentre os fatores ambientais, aqueles relativos a componentes do balanço de energia serão reportados adiante. Quanto aos fatores externos, podemos analisar a elevação do ângulo solar, ângulo zenital de visada, ângulo azimutal de visada e variabilidade espacial do dossel vegetativo. Os fatores relativos à cobertura propriamente dita, como a geometria dos componentes do dossel e emissividade da comunidade de plantas são relevantes, sendo discutidos adiante os fatores fisiológicos envolvidos.

A elevação angular do sol, observada ao longo de um dia, possui efeito na temperatura radiativa do dossel por duas razões : pelo efeito no aumento da energia recebida, que determina uma elevação na temperatura do dossel, e pela distribuição da energia na cultura devido à diferenciação temporal da penetração da radiação solar (BOISSARD et al., 1990). A primeira razão é claramente observável, já que a elevação solar ao longo de um dia causa um aumento na radiação líquida, aumentando linearmente as diferenças entre a temperatura do dossel e a temperatura do ar. $\mathrm{O}$ efeito da elevação na penetração e distribuição dos raios solares no dossel, causa uma diferenciação na dinâmica da distribuição da temperatura ao longo do dossel. Nestas condições, com a elevação solar, a penetração de luz à camadas inferiores do dossel se torna maior, implicando em menor sombreamento do solo, o que torna dificil a interpretação da temperatura com a contribuição radiativa do solo mais acentudada (BOISSARD et al., 1990).

As mudanças na irradiância solar causadas por núvens que se interpõem entre o disco solar e a superfície causam uma variação na temperatura da superficie, fato indesejável e que comumente ocorre em condições tropicais, notadamente no período primavera-verão-outono. Com o objetivo de estudar 
como as mudanças abruptas na radiação solar influenciam a temperatura da superficie, PENNINGTON \& HEATHERLY (1989) realizaram estudos com as culturas de algodão e soja, onde tomaram valores a cada dez segundos dos parâmetros temperatura do dossel (Td), temperatura do ar, umidade do ar, radiação solar global e velocidade do vento. Consideraram a maior queda nos valores da temperatura do dossel menos a temperatura do ar (Tdm) como resultado da redução na radiação solar global pela obstrução dos raios pela passagem de núvens densas. A relação entre a radiação solar e a temperatura do dossel observada foi linear, onde mudanças de modo a diminuir a intensidade do fluxo radiativo incidente provocaram uma queda na temperatura do dossel, desde que a velocidade do vento e a umidade do ar permanecessem constantes. Uma mudança brusca, segundo os autores, na radiação solar provocou mudanças mais lentas na Tdm, até atingir um novo equilíbrio da Td. Com base nos seus resultados, observaram que quando ocorre a mudança na radiação solar, obtida a cada dez segundos, a temperatura do dossel muda, no mesmo espaço de tempo, cerca de $30 \%$. Os autores identificaram problemas na adequação do uso da temperatura do dossel como dado de entrada para qualquer aferição em relação em relação à superficie, já que os valores que se obtém das amostragens podem não ser representativos da realidade, devido às alterações na radiação solar direta. Isto se acentua em regiões úmidas e com grande formação de núvens intermitentes.

Os resultados de medidas radiométricas, sob diferentes ângulos de visada, tem demonstrado que, desde que a temperatura radiante do dossel é uma função de sua geometria, os resultados obtidos de medidas em diversos níveis de aquisição (alturas) de dados podem sofrer influências indesejáveis. 
O efeito do ângulo zenital de visada (inclinação do objeto sensor em relação à perpendicular) na deteç̧ão da temperatura do dossel vegetativo, tem sido objeto de estudo por vários pesquisadores (BOISSARD et al., 1990). A variação do ângulo zenital segundo GUYOT (1983), causa uma resposta espectral diferenciada por parte do dossel vegetativo, considerando os comprimentos de onda relativos às regiões do visível e infravermelho próximo. Isto é também verdadeiro para a região do infravermelho termal, onde, nestes casos, o que ocorre é uma diferenciação dos elementos sensoriados e, como consequência, uma resposta espectral característica das suas contribuições. Já que dentro da gama de elementos sensoriados há diferenciação das temperaturas de cada um deles, e como a variação do ângulo de visada propicia um sensoreamento variável qualitativa e quantitativamente destes elementos, as tomadas de dados da temperatura radiometricamente medida podem sofrer efeitos devido a se assumir um ou vários ângulos de visada dentro do dossel.

A relação angular entre o azimute solar e o azimute de visada do aparelho é outro fator de perturbação das medidas. Medições feitas sobre cobertura com a cultura da soja, indicam que um ângulo zenital de 75 graus, a temperatura do dossel decai linearmente quando a diferença entre o azimute solar e 0 azimute de visada aumenta de 0 à 110 graus. Para um aumento de 110 à 180 graus, a temperatura permanece constante em relação às temperaturas medidas sobre os quatro pontos cardeais (NIELSEN et al., 1984).

A variabilidade espacial ocorrente num campo vegetado, resulta em diferenciação horizontal da temperatura da superfície do dossel e pode ser considerada como um fator determinante da inequação entre seus valores, com implicação em desuniformidade dos resultados obtidos via radiometria infravermelha. A variabilidade nas propriedades fisicas do solo pode induzir a 
um comportamento diferencial da água no perfil, implicando em uma diferenciação no comportamento estomático das plantas, o que resultaria em uma taxa transpiratória desuniforme ao longo do dossel. Esta preocupação, segundo BOISSARD et al. (1990), implica na necessidade de se ter um número representativo de amostragens da temperatura radiante, de modo a garantir um resultado global mais representativo da área de interesse. Segundo HATFIELD et al. (1983), a variabilidade das temperaturas no campo são mais acentuadas em solos nús e sêcos, do que em coberturas uniformes e completas. Os autores concluiram que medições ao acaso são mais eficientes que aquelas feitas sistematicamente, para efeito da estimativa da média. Uma outra conclusão importante foi a de que cerca de dez amostras em vegetação sob condições de níveis iguais ou superiores a $40 \%$ de umidade do solo são representativas, enquanto que vinte amostras para solos mais secos são necessárias. GARDNER et al. (1981) examinaram as temperaturas em milho, observando, ao meio do dia, variabilidade muito acentuada em condições de deficiência hídrica (cerca de 4,2 ${ }^{\circ} \mathrm{C}$ ), comparando-se com uma situação de maior disponibilidade hídrica (cerca de $\left.0,4^{\circ} \mathrm{C}\right)$.

Os fatores relativos às partes componentes do dossel, podem ser analisadas sob as características arquitetônicas da planta e sua forma de cultivo, como densidade populacional.

Um estudo realizado por KIMES et al. (1980), procurou estabelecer relações entre diferentes ângulos de visada sobre os alvos com variados estados de cobertura do solo, em respeito ao comportamento da temperatura da superfície da cultura do trigo, quando tomadas próximas ao meio do dia e no final da tarde, respectivamente horários de máximos e mínimos valores. Observaram que as maiores diferenças ao se variar o ângulo zenital de visada ocorreram para 
situações de cobertura incompleta, para o caso de plantas ainda verdes ou próximas à senescência. Para situações de solo quase totalmente exposto, bem como para cobertura completa seja na senescência seja em condições de vegetação ativa, a variação do ângulo zenital não implicou em diferenças significativas em relação às temperaturas obtidas, tanto no meio do dia quanto no período final do dia. As diferenças observadas nas situações de alguma exposição do solo foram mais acentuadas quando as temperaturas foram tomadas próximas ao meio do dia.

Diferenças sistemáticas na temperatura da superfície das folhas de trigo observadas por GUYOT E CHASSERAY (1981) entre variedades de folhas eretas e de angulação mais acentuadas, reforçam a tese de que é importante se observar o hábito de crescimento vegetal, onde uma maior exposição do solo, notadamente nos horários mais próximos ao meio do dia, pode contribuir para resultados cujos valores estejam sujeitos à sua influência.

A posição relativa de orientação das ruas de plantio, que implica na distribuição radiativa adentro das camadas mais profundas do extrato, resulta na porcentagem de sombra no extrato, bem como na irradiação do solo. Isto leva, ainda, a um maior fluxo radiativo, no caso de orientação leste-oeste, que causa um aquecimento mais acentuado do solo do que para uma condição de maior sombreamento, observado para orientação norte-sul (GUYOT \& CHASSERAY, 1981).

A exposição parcial ou total do solo quando da tomada de dados da temperatura radiante do dossel vegetativo pode causar, além de problemas relativos ao fluxo radiante emitido por este, interferindo na amostragem, problemas devido às diferenças na emissividade que existe entre o solo e as 
folhas. Estas, podem, ainda, variar grandemente de acordo com o tipo de solo (HEILMAN et al., 1981; HATFIELD, 1979).

\section{2 - Temperatura de Superfície, Condições Ambientais e Fisiológicas}

\subsection{1 - Balanço de Energia}

Os efeitos de condições ambientais sobre o dossel vegetativo, aliados àqueles relativos ao balanço de radiação ocorrente na superfície de seus elementos, podem ser descritos em conjunto, analisando o balanço local de energia ocorrente entre a vegetação e a atmosfera circunjacente. Este pode ser descrito da seguinte forma :

$Q^{*}+Q h+Q e+Q g=0$

onde $\mathbf{Q}^{*}$ é o resultado do balanço de radiação à superfície, ou radiação líquida; Qh é o fluxo de calor sensível devido à processos convectivos; Qe é o fluxo de calor latente proporcionado pela evaporação da água presente na superfície; $\mathbf{Q g}$ é o fluxo de calor no solo, negligenciado no balanço por muitos autores, devido à sua magnitude em condições de cobertura completa do terreno. 
O fluxo de calor sensível, que expressa a magnitude e a orientação das trocas de calor entre a superfície e o ar adjacente pelo processo convectivo, pode ser expresso da seguinte forma :

$Q_{h}=\frac{\text { p.cp. }\left(T_{s}-T_{a}\right)}{\mathbf{r a}}$

onde Ts é a temperatura da superfície; Ta é a temperatura do ar; p.cp é a capacidade calorífica em base volumétrica e ra é a resistência aerodinâmica.

O fluxo de calor latente, que determina os processos evaporativos da água, seja da superfície da planta e do solo, seja nos sítios evaporativos do mesófilo foliar, pode ser descrito com relação ao conceito de resistências à difusão :

$$
Q_{e}=\frac{p \cdot c p \cdot\left(e^{*}-e a\right)}{\gamma \cdot(r a+r c)}
$$

onde $e^{*}$ é a pressão de saturação do vapor à temperatura da superficie ; ea é a pressão atual de vapor no ar ; $\gamma$ é a constante pscicrométrica ; rc é a resistência da cobertura vegetal ao transporte de vapor de água ; ra é a resistência aerodinâmica ao fluxo de calor.

Uma análise dos termos do balanço de energia leva-se a considerar suas magnitudes dentro de determinadas condições atmosféricas e da superfície analisada. 
O fluxo de calor latente tem sido, sob condições comumente observadas, o de maior importância e magnitude na partição do balanço de energia radiante (SUMAYO et al., 1980; GATES, 1963). Ele se relaciona às condições de disponibilidade hídrica oferecida pela superfície. Sob condições de baixa disponibilidade hídrica aos processos transpiratórios, ocorre a regulação estomática de controle de perda de água. Nestas condições, a energia disponível tende a se orientar no sentido de promover o aquecimento do sistema, uma vez que, na ausência de água, ocorre um menor poder refrigerativo da planta (GATES, 1980; JACKSON, 1982; EHRLER et al., 1978).

As estimativas do fluxo de calor sensível e latente a partir de dados da temperatura radiante do dossel vegetativo tem possibiltado muitos estudos.

CHOUDHURY (1986) compararou, por uso de regressão linear, estimativas do fluxo de calor latente tomando como base a temperatura da superfície do dossel determinada radiometricamente, na equação do balanço de energia desenvolvida com base nas analogias das resistências ao transporte de vapor, e da mesma forma pelo método aerodinâmico, calculou o fluxo de calor sensível e obtive o fluxo de calor latente como fator residual. Segundo os seus resultados, houve grande correlação entre as duas estimativas, concluindo que a temperatura radiante proporcionou um dado de entrada válido à equação do balanço de energia, de modo a se obter satisfatoriamente valores estimados de evapotranspiração (fluxo de calor latente). Outra constatação observada foi a de que a temperatura estimada pela resolução do balanço de energia via método aerodinâmico, que chamou de temperatura aerodinâmica, diferiu significativamente das temperaturas obtidas radiometricamente.

De forma análoga, BRUNEL (1989) procurou obter relações estatísticas que pudessem ser usadas para se determinar a evaporação real mais 
facilmente do que com a utilização de outros modelos sofisticados, a partir das diferenças das temperaturas da superfície e do ar (Ts - Ta). Utilizou-se de estimativas do fluxo de calor sensível e obteve equações de regressão de seus valores e de (Ts - Ta). Segundo o autor, o fluxo de calor sensível pode ser satisfatoriamente estimado com medidas das temperaturas do ar e radiométrica, em condições de atmosfera instável, frequentemente observáveis ao longo de um dia. Outras observações referiram-se à razão entre a temperatura radiante e a radiação líquida, que torna acessivel a obtenção de valores da taxa evaporativa, onde obtiveram bons resultados comparando-se com outros métodos.

Vários outros estudos confirmam a aplicabilidade da temperatura de superfície nas estimativas dos fluxos de calor sensível e latente.

SMITH et al.(1989) realizaram um estudo onde compararam o fluxo de calor latente, obtido a partir do balanço de energia utilizando a temperatura do dossel para estimar o fluxo de calor sensível. Sua abordagem foi de avaliar a acuracidade das estimativas do fluxo de calor latente utilizando a temperatura do dossel e avaliar ainda o erro causado ao se usar a temperatura radiante ao invés da temperatura aerodinâmica quando se obtém valores horários da evaporação para a cultura do trigo. $O$ balanço de energia, de forma geral, superestimou o fluxo de calor latente para valores baixos, em comparação com os valores medidos, mas o subestimaram para valores altos. A acuracidade do modelo do balanço de energia foi limitado, quando se verificou que a temperatura da superficie diferiu da temperatura aerodinâmica. Esta diferença foi correlacionada linearmente ao fluxo de calor sensível, já que sob condições de estabilidade atmosférica a temperatura do dossel se encontrou abaixo da temperatura aerodinâmica e, sob instabilidade, acima. Como consequência, o fluxo de calor latente foi superestimado e subestimado sob condições de instabilidade e estabilidade atmosférica, 
respectivamente. Na média diária, contudo, estes efeitos opostos foram, segundo os autores, auto-cancelados, o que implicou em melhor concordância dos valores. É de se salientar, com base nestes resultados, que o uso operacional de estimativas da evaporação para nortear a irrigação é discutível.

\subsection{2 - Expressão Analítica de Ts - Ta}

Considerando o balanço de energia, podemos obter uma expressão para a diferença da temperatura da superfície e a temperatura do ar ( $\mathrm{Ts}_{\mathrm{s}}-\mathrm{Ta}$ ) em função da radiação líquida, déficit de pressão de vapor, resistência aerodinâmica e resistência da cobertura (JACKSON, 1982).

$$
T s-T a=\frac{\mathbf{r a}_{0} \mathbf{Q}^{*}}{\rho . c p} \cdot \frac{\gamma_{\cdot}(1+\mathbf{r c} / \mathbf{r a})}{\Delta+\gamma \cdot(1+\mathbf{r c} / \mathbf{r a})}-\frac{\left(\mathbf{e a}^{*}-\mathrm{ea}\right)}{\Delta+\gamma \cdot(1+\mathbf{r c} / \mathbf{r a})}
$$

onde se considera o fluxo de calor no solo neglegível. Nesta expressão, rc é a resistência da cobertura, (ea* - ea) é o déficit de pressão de saturação de vapor do ar, $\Delta$ é a declividade da curva de pressão de saturação em função da temperatura.

Considerando a resistência da cobertura infinita sob uma situação drástica de estresse hídrico, e ainda próxima de zero para uma situação de disponibilidade hídrica máxima, tem-se duas situações extremas nos valores de (Ts - Ta). Para rc tentendo ao infinito, tem-se o valor máximo desta diferença, e 
para rc próximo de zero, o limite mínimo. Duas novas equações podem advir destas situações :

$$
T_{s}-T_{a}=\frac{\text { ra. } Q^{*}}{\rho . c_{p}}
$$

$$
\mathbf{T s}-\mathbf{T a}=\frac{\mathbf{r a} \cdot \mathbf{Q}^{*}}{\rho . \mathbf{c p}} \cdot \frac{\gamma}{\Delta+\gamma}-\frac{\mathbf{e a}^{*}-\mathbf{e a}}{\Delta+\gamma}
$$

JACKSON (1982) procurou se basear nestas relações, sob diversas situações de disponibilidade hídrica, de modo a dar suporte teórico às observações empíricas feitas por IDSO et al. (1981), que demonstraram experimentalmente relações diversas entre ( $\mathrm{Ts}$ - Ta) e déficit de pressão saturante de vapor do ar.

As relações lineares entre ( $\mathrm{Ts}$ - Ta) e déficit de pressão de vapor do ar foram comprovados em inúmeros experimentos. $\mathrm{O}$ conceito foi apresentado e explorado por IDSO et al. (1981), com objetivo de se explorar influências microclimáticas, como do déficit de pressão de vapor saturado, sobre a temperatura do dossel. Em tais estudos, os autores verificaram linearidade entre os valores de (Ts - Ta) e o déficit de pressão de vapor para culturas diferentes, sujeitas à condições de evapotranspiração potencial, nenhuma nebulosidade e com ventos considerados calmos. As relações lineares inversas observadas serviram de base para se definir um índice capaz de identificar situações de sujeição à estresse hídrico. A base metodológica e as condições necessárias para se obter tal índice serão reportados adiante, onde se encontra uma demonstração de uma relação 
linear inversa entre (Ts - Ta) e déficit de pressão de vapor hipotética, definidas pelos autores como "baselines".

Outras investigações a respeito das relações obtidas entre $(\mathrm{Ts}-\mathrm{Ta}) \mathrm{e}$ déficit de pressão de vapor foram feitas em muitos trabalhos, cujos objetivos foram melhor caracterizar o status hídrico, passível de identificação com o comportamento observável em relação às baselines em determinada situação, e parâmetros que também o definem. Desta forma, IDSO et al. (1981), obtiveram boas correlações entre estes conceitos e o potencial da água na folha, extração da água do solo (IDSO et al., 1982). Em estudo mais recente, contudo, foi observado que os resultados obtidos para a caracterização destas relações são influenciadas pela localização, dentro do campo experimental e mesmo em abrigo fora do campo, dos pontos nos quais os valores da temperatura do ar e déficit de pressão são obtidos (IDSO et al, 1990). O estabelecimento das relações, contudo, são pouco influenciadas pela radiação líquida, desde que se tenha condições de céu limpo.

As correlações admissíveis em condições não neutras são tomadas para ajuste dos fluxos de momentum, que são inversamente proporcionais à resistência aerodinâmica. Esta, obtida a partir dos perfís logarítmicos de vento acima da superfície, são dependentes de parâmetros aerodinâmicos como deslocamento do plano zero (d) e rugosidade da superfície (Zo), que afetam indiretamente a diferença ( $\mathrm{Ts}-\mathrm{Ta}$ ) (JACKSON, 1982). Os autores citam como dificuldades inerentes à relação entre $(\mathrm{T} s-\mathrm{Ta})$ e resistência aerodinâmica o fato de que, à baixas velocidades de vento, a resistência aeorodinâmica torna-se muito alta (relação inversa, já que desfavorece o transporte dos elementos), implicando em relações irreais entre os dois parâmetros. Como consequência, valores de velocidade do vento baixos determinam maior dificuldade de trocas na camada 
limite, o que ocasiona, segundo MILLARD et al. (1981) uma variabilidade maior de valores da temperatura do dossel, relativamente à valores maiores da velocidade do vento, que homogeniza mais os elementos na camada limite, reduzindo a variabilidade das temperaturas do dossel.

Analisando a equação analítica para ( $\mathrm{T} s-\mathrm{Ta}$ ), observa-se o termo $\mathrm{rc}$, referente à resistência da cobertura, relativo ao controle físiológico, cujo fator variante é fundamentalmente a regulação estomática. A resistência da cobertura depende da disponibilidade hídrica, ainda que o mecanismo de abertura e fechamento estomático seja controlado por vários outros fatores, e variável de espécie para espécie. Quando há grande disponibilidade hídrica, a resistência da cobertura tende a zero, e a diferença ( $\mathrm{Ts}$ - $\mathrm{Ta}$ ) é exclusiva de fatores determinantes da diferença $(\mathrm{Ts}-\mathrm{Ta}$ ), como a radiação líquida e a resistência aerodinâmica.

Com o objetivo de avaliar mudanças na resistência da cobertura na cultura do trigo, ao longo de um dia e de forma sazonal, HATFIELD (1983) utilizou medidas relativas ao balanço de energia e avaliou os resultados obtidos para condições de irradiância e disponibilidade hídrica do solo. A partir dos resultados obtidos, concluiu que a resistência da cobertura pode ser calculada, a partir do balanço de energia, usando-se a temperatura do dossel como dado de entrada. A resistência de cobertura decresceu com o aumento da radiação líquida, bem como decresceu linearmente com o aumento na disponibilidade hídrica, e foi mensurável mesmo com alta disponibilidade hídrica. $O$ balanço de energia, segundo o autor, foi instrumento válido para a determinação da resistência da cobertura, onde se teve como base de cálculo valores da temperatura do dossel.

O'TOOLE \& REAL (1986), estimaram as resistências aerodinâmicas e da cobertura, sob condições de evapotranspiração potencial, tomando-se inicialmente a reta estatística de regressão entre o déficit de pressão de vapor e a 
diferença entre a temperatura do dossel e a temperatura do ar ( $\mathrm{T}_{\mathrm{s}}-\mathrm{T}_{\mathrm{a}}$ ) como dado de entrada na equação do balanço de energia. A regressão linear utilizada foi obtida por IDSO (1982) para diferentes espécies. De forma similar, obtiveram relações entre déficit de pressão de vapor e (Ts - Ta) para espécies não concordantes com as primeiras e, da mesma forma, avaliaram a utilização destas relações para o cálculo das resistências aerodinâmica e da cobertura com base nos valores por eles encontrados. A comparação dos resultados obtidos, utilizando as regressões obtidas por IDSO (1982) e no próprio experimento, demonstraram incompatibilidade com o esperado para as resistências da cobertura, principalmente. Reportaram que as diferenças entre as equações obtidas foi uma das causas, já que foram desenvolvidas por espécies diferentes, implicando em diferentes sistemas de controle de perda de água. Outro fator salientado e de importância na determinação das resistências foi a de que condições representativas de velocidade do vento, notadamente como influenciador da resistência aerodinâmica, e ainda uma melhor avaliação das interações entre (Ts Ta) e déficit de pressão de vapor, devem servir como parâmetro de análise para a determinação, a partir do balanço de energia, da resistência da cobertura, que possui especificidade ecofisiológica.

IDSO et al. (1982), desenvolveram um estudo onde procuraram obter relações entre a diferença ( $\mathrm{Ts}$ - Ta) e a resistência difusiva da folha e a fotossíntese líquida na cultura do algodão. Segundo seus resultados, há uma forte tendência dos dados da resistência estomática exibir um valor mínimo ao meio do dia, com aumento no nascer e por do sol, para uma situação de evapotranspiração potencial. Concluiram, também, que a resistência estomática demonstrou um comportamento esperado a um aumento na diferença ( $\mathrm{Ts}-\mathrm{Ta}$ ), obtida com base nas suas relações com o déficit de pressão de vapor, sendo que, apesar de não 
comprovado estatisticamente, a resistência estomática aumentou grandemente com os valores de ( $\mathrm{Ts}-\mathrm{Ta}$ ), quando estes aumentavam. A fotossíntese líquida foi estatisticamante comparada com a diferença ( $\mathrm{Ts}-\mathrm{T}$ ) e apresentou boa correlação, sendo observada uma relação linear inversa. A fotossíntese líquida praticamente foi suprimida ao se atingir uma condição máxima de diferença (Ts Ta).

\subsection{3 - Índice de Estresse Hídrico e Aplicações}

A possibilidade de se quantificar o grau de estresse hídrico de uma cultura com base em medidas da temperatura do dossel vegetativo, foi previamente analisada por IDSO et al. (1977). Em sua proposição, foi desenvolvido um índice que contabiliza as diferenças entre a temperatura radiante do dossel com a temperatura do ar, cujos valores eram dependentes do estado hídrico ao qual se encontrava a cultura. $O$ índice contabiliza estas diferenças e as soma, ao longo do tempo decorrente da possível queda na disponibilidade hídrica; a partir do resultado deste somatório, constata-se o estado hídrico da cultura. Parte da suposição é de que, quando a água se torna menos disponível, a temperatura do dossel passa a ser progressivamente maior que a temperatura do ar, o que se demonstrará no somatório. Segundo JACKSON (1982), eles definiram o Grau Diário de Estresse ("Stress Degree Day"), assumindo-se que os fatores ambientais envolvidos, como pressão de vapor, radiação líquida e vento, manifestariam-se na temperatura do dossel. 
O índice de estresse hídrico proposto por IDSO et al. (1977) foi relacionado à produção final, como detector de produtividade (IDSO et al., 1981; WALKER \& HATFIELD, 1979). Nestes estudos foi demonstrado, a partir de diferentes estados de disponibilidade hídrica, que a produção em trigo e feijoeiro estava linearmente correlacionada com o "Stress Degree Day". A produção diminuia sempre que o índice apresentava valores mais altos. A relação existente foi explicada em termos de uso da água, onde se encontrou também uma relação linear inversa com a soma diária dos valores de (Ts - Ta) (WALKER \& HATFIELD, 1979).

Segundo STEINMETZ et al. (1989), afora os aspectos práticos do "Stress Degree Day", este deve ser considerado como um índice empírico, já que muitos são os fatores que afetam as relações entre a temperatura e o "status" hídrico da cultura.

De fato, procurando uma melhoria no "Stress Degree Day", IDSO et al. (1981) consideraram que, à qualquer déficit de pressão de vapor, há um limite teórico da diferença $\left(\mathrm{T}_{\mathrm{s}}-\mathrm{Ta}\right.$ ) superior e inferior, decorrente da possível queda na disponibilidade hídrica, referente à duas condições extremas. $\mathrm{O}$ limite superior seria correspondente a uma situação de transpiração zero, ou próxima de zero. $\mathrm{O}$ limite inferior representaria uma situação onde as plantas estivessem transpirando livremente. Desta forma, definiram o índice de estresse hídrico da cultura (Crop Water Stress Index) como a diferença normalizada entre o limite mínimo, para uma condição comparativa entre os dois limites teóricos :

$$
\text { CWSI }=\frac{\left(T_{s}-T_{a}\right)-\left(T_{s}-T_{a}\right) \operatorname{lm}}{\left(T_{s}-T_{a}\right) l M-\left(T_{s}-T_{a}\right) l m}
$$


onde : (Ts - Ta) $1 \mathrm{~m}$ corresponde aos valores tomados no limite mínimo, ou sem restrições hídricas; e ( $\mathrm{Ts}-\mathrm{Ta}$ ) $\mathrm{lM}$ corresponde aos valores tomados no limite máximo, sob forte restrição hídrica.

Os valores do CWSI são relativos à posição entre os limites máximos e mínimos, definidos pelas "linhas básicas" ("baselines") (JACKSON et al., 1981). Estas, desenvolvidas segundo IDSO et al. (1981), definem a relação linear observada entre a diferença ( $\left.T_{s}-T_{a}\right)$ e o déficit de pressão de vapor do ar, sob condições de não restrição hídrica. Esta relação, observada na equação analítica de (Ts - Ta) em função dos parâmetros do balanço de energia, conduz ao ponto de partida para a caracterização de uma cultura qualquer, sob quaisquer condições hídricas. Observando-se a figura 1, que exemplifica uma relação hipotética entre (Ts - Ta) e déficit de pressão de vapor do ar ("linha básica"), tem-se que os limites mínimos estariam representado pela reta transversal ("linha básica") e os limites máximos pelas retas paralelas ao eixo da abcissa.

Cabe definir, inicialmente, como são obtidas tais retas (paralelas ao eixo da abcissa). Os autores a definiram partindo do princípio de que o limite máximo corresponderia a um estado de transpiração zero, ou seja, na ausência de um gradiente de pressão de vapor. Contudo, a interceptação da "linha básica" com o eixo da ordenada (valor zero de déficit de pressão de vapor), sendo positivo, neste ponto existe um gradiente de temperatura positivo entre a superfície e o ar, que implica em ainda existir um gradiente de pressão de vapor. Este gradiente cessaria, conceitualmente, em uma atmosfera "supersaturada", e representa um estado onde os valores de (Ts - Ta) não mais dependem do défifit de pressão de vapor. Os valores de $\left(\mathrm{Ts}_{\mathrm{s}}-\mathrm{T} \mathrm{a}\right)$ para este estado necessitam ser determinados. Inicialmente, os autores calcularam as pressões de vapor, tomando-se por base as temperaturas da superfície e a do ar, no ponto zero de déficit de pressão de vapor. 
A diferença encontrada revela justamente o gradiente ainda existente entre a superfície e o ar. Para se levar em conta este gradiente, os autores encontraram o ponto de interceptação entre a extensão da "linha básica", com o ponto correspondente ao valor do gradiente encantrado, na abcissa (região negativa, de "supersaturação"). Os limites máximos puderam assim ser conhecidos, ao se extender este ponto de interceptação, paralelamente ao eixo da abcissa. Temos, então, que os limites máximos dependem da temperatura do ar. Os autores determinaram, desta forma, os limites máximos possíveis encontrados para uma gama de temperaturas do ar.

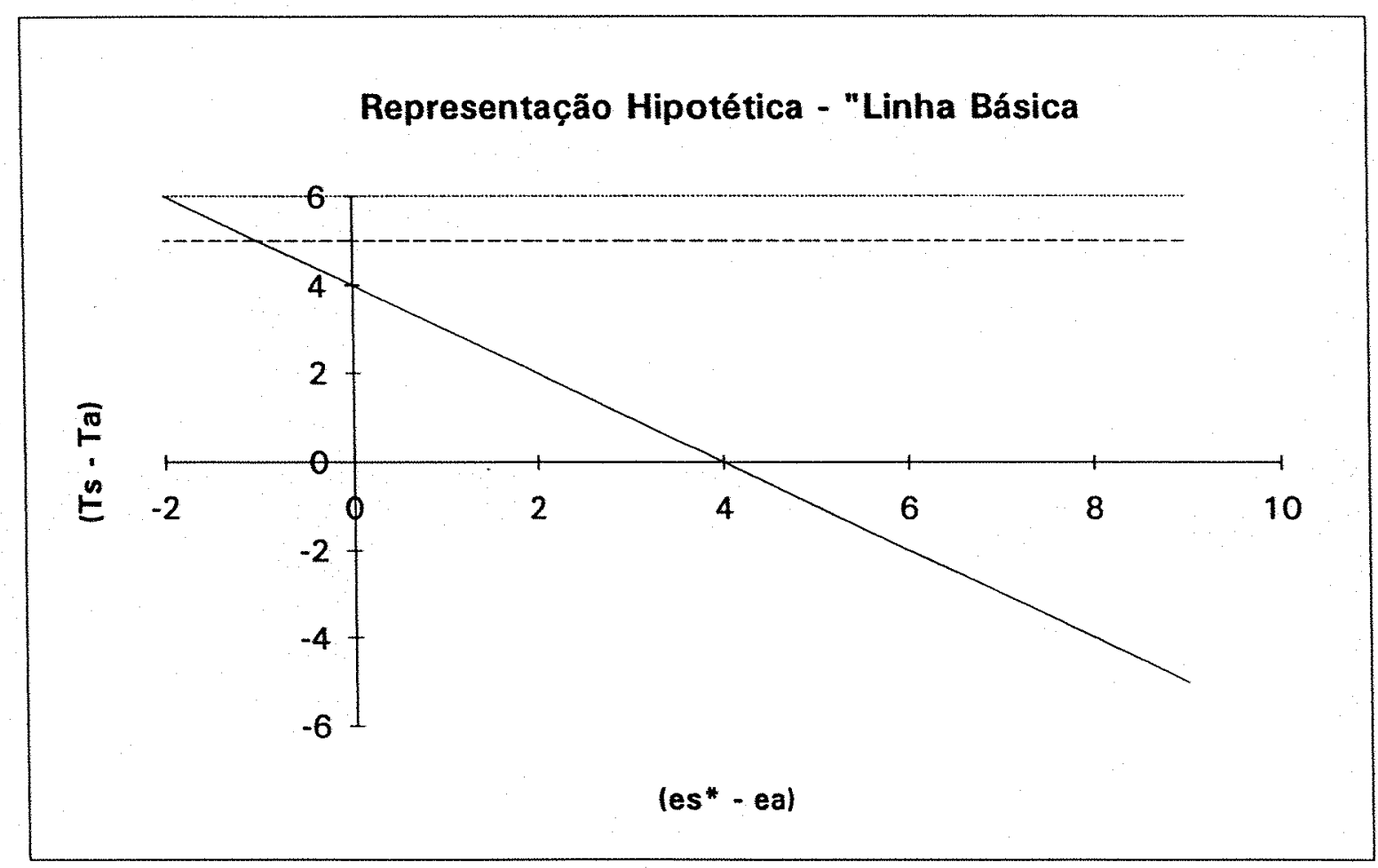

Figura 1 - Representação Hipotética de uma "Linha Básica"

Os valores do CWSI, então, como a razão entre as diferenças entre ( $\mathrm{Ts}$ - Ta), tomados a um determinado momento, e (Ts - Ta) dado pela "linha básica", e a diferença de (Ts - Ta) entre os dois limites. Os valores de (Ts - Ta) para o limite mínimo se dá pela "linha básica", para cada valor de déficit de 
pressão de vapor encontrado, e o limite máximo, para cada valor de temperatura do ar encontrado.

Procurando um fundamento teórico para o CWSI, JACKSON et al. (1981) desenvolveram a partir do balanço de energia, os limites máximos e mínimos, encontrando os diferentes fatores microclimáticos e fisiológicos que atuam no índice. A partir das equações analíticas desenvolvidas em função de (Ts - Ta), para os dois limites de estado hídrico, o CWSI foi definido como :

$$
\text { CWSI }=\frac{\gamma \cdot\{1+(\mathbf{r c} / \mathbf{r a})\}-\gamma^{*}}{\Delta+\gamma \cdot\{1+(\mathbf{r c} / \mathbf{r a})\}}
$$

$$
\gamma^{*}=\gamma \cdot(1+\mathbf{r c p} / \mathbf{r a})
$$

onde rcp é a resistência da cobertura à evapotranspiração potencial. A razão (rc/ra) pode ser obtida considerando o desenvolvimento da equação o desenvolvimento da equação do balanço de energia :

$$
\frac{\mathbf{r c}}{\mathbf{r a}}=\frac{\left\{\left(\gamma \cdot \mathbf{r a} \cdot \mathbf{Q}^{*}\right) /\left(\mathbf{p} \cdot \mathbf{c p}_{\mathbf{p}}\right)\right\}-\left\{\left(\mathbf{T}_{\mathbf{s}}-\mathbf{T a}\right) \cdot(\Delta+\gamma)\right\}-\left(\mathbf{e a}^{*}-\mathbf{e a}\right)}{\{\gamma \cdot(\mathbf{T s}-\mathbf{T a})\}-\left\{\left(\mathbf{r a} \cdot \mathbf{Q}^{*}\right) /\left(\rho \cdot \mathbf{c p}_{\mathbf{p}}\right)\right\}}
$$

Estas relações mostram, analiticamente, a composição de processos que determinam as observações empíricas mostradas anteriormente. Os autores 
ainda consideram que o CWSI é um índice que revela o estado atual de disponibilidade hídrica, $o$ que pode ser conceituado em termos de evapotranspiração real (ETR), em relação ideal de evapotranspiração potencial (ETP), ou seja :

CWSI $=1-($ ETR/ETP $)$

O CWSI é, portanto, um índice cujos valores variam de um estado ideal à um estado de extrema deficiência hídrica, com uma gama de valores de 0 à 1,0 .

Vários experimentos tem demonstrado que o CWSI é um indicador de condições hídricas as quais estão sujeitas as culturas (IDSO et al., 1981; NAKAYAMA \& BUCK, 1984).

A temperatura da superfície tem sido tomada como base para a avaliação dos índices de estresse hídrico desenvolvidos, o SDD e o CWSI (DIAS et al., 1983). Desta forma, procurou-se relaciona-los à produção na cultura do trigo, que foi submetido à diferentes níveis de água no solo, monitorados por meio de método do balanço de água no solo, via moderação de neutrons. Os autores salientam que a relação entre a evapotranspiração obtida pelo balanço hídrico no solo e os índices estudados foi linear inversa, sendo que o índice estatístico de correlação foi maior quando foi usado o SDD no estudo, em comparação ao CWSI. As relações obtidas entre os índices estudados e a produção, permitiram concluir que o SDD foi o que melhor se apresentou para o uso na previsão final 
da produção, ainda que de modo comparativo não houvesse diferenças acentuadas quanto ao CWSI.

A partir da assertativa de que o CWSI seja um índice capaz de identificar sujeições à estresse hídrico e de prever produção, HALIM et al. (1990) procuraram identificar sua relação com as condições nutricionais de partes de planta, cuja qualidade é extremamente afetada por períodos de severo estresse hídrico. Para tanto, submeteram a cultura da alfafa à diferentes tratamentos, que representavam diferentes estados de água no solo, determinados através de sonda de neutrons, e observaram a composição química de partes da planta, do pecíolo e folhas, secas em estufas. As relações obtidas indicaram que o CWSI foi extremamente bem correlacionado à produção, muito mais de que à qualidade proporcionada devido ao estresse hídrico, nos órgãos estudados.

A detecção do estresse hídrico utilizando o CWSI foi estudada por outros autores, que demonstraram sua utilidade, o que denota consistência no modelo (SAHA et al., 1986).

O monitoramento da irrigação através da utilização da temperatura da superficie, bem como do CWSI na qual se baseia, também tem norteado alguns estudos. NIELSEN (1989), procurou estudar a aplicabilidade deste índice no monitoramento da irrigação para a cultura da soja e determinar qual o nível de efeito sobre a produção final para diversos valores de CWSI, a partir dos quais se efetuaria a aplicação de água $(0,1 ; 0,2 ; 0,4$ e 0,6$)$. O valor mais alto do CWSI utilizado para a aplicação de água produziu a maior quebra de produção e a menor quantidade de água aplicada. Os resultados mostraram que não houve diferença significativa na água aplicada, no uso da água e na produção final quando se usou os valores de 0,4 e 0,6 do CWSI. $O$ autor justificou esta constatação como uma 
resposta ao rápido fechamento estomático das plantas sujeitas a algum valor crítico de disponibilidade hídrica. 


\section{MATERIAIS E MÉTODOS}

\subsection{MATERIAIS}

\subsubsection{Localização do Ensaio, Solo e Clima}

O ensaio foi conduzido na fazenda experimental do CPQBA - Centro de Pesquisas Químicas, Biológicas e Agrícolas - UNICAMP, localizada no município de Paulínia, Estado de São Paulo, cujas cooordenadas Geográficas são $22^{\circ} 43^{\prime} \mathrm{S}, 47^{\circ} 38 \mathrm{~W}$ e a altidude de $576 \mathrm{~m}$.

O solo do local onde se instalou o experimento é caracterizado como Latossolo Roxo, cujas características químicas, avaliadas através de amostragens e processamento laboratorial no ano de 1990 , anteriormente à instalação de um ensaio com a cultura da soja (ano agrícola de 1990-91), são mostradas a seguir na tabela (1).

A área total do ensaio foi de 5.000 metros quadrados, com dimensões de $100 \times 50$ metros.

O clima da região, segundo a classificação de Köpen, é do tipo Cwa, especificado como sub-tropical com chuvas de verão e inverno relativamente 
sêco. A temperatura média anual é de $21,6^{\circ} \mathrm{C}$, sendo a máxima $27,3^{\circ} \mathrm{C}$ e a mínima de $15,9^{\circ} \mathrm{C}$. A umidade relativa do ar média é de $72,1 \%$, e a precipitação pluviométrica anual média $1381,2 \mathrm{~mm}$.

\begin{tabular}{|c|c|c|c|c|c|c|c|c|c|}
\hline $\mathrm{pH}$ & $\mathrm{M} . \mathrm{O}$ & $\mathrm{P}$ & $\mathrm{K}$ & $\mathrm{Ca}$ & $\mathrm{H}+\mathrm{Al}$ & $\mathrm{S}$ & $\mathrm{T}$ & $\mathrm{Al}$ & $\mathrm{V}$ \\
\hline$(1)$ & $\%$ & \multicolumn{8}{|c|}{$\mathrm{mg} / \mathrm{cm}^{3}$} \\
\hline 5,5 & 2,7 & 18 & 0,37 & 4,8 & 1,5 & 6,67 & 9,17 & 0 & 71 \\
\hline
\end{tabular}

Tabela 1 - Características Químicas do Solo do Local do Experimento

(1) - $\mathrm{pH}$ medido em $\mathrm{CaCl}_{2}$

(2) - extraido em ácido sulfúrico $\left(\mathrm{H}_{2} \mathrm{SO}_{4}\right), 0,05 \mathrm{~N}\left(\mu \mathrm{g} / \mathrm{cm}^{3}\right)$

(3) - TFSA

\subsection{2 - Caracterização do Cultivar Utilizado}

O cultivar de trigo utilizado foi o Tucuruí (IAC-24), cujas características são as seguintes : altura média de $80 \mathrm{~cm}$, ciclo precoce de 120 dias, da maturação à colheita; aurícola violácea; posição das folhas intermediária; coloração da panícola creme, aristada, oblonga; grãos avermalhados com comprimento médio de 5,91 $\mathrm{mm}$, largura de 3,05 $\mathrm{mm}$ e 2,47 $\mathrm{mm}$ de espessura, em média.

\subsubsection{Instalação e Condução do Ensaio}

O solo foi previamente revolvido, em uma operação de preparo que consistiu de uma aração e duas gradagens, o que permitiu condições de um bom 
destorroamento, de modo a garantir uma germinação uniforme das plântulas. Anteriormente a esta operação, os restos de cultura e as plantas daninhas existentes foram destruidas por meio do uso de enxada rotativa. Posteriormente foram retirados do local a "palhada" restante, arrastando-a com trator, amontoando-a na beirada do campo. O "cisco" presente ainda após as operações de aração e gradagem foi retirado, por via manual.

O plantio foi realizado mecanicamente no dia 20/05/91, respeitando uma densidade de 60-70 plantas por metro linear, com espaçamento de $20 \mathrm{~cm}$ entre linhas, aproximadamente.

A adubação requerida no plantio, calculada com base nas características químicas reveladas pela análise de solo, exigiu a aplicação de 2040-20 kg/ha de $\mathrm{N}, \mathrm{P}_{2} \mathrm{O}_{5}$ e $\mathrm{K}_{2} \mathrm{O}$, respectivamente. Tal proporção e quantificação de elementos foi conseguida utilizando-se $100 \mathrm{~kg}$ da formulação 10-10-10 em adição à $50 \mathrm{~kg}$ de superfosfato simples, conseguida por mistura utilizando-se betoneira manual. Em cobertura, utilizou-se $100 \mathrm{~kg} / \mathrm{ha}$ de uréia aos 30 dias após a emergência. Tanto a adubação de plantio quanto a adubação de cobertura foram feitas por espalhamento (à lanço) mecânico.

O controle de doenças consistiu de uma única aplicação do fungicida sistêmico Propiconazole, do grupo químico dos Triazois, de nome comercial Tilt, quando se detectou o surgimento de sintomas iniciais de ferrugem. Esta foi suficiente para o controle de outras doenças, não sendo detectado nenhum sintoma que caracterizasse sua ocorrência, ao longo do ciclo da cultura.

A ocorrência de pragas não foi detectada sendo, portanto, inexistente seu controle.

Quanto ao sistema de irrigação utilizado, foram usadas cinco linhas de aspersão, espaçadas de doze metros, com oito aspersores em cada linha, 
espaçadas doze metros umas das outras. As linhas situaram-se longituninalmente ao campo, acompanhando as linhas de plantio.

\subsection{4 - Levantamento dos Dados Experimentais - Instrumental}

\subsubsection{1 - Radiômetro Líquido}

Foi utilizado um radiômetro líquido inflável, tipo Funk, marca Midleton, cuja constante de calibração é $28,173 \mathrm{mV} / \mathrm{cal}^{\mathrm{cm}}{ }^{-2} \cdot \mathrm{min}^{-1}$. Este foi instalado à $40 \mathrm{~cm}$ acima do topo da cultura (dossel).

\subsubsection{2 - Piranômetro}

Um piranômetro de ponto, marca LI-COR, com constante de

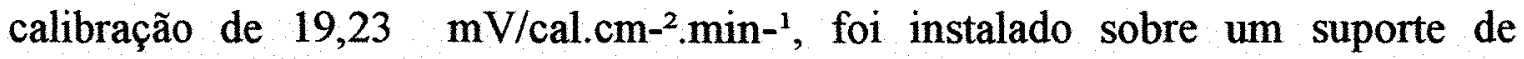
madeira, acima do topo da cultura $(70 \mathrm{~cm})$.

\subsubsection{3 - Termômetro de Infravermelho}

Utilizou-se para as medidas da temperatura radiante do dossel, um radiômetro de infravermelho (pirômetro), modelo Pyrovar, de fabricação alemã. Trata-se de um instrumento portátil, leve (cerca de $1,25 \mathrm{~kg}$ ), com resolução de 0,1 $\mathrm{K}$ e banda espectral de 8-35 $\mu \mathrm{m}$. Suas dimensões são de 259 × 243 × $96 \mathrm{~mm}$. O sistema de acionamento do aparelho se dá por um cursor manual, que possui duas posições. A primeira dá a leitura da temperatura num visor digital, diretamente em 
${ }^{\circ} \mathrm{C}$, e a segunda fixa este valor. Possui um sistema de ajuste para emissividade, temperatura ambiente, e temperatura máxima registrada. Por ser um modelo portátil, é facilmente transportável a campo, sendo que um tripé móvel foi utilizado como elemento de fixação do aparelho.

\subsubsection{4 - Anemômetros}

Os anemômetros tipo caneca, de fabricação C.I. Casela \& Co Ltda, foram montados em um suporte de metal (mastro), obedecendo as seguintes alturas : 1,10 e $1,85 \mathrm{~m}$. A localização do mastro foi sempre a mesma, no interior do campo experimental, à cerca de 30 metros de uma das bordas e 60 metros da outra.

\subsubsection{5 - Conjunto Psicrométrico}

Foi instalado um conjunto de dois pares psicrométricos, em dois diferentes níveis de altura : 1,5 e $2,3 \mathrm{~m}$. O conjunto constou de dois tubos de PVC branco, que serviram como suporte, sendo que um deles foi destinado ao conjunto úmido. Foram fixados nos pontos descritos quatro termistores adquiridos no comércio, para cada perfil. O perfil úmido recebeu um revestimento de gase (cada termistor), onde se umidecia com água destilada cada termistor, sempre 15 minutos antes das leituras. Cada ponto de fixação dos termistores recebeu uma proteção para evitar a incidência dos raios solares, que constou de anteparos de PVC branco fixados nos pontos de fixação.

As leituras foram obtidas por intermédio de um ohmímetro digital, sendo, portanto, obtidas em termos de resistência do termistor (ohm). Para 
aferição das leituras em ${ }^{\circ} \mathrm{C}$, todos os termistores foram calibrados individualmente, o que possibilitou a obtenção de uma equação de calibração para cada um deles. Para a calibração, foram feitas leituras simultâneas da temperatura da água, com variação de $40^{\circ} \mathrm{C}\left(5-45^{\circ} \mathrm{C}\right.$, aproximadamente). A temperatura da água foi obtida por leitura de termômetro de mercúrio e, simultaneamente, da resistência do termistor, com o ohmímetro digital. Obtiveram-se seis equações de calibração, por meio de regressão linear entre as leituras em ${ }^{\circ} \mathrm{C}$ e o logarítmo neperiano das leituras em resistência. Com estas, tornou-se possível a transformação dos dados de campo $\mathrm{em}^{\circ} \mathrm{C}$, individualmente.

\subsubsection{6 - Aquisição de Dados}

Foi utilizado um data-logger, marca LI-COR, modelo LI-1000, para a aquisição dos dados de radiação líquida e radiação solar global. O sistema foi programado para receber e registrar em memória leituras a cada dez minutos, instantaneamente.

\subsubsection{7 - Tensiometria}

Foram instaladas seis baterias de tensiômetros, cada qual com três unidades, obedecendo as profundidades de 15,35 e $55 \mathrm{~cm}$. Estas leituras foram feitas utilizando-se de régua graduada e, conforme a coluna de mercúrio se distendia no capilar, lia-se a altura entre o nível de mercúrio na cuba e no capilar, ambos fixos em suporte de madeira. 


\subsection{Métodos}

\subsubsection{Tensiometria e Irrigação}

Os valores obtidos das medições de campo das alturas capilares do mercúrio foram transformadas em potencial da água do solo, de modo a atingir dois objetivos principais : determinar a frequência da água a ser aplicada via irrigação e diferenciar duas situações de disponibilidade hídrica do solo. Os valores do potencial matricial da água do solo foram obtidos pela seguinte relação:

$\varphi \mathrm{m}=-12,6 . \mathrm{h}+\mathrm{h} 1+\mathrm{h} 2$

onde h é a altura do mercúrio no capilar; h1 é a altura da cuba de mercúrio e h2 é a profundidade do tensiômetro.

Com o objetivo de se calcular a quantidade de água a ser aplicada via irrigação, tomaram-se dados da evaporação do Tanque Classe $\mathrm{A}$, situado no posto meteorológico da UNICAMP-FEAGRI, à três quilometros de distância do local do ensaio, e transformaram-se seus valores em evapotranspiração de referência, obtidos diariamente, conforme a seguinte metodologia : 
ETo $=$ ECA.$k p$

$\mathbf{E T M}=\mathbf{E t o} \cdot \mathbf{k c}$

onde ETo é a evapotranspiração de referência diária; ECA é a evaporação do tanque classe A, ETM é a evapotranspiração máxima, kc é o coeficiente de cultura e kp é o coeficiente de tanque.

Os valores do coeficiente de cultura foram obtidos com base na proposição de DOOREMBOS \& KASSAM (1979), para os diversos estádios fenológicos ao longo do ciclo da cultura.

Os valores da precipitação pluviométrica eram obtidos no posto meteorológico próximo (cerca de $200 \mathrm{~m}$ ) do local.

O procedimento de aplicação de água foi baseado nestes valores de evapotranspiração de referência e nos valores dos potenciais da água do solo, indicado pelos tensiômetros. Sempre que os tensiômetros atingiam valores próximos a $-0,06 \mathrm{MPa}$ a aplicação de água ocorria na quantidade determinada pelos valores acumulados da evapotranspiração de referência, desde a última aplicação.

\subsubsection{Caracterização dos Tratamentos}

O campo experimental foi dividido em duas partes iguais, de dimensões de $50 \times 50 \mathrm{~m}$, onde cada qual recebeu diferentes quantidades de água aplicada por irrigação, caracterizando os "tratamentos", chamados com e sem irrigação. 
Tal diferenciação teve início no período fenológico correspondente ao emborrachamento-espigamento, período a partir do qual só se irrigou metade da área. Até então o campo foi, quando necessário, igualmente irrigado.

Duas foram as razões de se procurar a diferenciação dos tratamentos no referido período : tornar possível a detecção da temperatura radiante do dossel com uma mínima ou nenhuma exposição do solo, já que o crescimento da cultura se encontraria completa; estudar um período fenológico onde a escassez de água se tornaria mais significativa na resposta em produção pela cultura, haja visto o aumento no consumo hídrico nas fases reprodutivas (floração-enchimento de grãos).

\subsubsection{Levantamento dos Dados}

O levantamento dos dados teve início no final do mês de julho (dia 20/07) e término no final do mês de agosto (22/08).

Este período compreedeu as fases fenológicas de floração e enchimento de grãos, sendo que em oito dias procedeu-se o levantamento dos seguintes parâmetros : temperatura radiante do dossel, radiação solar global, radiação líquida, temperatura do ar em dois níveis $(1,5$ e $2,3 \mathrm{~m})$, temperatura do bulbo úmido nos mesmos níveis, e velocidade do vento em dois níveis $(1,10$ e $1,85 \mathrm{~m})$.

Foram obtidos os parâmetros citados em diferentes épocas, sempre sob condições de cada tratamento. Desta forma, com exceção da temperatura radiante do dossel, radiação solar e velocidade do vento, os demais parâmetros 
eram obtidos hora sobre o tratamento de estresse hídrico, hora sobre o tratamento irrigado. Ao todo e com a finalidade de exposição dos resultados, foram obtidos cinco dias de medidas no tratamento não irrigado $(29 / 07,07 / 08,11 / 08,18 / 08$ e 22/08) e três dias no tratamento irrigado (27/07, 06/08 e 13/08). Estes parâmetros foram obtidos a cada hora, das 11 às 16 horas. Além destes, em outros três dias (20/07; 24/07 e 15/08) foram feitas observações somente da temperatura da superfície e da temperatura do bulbo sêco e úmido.

A temperatura radiante do dossel foi obtida tomando-se dez pontos em cada tratamento, conhecidos e fixos, os quais foram sensoriados sempre a cada hora, iniciando-se cerca de dez minutos antes e terminando dez depois. Foi mantido um ângulo de visada constante (20 graus em relação à perpendicular, o que foi possível devido à fixação do aparelho sobre um tripé, onde um medidor angular apoiado sobre o aparelho indicava a sua inclinação. Caminhava-se ao longo do campo, de um ponto a outro de amostragem com o conjunto tripéradiômetro e, desta forma, procedia-se as leituras. Em cada ponto eram obtidas três leituras, utilizando-se a média destas como sendo o resultado da amostragem.

\subsubsection{Tratamento dos Dados Coletados}

\subsubsection{Temperatura do Dossel}

Os valores obtidos da temperatura do dossel vegetativo, para efeito de sua utilização nos modelos a serem descritos, foram transformados em médias 
aritméticas simples. Desta forma, sempre que se utilizar seus valores, está se contabilizando a média de dez leituras, para cada tratamento.

\subsubsection{Umidade do Ar e Déficit de Pressão de Vapor}

Com os valores transformados, segundo o ítem 3.1.4.5, das temperaturas do bulbo úmido e sêco, procedeu-se a determinação das pressões de vapor de acordo com a equação de Tetens, segundo Monteith (1990) :

$\operatorname{es}(T)=\operatorname{es}\left(T^{*}\right) \cdot \exp \cdot\left\{A \cdot\left(T-T^{*}\right) /\left(T-T^{\prime}\right)\right\}$

onde es( $\left.\mathbf{T}^{*}\right)$ é a pressão saturante de vapor $(\mathrm{kPa}) ; \mathbf{A}$ é uma constante $(17,27)$; $\mathbf{T}^{*}$ equivale à $273 \mathrm{~K}$, onde es( $\left.\mathbf{T}^{*}\right)$ equivale à $0,611 \mathrm{kPa} ; \mathbf{T}$ é a temperatura do ar e $\mathbf{T}^{\prime}$ equivale à $36 \mathrm{~K}$.

Os valores das pressões parciais de vapor (ea) foram determinadas segundo a equação psicrométrica :

$\mathbf{e a}=\mathbf{e s}(\mathbf{u})-\gamma \cdot\left(\mathbf{T}-\mathbf{T}^{\prime}\right)$

onde es(u) é a pressão saturante de vapor, à temperatura $\mathbf{T}^{\prime} ; \gamma$ é 0 coeficiente psicrométrico. 
Os valores finais utilizados representam aqueles correspondente à média aritmética entre os niveis subsequentes de medidas $(1,5$ e $2,3 \mathrm{~m})$, que representam a altura correspondente à média geométrica entre os mesmos níveis, procedimento este adotado por ANDRÉ (1981).

O déficit de pressão de vapor nada mais é do que a diferença entre o estado saturado e o atual, em relação à umidade. Assim, es(T) - ea representa a umidade atual do ar nos diferentes níveis de medida.

\subsubsection{Caracterização do Estado Atmosférico}

O estado atmosférico, no que diz respeito à condição de estabilidade, instabilidade ou neutralidade atmosférica, foi caracterizada pela obtenção e análise do número de Richardson (Ri). Este é um parâmetro adimensional que relaciona os processos convectivos devido à ação térmica ou por forças mecânicas (convecção livre ou forçada). Desta forma, ele permite avaliar sob qual ação predominante a atmosfera esta sujeita em um determinado momento, indicando o tipo de turbulência e, portanto, o grau de estabilidade, instabilidade ou de neutralidade atmosférica. Sua determinação leva em consideração medidas da velocidade do vento em dois níveis e da temperatura do ar nos mesmos níveis :

$$
\mathbf{R i}=\{\mathbf{g} \cdot(\Delta \mathbf{T} / \Delta \mathbf{z})\} /\{\mathbf{T} .(\Delta \mathbf{U} / \Delta \mathbf{z})\}
$$

onde $\Delta \mathbf{T}$ é a diferença entre a temperatura do ar em dois níveis subsequêntes; $\Delta \mathbf{z}$ é a diferença entre as alturas de dois níveis subsequêntes; $\Delta \mathbf{U}$ é a variação da 
velocidade do vento nos dois níveis subsequêntes; $\mathbf{T}$ é a temperatura média nos níveis considerados.

Segundo PRIESTLEY (1955), citado por ANDRÉ (1981), os limites do parâmetro de estabilidade Ri são os seguintes :

$\mathrm{Ri}<-0,03$, início de convecção livre;

$-0,03<\mathrm{Ri}<-0,02$, regime de transição;

$-0,02<\mathrm{Ri}<0$, conveç̧ão forçada.

A fim de proporcionar uma correção para condições não adiabáticas, utilizou-se o parâmetro adimensional $\phi \mathrm{m}$, definido por vários autores como uma função do número de Richadson :

$$
\begin{aligned}
& \phi \mathbf{m}=(1+5 . R \mathbf{i})^{-1} \\
& \phi \mathbf{m}=(1-16 . R \mathbf{i})^{-0,25}
\end{aligned}
$$

A equação 19 foi utilizada para condições de estabilidade, e a equação 20 para condições de instabilidade, observadas em relação aos valores encontrados de Ri. Para o obtenção dos valores de Ri, considerou-se dois níveis de medida.

\subsubsection{Parâmetros Aerodinâmicos}


O perfil de vento foi determinado tomando-se as médias horárias, onde os anemômetros acumulavam a velocidade do vento em metros, que foram transformadas $\mathrm{em} \mathrm{cm} / \mathrm{s}$, dividindo-se os valores registrados pelo período de uma hora. Os parâmetros aerodinâmicos referentes ao deslocamento do plano zero (d) e rugosidade da superfície, foram obtidos observando-se proposições da literatura para a cultura do trigo, adotando-se os valores de $d=0,75$.h e $\mathrm{Zo}=0,15$.h.

A velocidade de friç̧ão $\left(u^{*}\right)$ foi obtida segundo expressão a partir do perfil logaritmico de vento, descrita em MONTEITH (1989) :

$u^{*}=(d u / d z)^{*}\{k \cdot(z-d)\}$

onde $\mathbf{k}$ é a constante de von Karman; du/dz é a variação da velocidade do vento no espaço, entre dois níveis de altura; d é o deslocamento do plano zero.

\subsubsection{5 - Resistência Aerodinâmica}

A resistência aerodinâmica foi obtida, para cada hora, segundo a equação desenvolvida em relação ao perfil logaritmico de vento, de acordo com BARLEY \& DAVIES (1981) :

$$
\begin{aligned}
& \operatorname{ram}=\operatorname{Ln}\left\{\left(\mathrm{z}-\mathrm{d}+\mathrm{Zo}_{0}\right) / \mathrm{Z}_{0}+\phi \mathrm{m}^{2}\right\} / \mathrm{k} \cdot \mathrm{U}(\mathrm{z}) \\
& \mathrm{ra}=\mathrm{ram}+6,266 \cdot\left(\mathrm{u}^{*}\right)^{-2 / 3}
\end{aligned}
$$




\subsubsection{6 - Resistência da Cobertura}

A resistência da cobertura foi determinada de acordo com a equação originária do balanço de energia, de acordo com HATFIELD (1985):

$$
\mathbf{r c}=\frac{\rho . c p}{\gamma} \cdot \frac{\left.\left\{\left[\mathrm{es}\left(\mathrm{Ts}_{\mathrm{s}}\right)-\mathrm{ea}\right)\right]\right\}}{\left\{\mathrm{Q}^{*}-[\rho . c p .(\mathrm{Ts}-\mathrm{Ta}) / \mathrm{ra}]\right\}}-\mathbf{r a}
$$

\subsubsection{7 - Fluxos de Calor Latente e Sensível}

Os fluxos de calor latente (LE) e sensível (H) foram determinados partindo-se da equação geral do balanço de energia, tendo como dado de entrada a temperatura de superficie :

$$
H=\rho \cdot c p \frac{\left(T_{s}-T_{a}\right)}{r a}
$$

$$
L E=\rho \cdot c p \cdot \frac{\left(e_{s}(T s)-e a\right)}{\gamma_{\cdot}(r a+r c)}
$$




\subsubsection{8 - Índice de Estresse Hídrico}

Foram determinados, para cada hora, nos dias observados, o CWSI ("Crop Water Stress Index"), da forma como inicialmente proposta por IDSO et al. (1981), e da forma analiticamente desenvolvida por JACKSON (1982).

O índice proposto inicialmente por IDSO et al. (1981) procura associar três condições distintas. A primeira se encontraria sob uma condição de total disponibilidade hídrica, onde a cultura estaria perdendo água por evapotranspiração potencial, ou seja, onde não se verificaria restrições à transpiração. Nesta situação, observaram os autores uma relação linear entre (Ts Ta) e o déficit de pressão de vapor do ar. Desde que haja a condição prevista, estaria esta situação representada pela reta de regressão qua define a relação linear observada. A segunda situação, também extrema, representaria uma condição de evapotranspiração nula, onde a transpiração cessaria. A terceira situação representaria uma condição real, observada a qualquer instante, e que estaria necessariamente entre as duas outras situações extremas.

Desta forma, os autores definiram o CWSI como consta do ítem 2.2.3, equação 2.2.3.1.

Resta, portanto, a determinação dos valores esperados de (Ts - Ta) para a condição extrema de transpiração zero. Conforme explicitado no ítem 2.2.3, tal situação varia em função da temperatura do ar. Foram determinados, portanto, para cada temperatura do ar observada, para cada dia e hora em que foram determinadas, os limites máximos, onde se determinou a equação da reta que os define. 
O CWSI foi determinado também baseando-se na proposição teórica que consta do ítem 2.2.3, equação 2.2.3.2. Os valores da resistência da cobertura foi obtida conforme o ítem 3.2.4.6, sendo que os valores do coeficiente psicrométrico foram considerados constante, onde se desprezou as possíveis correções, que contam na equação 2.2.3.3.

Ressalte-se que a razão rc/ra foi obtida dividindo-se ambos os parâmetros, obtidos individualmente conforme os métodos descritos (equações 3.2.4.5.1 e 3.2.4.6.1). Não se utilizou, portanto, a equação 2.2.3.4, que apenas serviu de demostração dos métodos utilizados pelo autor.

\subsubsection{9 - Relações Empíricas}

A partir dos dados coletados no tratamento irrigado, nos respectivos dias, selecionaram-se 33 valores de déficit de pressão de vapor do ar, em diversos horários, e os respectivos valores de Ts - Ta. Com estes valores, encontrou-se, por regressão linear simples, uma reta que define como variável independente os valores de $(e s(T)-e a)$.

De acordo com a metodologia descrita, que serve de base para o desenvolvimento do CWSI proposto por IDSO et al.(1981), obteve-se, pelo uso da equação de regressão determinada, os índices para todos os horários e dias. Os valores máximos possíveis, ou limite máximo, de Ts - Ta, segundo o método descrito, foram obtidos considerando a temperatura do ar para cada hora determinada. Sua estimativa considerou a determinação de uma equação de 
regressão entre valores de $\mathrm{Ta}$, variando de 15 a $35^{\circ} \mathrm{C}$, e os respectivos de es(Ts) ea.

Foram comparados os índices obtidos pelas duas metodologias propostas, bem como com aqueles considerando, para a cultura do trigo, as relações lineares obtidas por IDSO et al. (1981). 


\section{RESULTADOS E DISCUSSÃO}

\section{1 - Caracterização dos Tratamentos}

O experimento, caracterizado pelos tratamentos denominados irrigado e não irrigado, pode ser satisfatoriamente diferenciado desta forma, devido à falta de precipitação a partir do momento em que se deixou de irrigar a metade do campo experimental.

Os valores relativos à precipitação, irrigação, evaporação do tanque Classe A, bem como os valores determinados da evapotranspiração de referência (ETo) e evapotranspiração máxima (ETM) diários e acumulados, para o tratamento irrigado, podem ser visualizados na tabela 3 do apêndice. De forma análoga, tem-se os valores relativos ao tratamento não irrigado na tabela 4 .

Pode-se verificar, analisando ambos os quadros, que o tratamento não irrigado recebeu, por intermédio de irrigações efetuadas, uma última adição de água no dia 07/07, correspondente a $25,20 \mathrm{~mm}$. A partir deste dia deixou-se de irrigar metade do campo experimental. Após esta data, o tratamento não irrigado recebeu adição de água nos dias $11 / 07$ e 08/08, equivalente à 13.8 e $9.2 \mathrm{~mm}$, respectivamente, pelas chuvas ocorridas. 
Em contrapartida, no tratamento irrigado procedeu-se seis irrigações após o dia em que se deixou de irrigar metade do campo experimental. Neste dias, sendo eles 22/07, 29/07, 03/08, 09/08, 14/08 e 22/08, foram adicionados 25, 26, $25,15,24$ e 10,5 mm, respectivamente. Este valores foram, portanto, o "diferenciador" entre os tratamentos, ou seja, foram adicionados numa metade do campo apenas. $\mathrm{O}$ tratamento não irrigado foi submetido, portanto, à um severo grau de estresse hídrico, uma vez que deixou de receber uma quantidade de água equivelente à $125,5 \mathrm{~mm}$, que foram adicionadas observando-se os métodos descritos no ítem 3.2.1.

Em relação aos métodos empregados para se determinar a quantidade de água a ser aplicada, bem como a época de aplicação (ítem 3.2.1), estes foram de grande valia, uma vez que os tensiômetros acusaram satisfatoriamente a necessidade de aplicação, que se deu sempre considerando os valores acumulados da evapotranspiração máxima do período entre as irrigações.

$\mathrm{Na}$ tabela 3 do apêndice, constam também os valores relativos aos potenciais matriciais acusados pelos tensiômetros.

Pode-se notar que os tensiômetros, considerando o período posterior à 07/07, data da última irrigação, responderam satisfatoriamente. Neste sentido, sempre que se procedia irrigações, os valores dos potenciais matriciais caiam drasticamente, apresentando valores crescentes a partir de então.

Os valores encontrados, que nortearam as irrigações foram, para a profundidade de $15 \mathrm{~cm}$, de -0,055 MPa (dia 22/07); -0,05 Mpa (dia 29/07); -0,046 Mpa (dia 03/08); -0,053 MPa (dia 08/08); -0,048 MPa (dia 14/08) e -0,056 MPa (dia 21/08).

Nestes dias, a quantidade total de água aplicada se equivaleu à evapotranspiração máxima acumulada desde à última irrigação. Assim, no dia 
22/07, a evapotranpiração máxima acumulada atingiu um valor de $42,86 \mathrm{~mm}$ desde à última irrigação $(07 / 07)$. Neste período houve um total de $13,8 \mathrm{~mm}$ relativos às chuvas ocorridas, e a quantidade de água aplicada foi de $25 \mathrm{~mm}$, totalizando $38,8 \mathrm{~mm}$ de água recebida. No dia 29/07, a evapotranspiração máxima acumulada desde à última irrigação foi de $28,23 \mathrm{~mm}$, sendo irrigado $26 \mathrm{~mm}$. No dia 03/08, houve aplicação de água correspondente à $25 \mathrm{~mm}$, sendo que a evapotranspiração máxima acumulada desde $29 / 07$ foi de $25,73 \mathrm{~mm}$. No dia 09/08, foram aplicados $15 \mathrm{~mm}$ de água por irrigação que, acrescidos de $9,2 \mathrm{~mm}$ de precipitação, totalizam $24,2 \mathrm{~mm}$, contra $23,31 \mathrm{~mm}$ de evapotranspiração máxima acumulada desde 03/08. No dia 14/08, houve irrigação de $24 \mathrm{~mm}$, sendo a evapotranspiração máxima acumulada desde $09 / 08$ foi de $20,79 \mathrm{~mm}$. Finalmente, no dia 22/08, houve irrigação de $10,5 \mathrm{~mm}$, sendo que a evapotranspiração máxima acumulada desde $14 / 08$ foi de $68,44 \mathrm{~mm}$. Nesta última irrigação, contudo, as amostragens no tratamento irrigado já haviam sido encerradas, sendo a última ocorrida no dia 13/08. Não houve, portanto, influência nos dados coletados no tratamento irrigado devido à última irrigação não ter sido corretamente efetuada.

O importante é notar que a condição de evapotranspiração potencial foi satisfeita nos dias em que se procedeu as amostragens no tratamento irrigado. Nestes dias, 22/07, 06/08 e 13/09, os potenciais matriciais foram de $-0,055 \mathrm{MPa}$, $-0,023 \mathrm{MPa}$ e -0,033 $\mathrm{MPa}$, respectivamente, na profundidade de $15 \mathrm{~cm}$.

No tratamento não irrigado não se pode obter valores dos potenciais matriciais nos dias amostrados. Isto porque os tensiômetros não mais registravam valores concordantes entre si, sendo desprezadas as medidas obtidas. Este comportamento era esperado, uma vez que sabe-se que os tensiômetros não registram satisfatoriamente valores superiores à $-0,080 \mathrm{MPa}$. Tais valores foram 
registrados antes do primeiro dia de amostragem no tratamento não irrigado (dia 29/07).

\section{2 - Temperatura da Superfície}

Os valores da temperatura da superfície (Ts), obtidas sempre para as duas condições de estado hídrico as quais se submeteu a cultura, nos dias e horas amostradas, podem ser visualizadas nas tabelas $5,8,11,14,17,20,23$ e 26 do apêndice. O comportamento de suas médias são mostrados nas figuras $2,3,4$ e 5 , onde aparecem seus valores horários, para cada dia considerado.

Pela análise destes resultados, observa-se que a temperatura da superfície obtida no tratamento sujeito à estresse hídrico (não irrigado) foi sempre superior, em todos os dias e quase todos os horários, aos valores obtidos no tratamento irrigado. A única excessão ocorreu no dia 13/08, no horário das 13 horas. Tal comportamento está de acordo com o descrito na literatura (IDSO et al. 1981; JACKSON 1982; STEINMETZ et al.,1989), sobre a diferença de temperatura de superfície vegetada quando sob condições hídricas distintas no solo.

De forma análoga, as diferenças observáveis se tornam mais acentuadas à medida em que a disponibilidade hídrica da cultura diminui, para a condição não irrigada, em comparação com o tratamento irrigado. Pode-se notar que, para o dia $27 / 07$, a diferença máxima foi de $2.4{ }^{\circ} \mathrm{C}$, observada às 13 horas. Esta diferença chega a $6.7^{\circ} \mathrm{C}$ às 15 horas do último dia amostrado (22/08). Isto revela que as diferenças se acentuam à medida que as diferentes condições 
hídricas as quais se submeteu as culturas também se distanciam, ou seja, à medida em que a severidade do estresse hídrico aumenta.

Contudo, esta assertativa apenas seria inequívoca se tais diferenças se acentuassem sempre, de um dia de amostragem para outro. Isto contudo não foi verificado, o que nos leva a crer que outros fatores influenciam na temperatura da superfície. Os valores das diferenças das temperaturas da superfície, de maneira genérica, a partir do primeiro dia de amostragem, até o último, sofreram uma queda nos dias 11/08 e 13/08, notadamente. Este fato é esperado, uma vez que outros fatores, sejam eles a radiação líquida, o déficit de pressão de vapor do ar, o vento, bem como as condições atmosféricas atuam no sistema de modo interativo, de modo que a resposta a um aumento de temperatura ou não da superfície do dossel não seja unicamente função das condições de disponibilidade hídrica as quais estão sujeitas.

\section{3 - Condições Micrometeorológicas}

\subsection{1 - Resistência da Cobertura}

As figuras $6,7,8$ e 9 mostram a variação dos valores horários da resistência da cobertura e da resistência aerodinâmica para cada dia amostrado. Os valores correspondentes aos mostrados no gráfico constam nas tabelas 7,10 , $13,16,19,22,25$ e 28 do apêndice. 

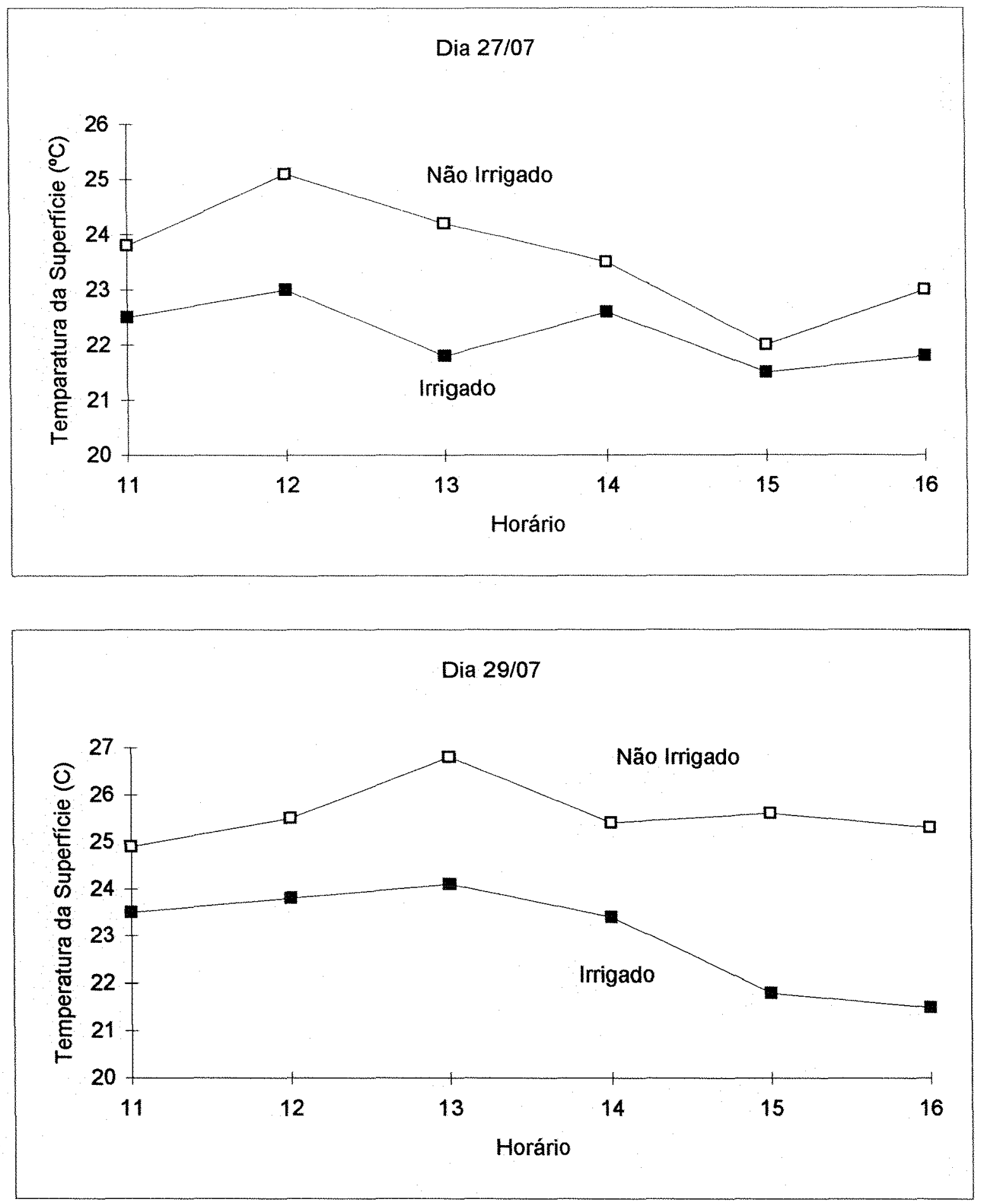

Figura 2 - Variação Horária da Temperatura da Superfície para o Tratamento Irrigado e o Não Irrigado nos dias 27/07/91 e 29/07/91 em Trigo 
Dia 06/08

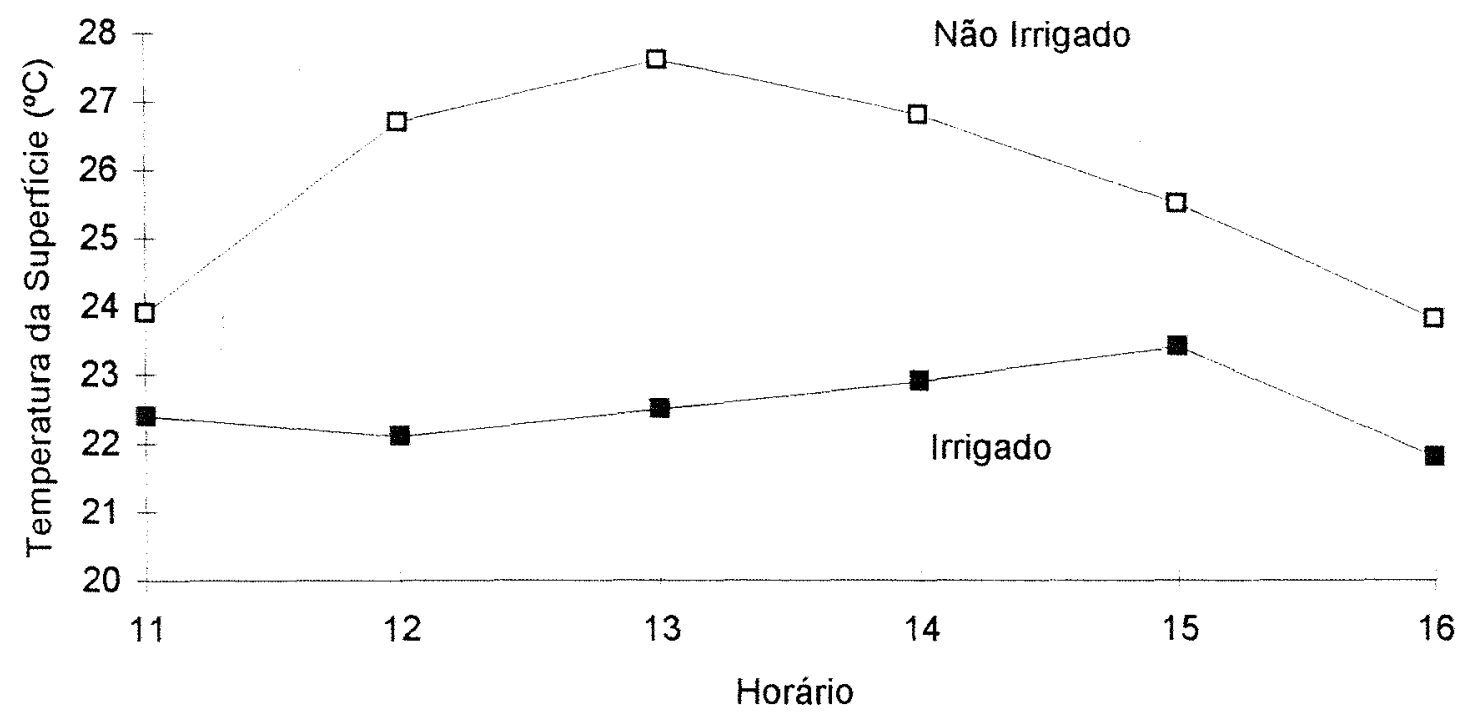

Dia $07 / 08$

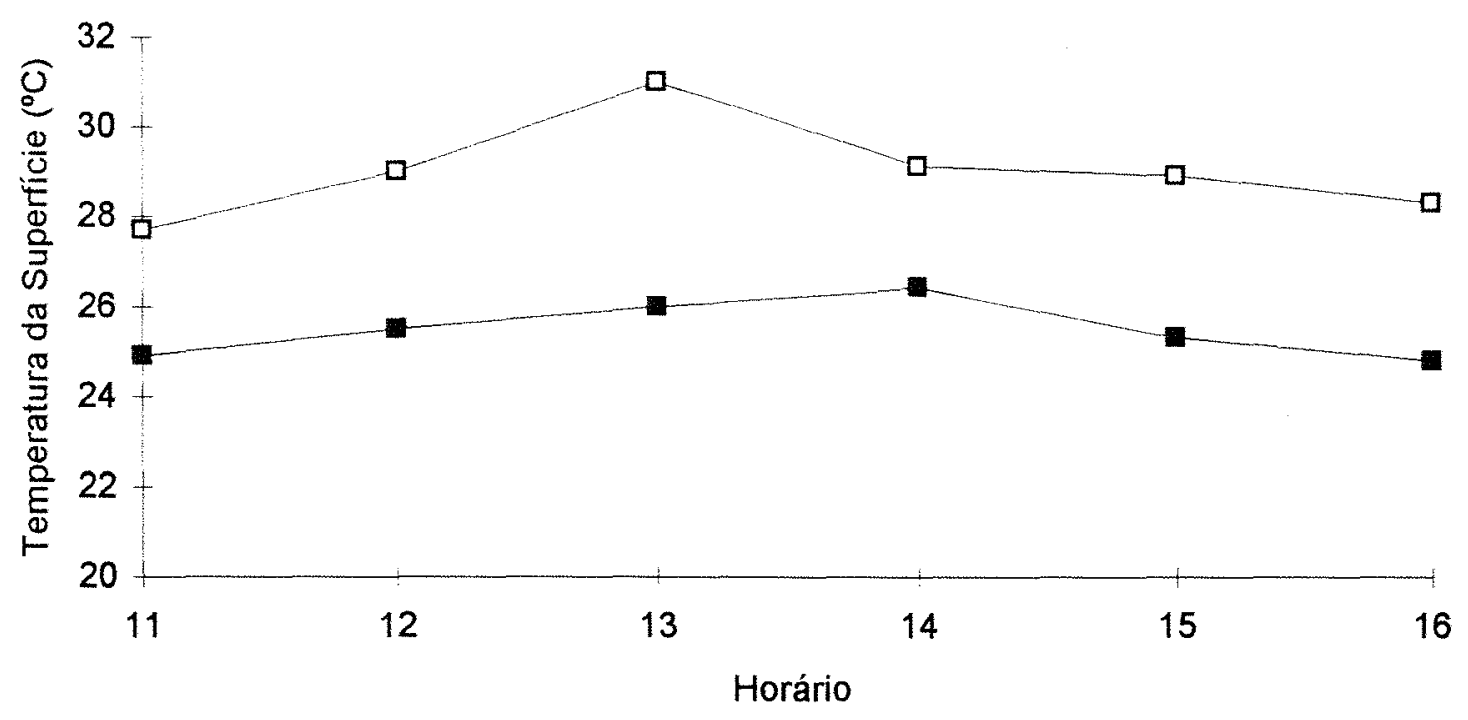

Figura 3 - Variação Horária da Temperatura da Superfície para o Tratamento Irrigado e o Não Irrigado nos dias 06/08/91 e 07/08/91 em Trigo 

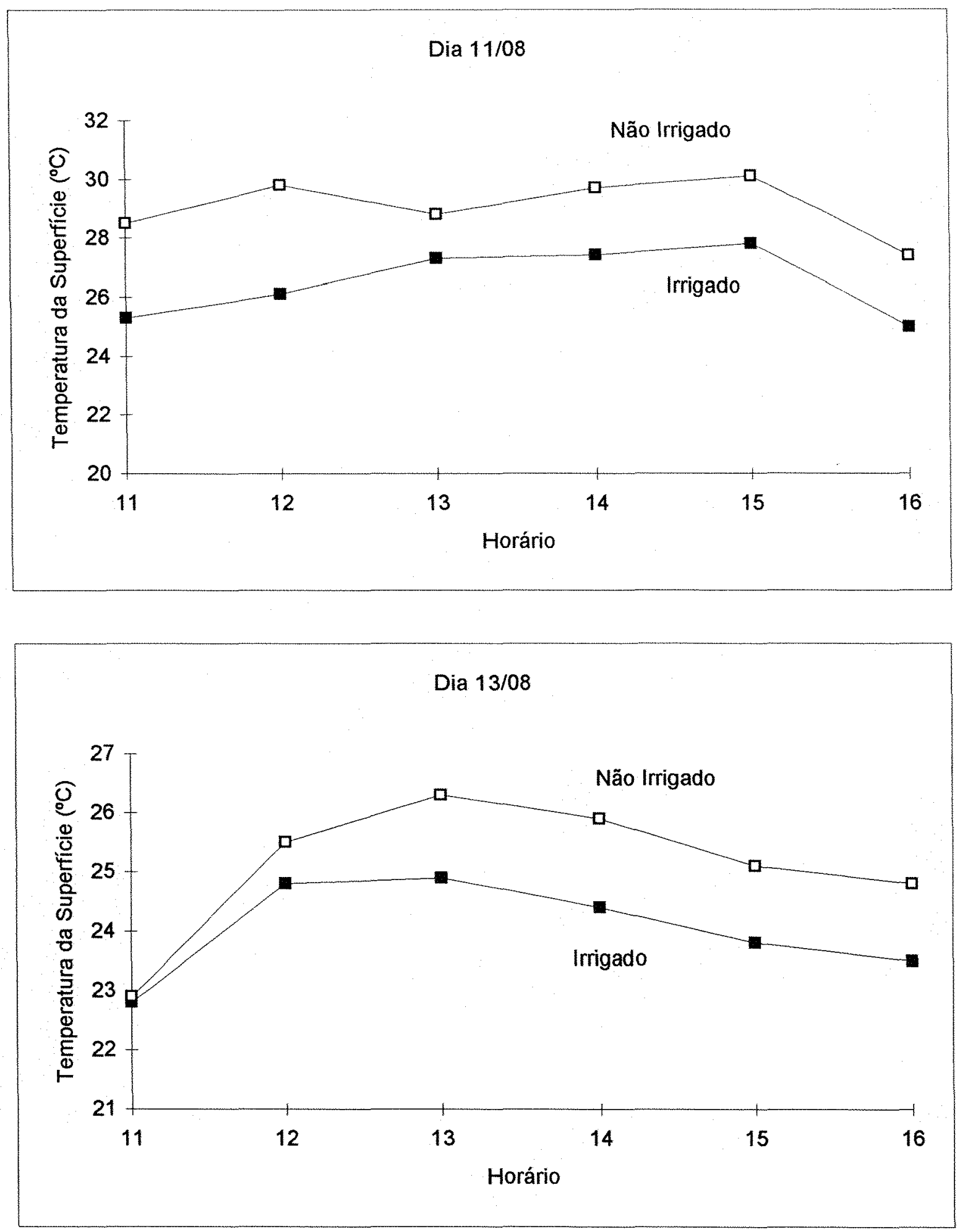

Figura 4 - Variação Horária da Temperatura da Superfície para o Tratamento Irrigado e o Não Irrigado nos dias 11/08/91 e 13/08/91 em Trigo 

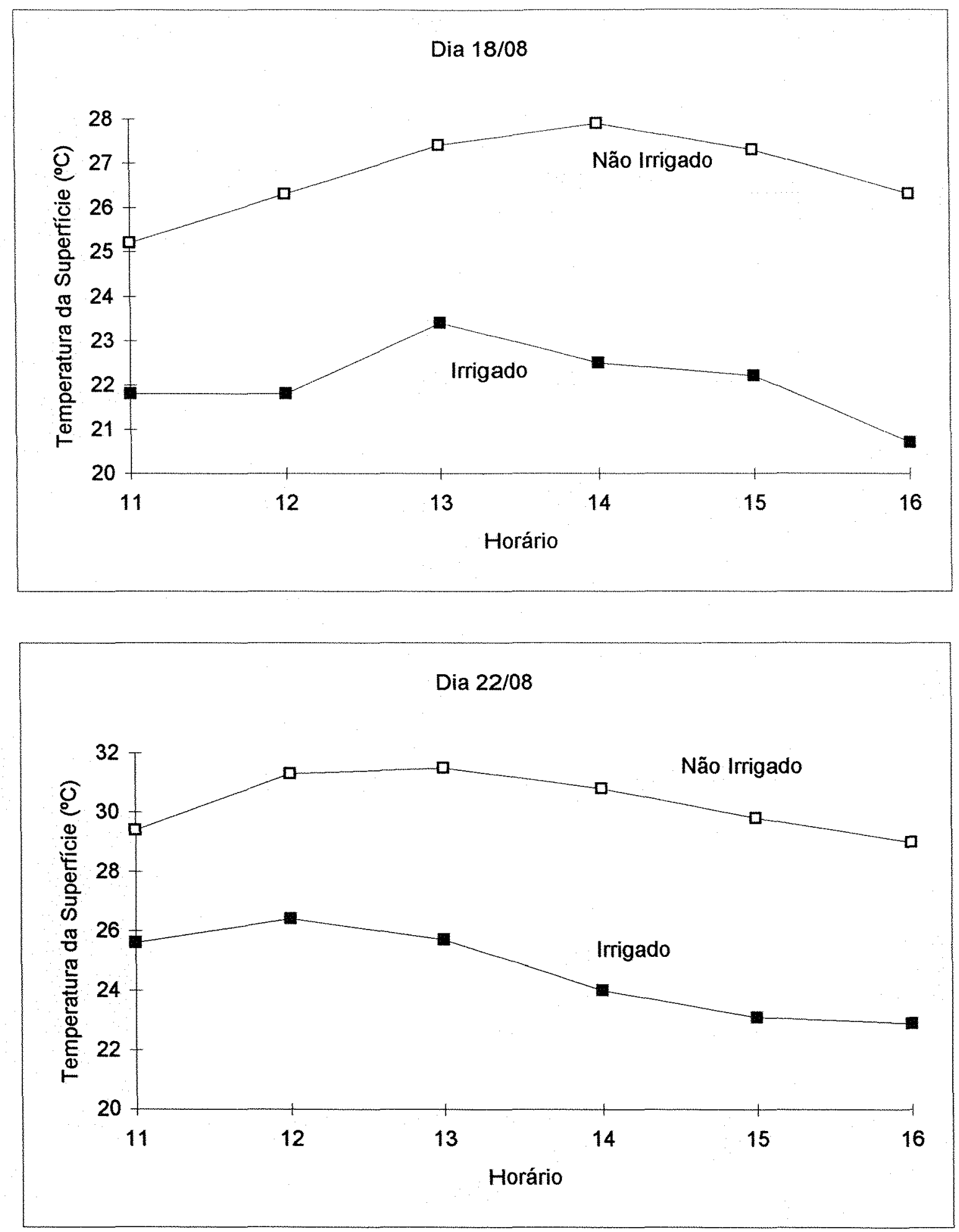

Figura 5 - Variação Horária da Temperatura da Superfície para o Tratamento Irrigado e o Não Irrigado nos dias 18/08/91 e 22/08/91 em Trigo 
O gráfico inclui os valores de ra e rc em conjunto. Procedeu-se desta maneira devido ao fato observado de que o comportamento da resistência aerodinâmica foi bastante semelhante para todos os dias em questão. Assim podese avaliar graficamente as diferenciações ocorridas no comportamento da resistência da cobertura, para cada dia amostrado, à medida em que a disponibilidade hídrica para a cultura progressivamente diminuia. Tal comparação se dá a medida em que a resistência aerodinâmica pouco variava e a resistência da cobertura produzia respostas às condições hídricas.

Os valores encontrados nos dias onde as amostragens ocorreram nos horários das 11 às 16 horas, são mostrados na tabela 2.

Nota-se, primeiramente, que os valores da resistência da cobertura obtidos não são coincidentes para os três dias, nos respectivos horários. Os únicos valores que se mostraram próximos foram os relativos às 11,12 e 15 horas dos dias 27/07 e 13/08, e os relativos à 14 horas dos dias $27 / 07$ e 06/08. Outro aspecto concordante diz respeito ao horário das 16 horas, onde se encontrou um acréscimo acentuado dos valores nos dias $27 / 07$ e $06 / 08$. Essa tendência de aumento no final da tarde é consequência do aumento da resistência estomática à difusão de vapor.

Os valores observados são, para todos os dias amostrados, bastante superiores aos obtidos por HATFIELD (1985) que, para a cultura do trigo e sob condições de evapotranspiração potencial, revelaram ser de 20 à $25 \mathrm{~s} / \mathrm{m}$ nos horários próximos ao meio do dia. De forma análoga, SMITH et al. (1985) obtiveram sob condições semelhantes valores próximos à $40 \mathrm{~s} / \mathrm{m}$, para a cultura do trigo, cuja concordância apenas se deu em um dos horários observados (16 horas, dia 06/08). 

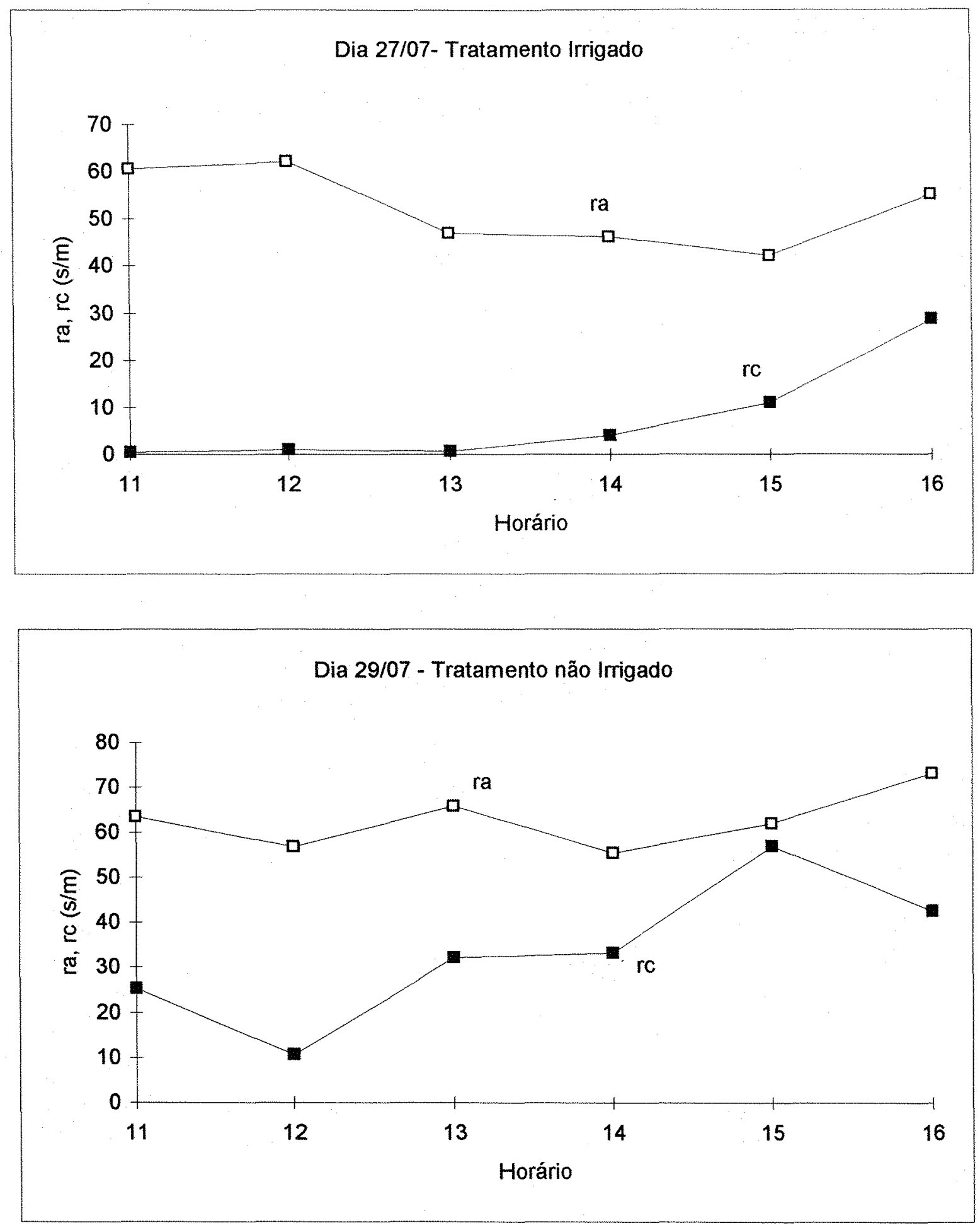

Figura 6 - Comportamento Horário da Resistência da Cobertura (rc) e da Resistência Aerodinâmica (ra) 

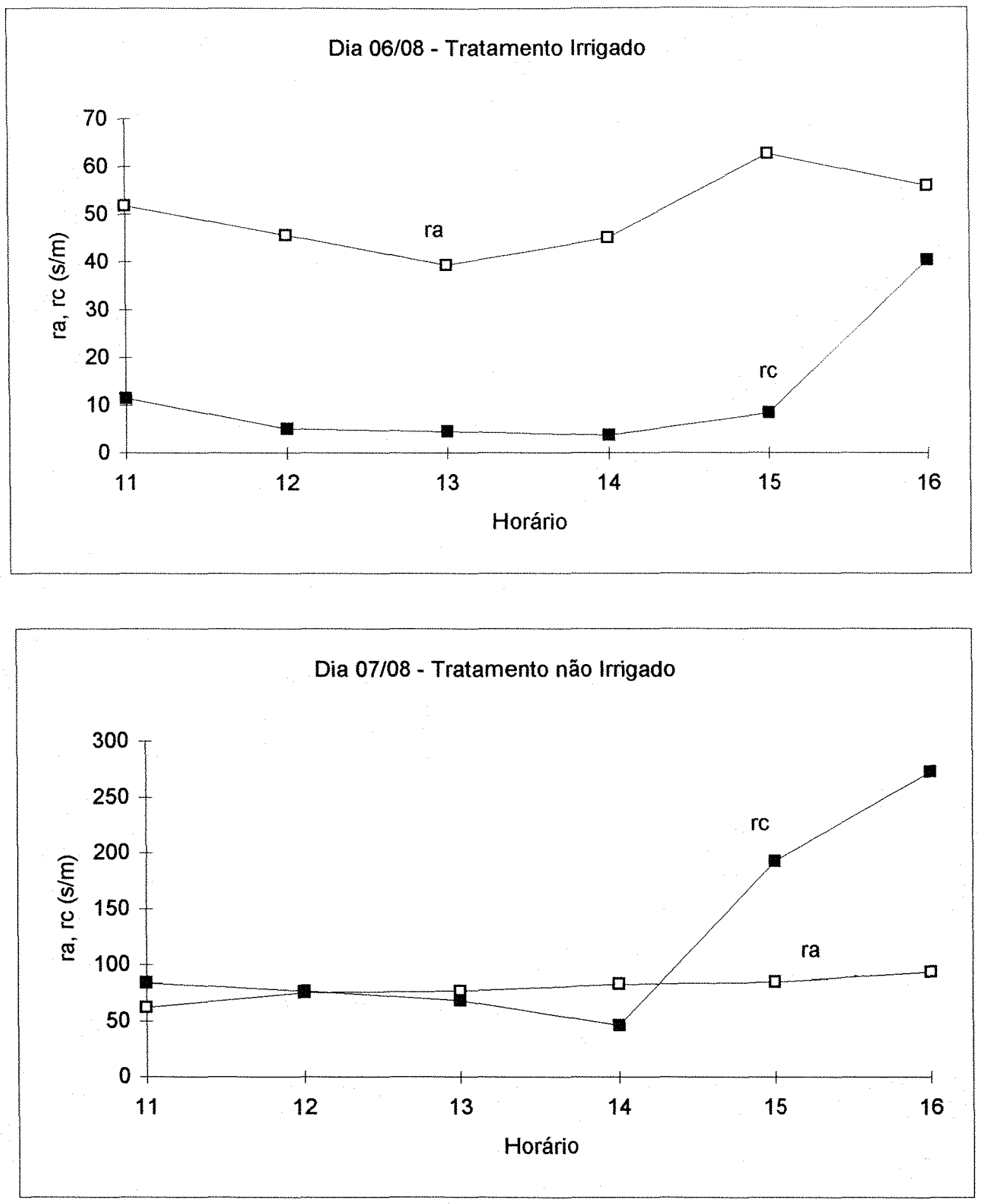

Figura 7 - Comportamento Horário da Resistência da Cobertura (rc)

e da Resistência Aerodinâmica (ra) 


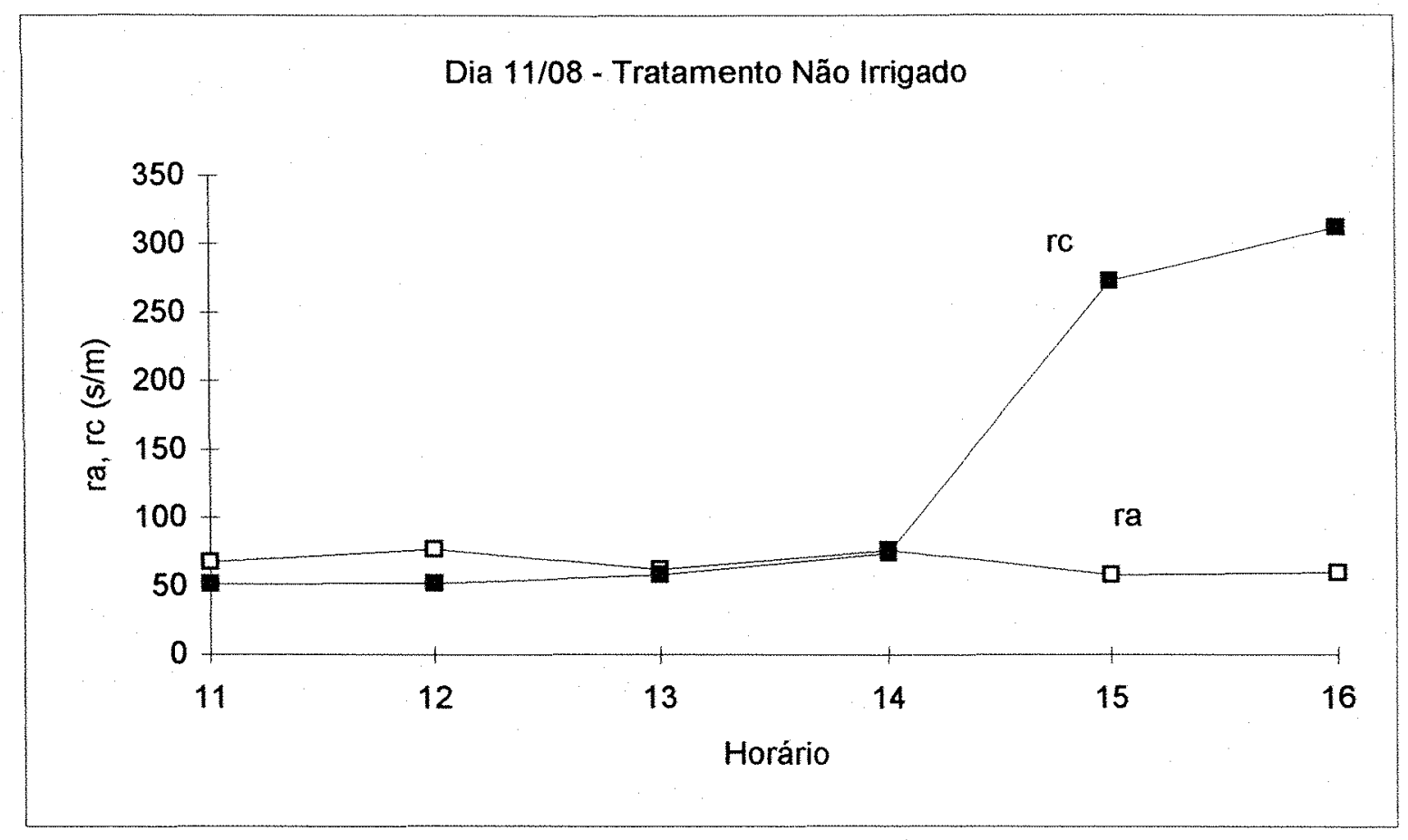

Dia 13/07 - Tratamento Irrigado

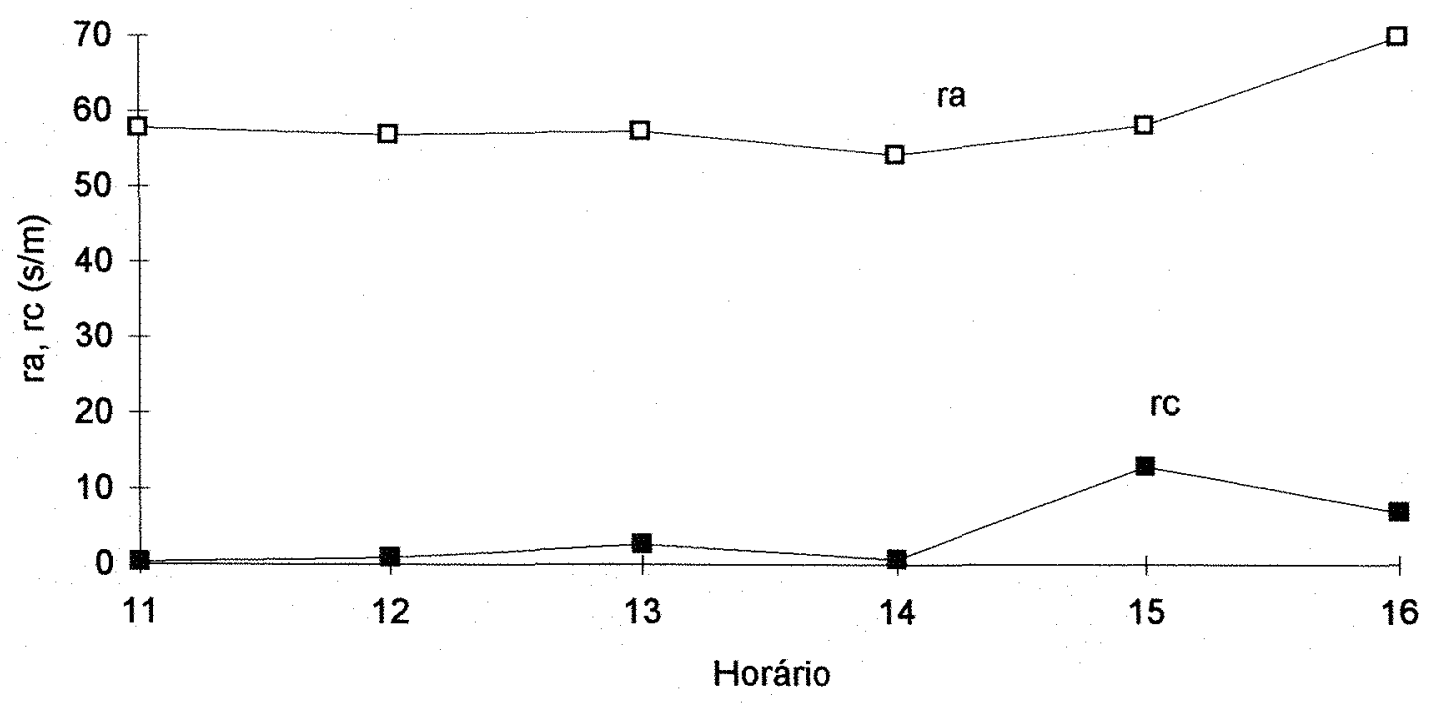

Figura 8 - Comportamento Horário da Resistência da Cobertura (rc) e da Resistência Aerodinâmica (ra) 

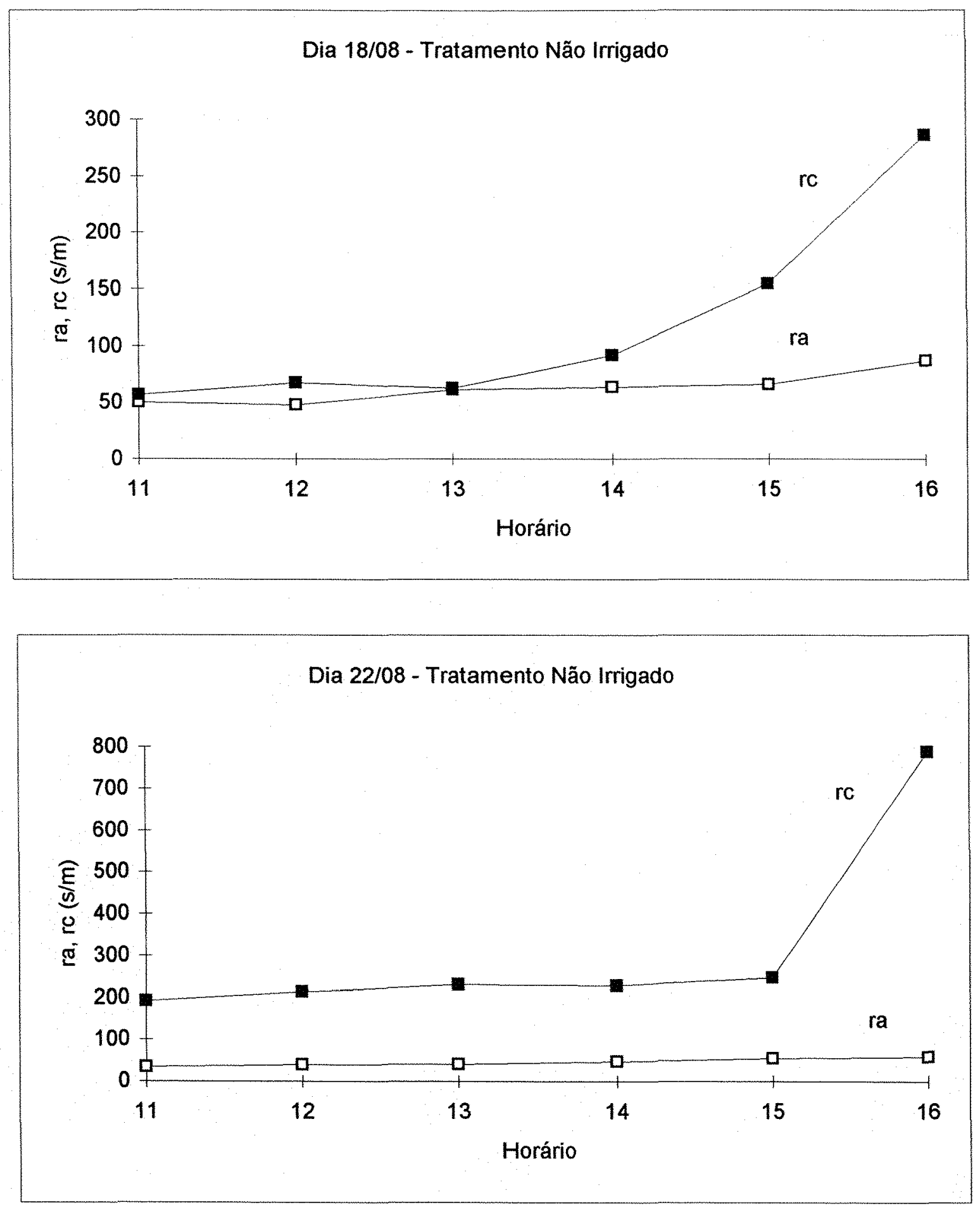

Figura 9 - Comportamento Horário da Resistência da Cobertura (rc) e da Resistência Aerodinâmica (ra) 
Tabela 2 - Valores Horários ds Resistência da Cobertura $(\mathrm{s} / \mathrm{m})$ nos vários dias de observação, nos Tratamentos Irrigado e Não Irrigado, em Trigo.

\begin{tabular}{|c|c|c|c|c|c|c|}
\hline Dia/Hora & 11 & 12 & 13 & 14 & 15 & 16 \\
\hline \multicolumn{7}{|c|}{ Irrigado } \\
\hline $27 / 07$ & 0,4 & 1,0 & 0,7 & 4,0 & 11,0 & 28,7 \\
\hline $06 / 08$ & 11,4 & 5,0 & 4,4 & 3,7 & 8,3 & 40,3 \\
\hline $13 / 08$ & 0,3 & 0,9 & 2,7 & 0,7 & 13,0 & 7,0 \\
\hline \multicolumn{7}{|c|}{ Não Irrigado } \\
\hline $29 / 07$ & 25,3 & 10,7 & 32,1 & 33,2 & 56,9 & 42,6 \\
\hline $07 / 08$ & 84,0 & 76,8 & 68,1 & 46,2 & 192,3 & 272,5 \\
\hline $11 / 08$ & 81,7 & 51,8 & 58,4 & 74,4 & 272,3 & 312,0 \\
\hline $18 / 08$ & 56,8 & 67,7 & 63,0 & 91,9 & 154,5 & 286,3 \\
\hline $22 / 08$ & 192,1 & 213,6 & 231,5 & 228,6 & 247,4 & 788,4 \\
\hline
\end{tabular}

O comportamento observado nos gráficos, contudo, demonstra que, mesmo com discrepâncias entre os valores obtidos para os três dias observados, houve tendência de os valores da resistência da cobertura serem sempre muito inferiores aos da resistência aerodinâmica.

De uma forma geral, os valores da resistência da cobertura nos dias observados no tratamento irrigado foram bastante baixos, ainda que mensuráveis, o que indica que estes podem assim ser determinados em condições de evpotranspiraçào potencial. É de se salientar que os valores encontrados foram condizentes com o esperado, no sentido em que foram e deveriam ser baixos. É discutível a adoção de um comportamento padrão em relação à resistência da 
cobertura, uma vez que estes dependem não apenas das condições hídricas, mas também de outros fatores ambientais e fisiológicos.

Nota-se pela observação dos dias 29/07, 07/08, 11/08, 18/08 e 22/08 que as curvas relativas à resistência da cobertura (rc) nos tratamentos não irrigados encontram-se progressivamente próximas e mais distantes das curvas relativas à resistência aerodinâmica ( $\mathrm{rc})$.

Pela análise dos valores encontrados, bem como pelas curvas apresentadas, nota-se que os valores da resistência da cobertura obtidos no tratamento não irrigado foram bastante superiores aos encontrados no tratamento irrigado. Tais valores, no tratamento não irrigado, demonstraram obedecer uma tendência ao crescimento conforme a deficiência hídrica aumentava, uma vez que o tratamento não irrigado progressivamente se submeteu à um grau mais severo de deficiência hídrica. A resposta encontrada nos valores da resistência da cobertura foram condizentes com o tratamento dado à cultura, uma vez que seus valores se mostraram suficientemente elevados, principalmente se comparados aos valores obtidos no tratamento irrigado.

Observando, contudo, os valores encontrados por SMITH et al. (1985), de $389,1 \mathrm{~s} / \mathrm{m}$ sob condições de restrição hídrica, nota-se que os dados obtidos foram quase sempre bastante inferiores. Outros estudos revelam uma variação considerável entre os valores obtidos. SMITH et al. (1988) encontraram valores médios de $76 \mathrm{~s} / \mathrm{m}$, para condições de restrições hídricas na cultura do trigo.

Estes resultados apenas ilustram a dificuldade de se analisar comparativamente valores relativos à resistência da cobertura, mesmo para culturas e métodos semelhantes de obtenção de seus valores, pois eles dependem das condições ambientais nas quais foram obtidos. 
Neste experimento, como discutir-se-á adiante, a resistência da cobertura pode ser correlacionada com o CWSI, obtido pela equação 2.2.3.2. Desta maneira, procurou-se determinar qual $o$ fator que influenciou $o$ comportamento do índice, explicando as distorções ocorridas.

\subsection{2 - Balanço de Energia}

A partir dos métodos descritos no ítem 2.2.1, baseados na temperatura da superfície, foi obtida a partição de saldo de radiação $\left(\mathrm{Q}^{*}\right)$ nos fluxos de calor sensível $(\mathrm{Qh})$ e latente $(\mathrm{Qe})$ para todos os dias amostrados, nos horários das 11 às 16 horas. $\mathrm{O}$ valores encontrados podem ser visualizados nas figuras $10,11,12$ e 13 .

Nota-se pelas figuras que o comportamento dos fluxos determinados foram compatíveis com o esperado nos dias $27 / 07,06 / 08$ e 13/08, quando se procedeu a amostragem no tratamento irrigado. Isto porque se observa uma grande participação do fluxo de calor latente dentro do balanço, indicando que a cultura se encontra sob condições de grande disponibilidade hídrica. Observa-se, além deste fato, uma presença relativa minoritária do fluxo de calor sensível, indicando que a dissipação de energia dentro do sistema se deu prioritariamente por evaporação.

Em contrapartida, observou-se nestes dias, valores de fluxo de calor latente superiores aos valores medidos da radiação líquida, indicando a presença de adição energética de fora do sistema. Sob estas condições, tem-se reportado 

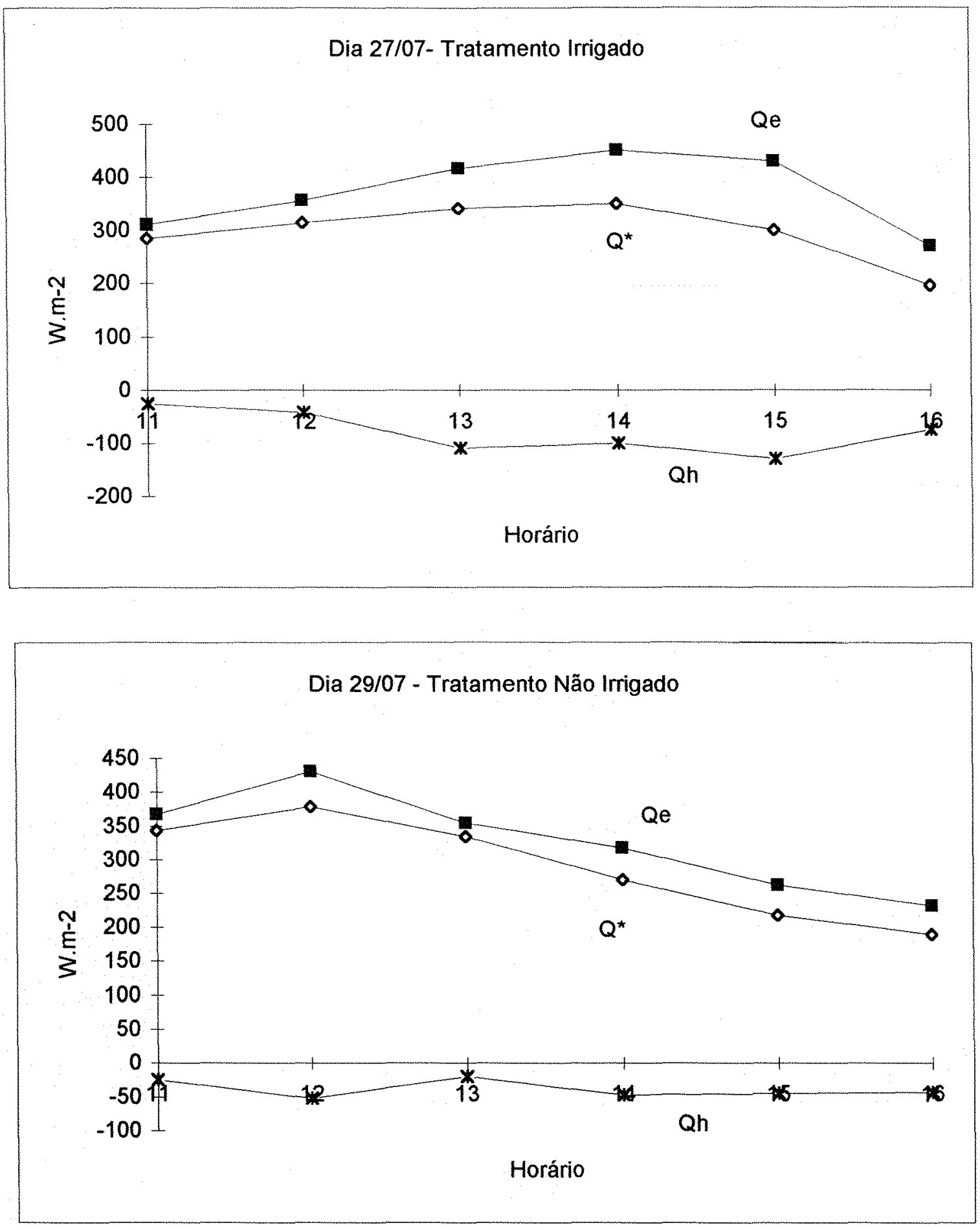

Figura 10 - Fluxos Horários de Saldo de Radiação (Q*), Calor Latente (Qe) e de Calor Sensivel (Qh) 

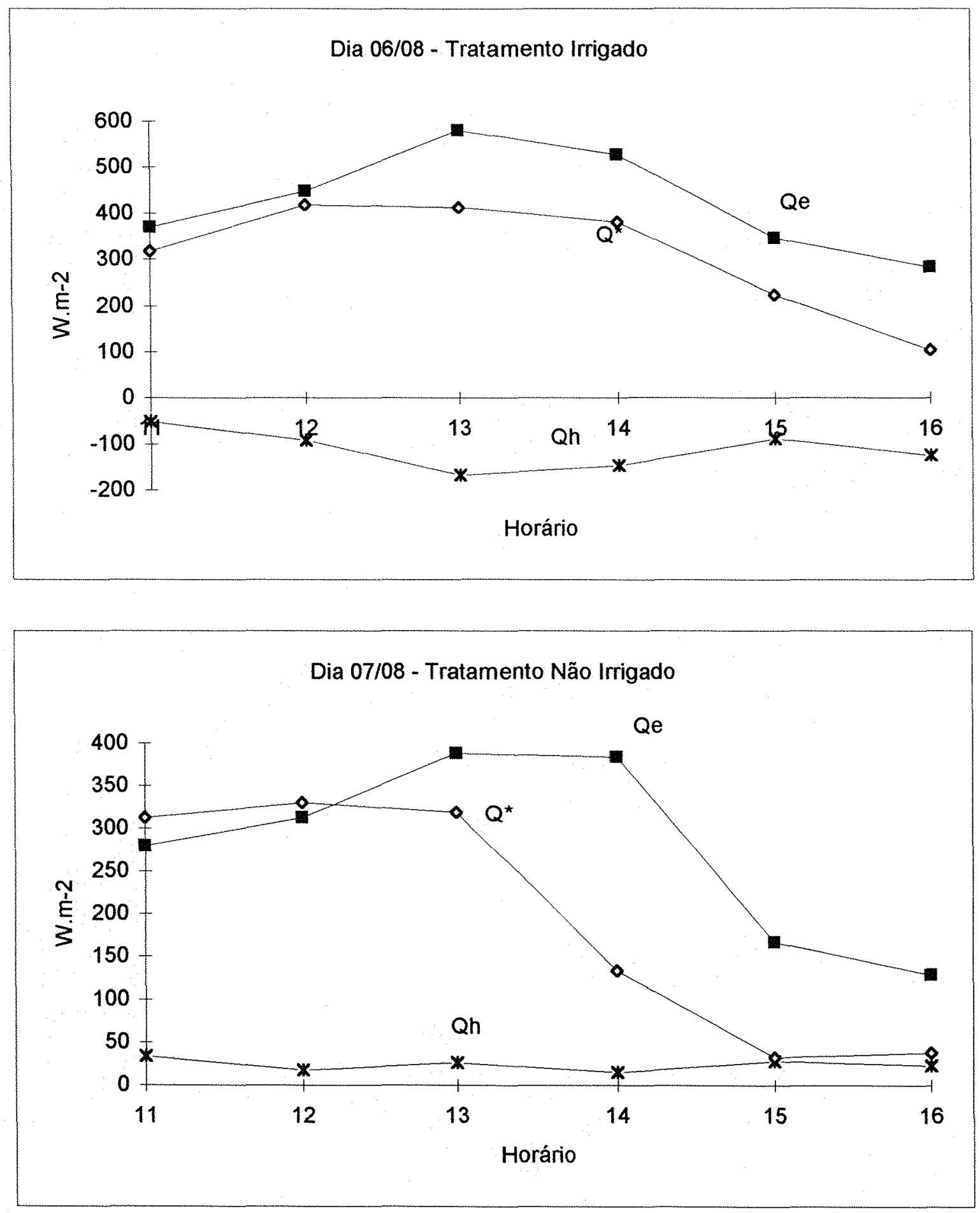

Figura 11 - Fluxos Horários de Saldo de Radiação (Q*), Calor Latente (Qe) e de Calor Sensivel ( $Q h)$ 

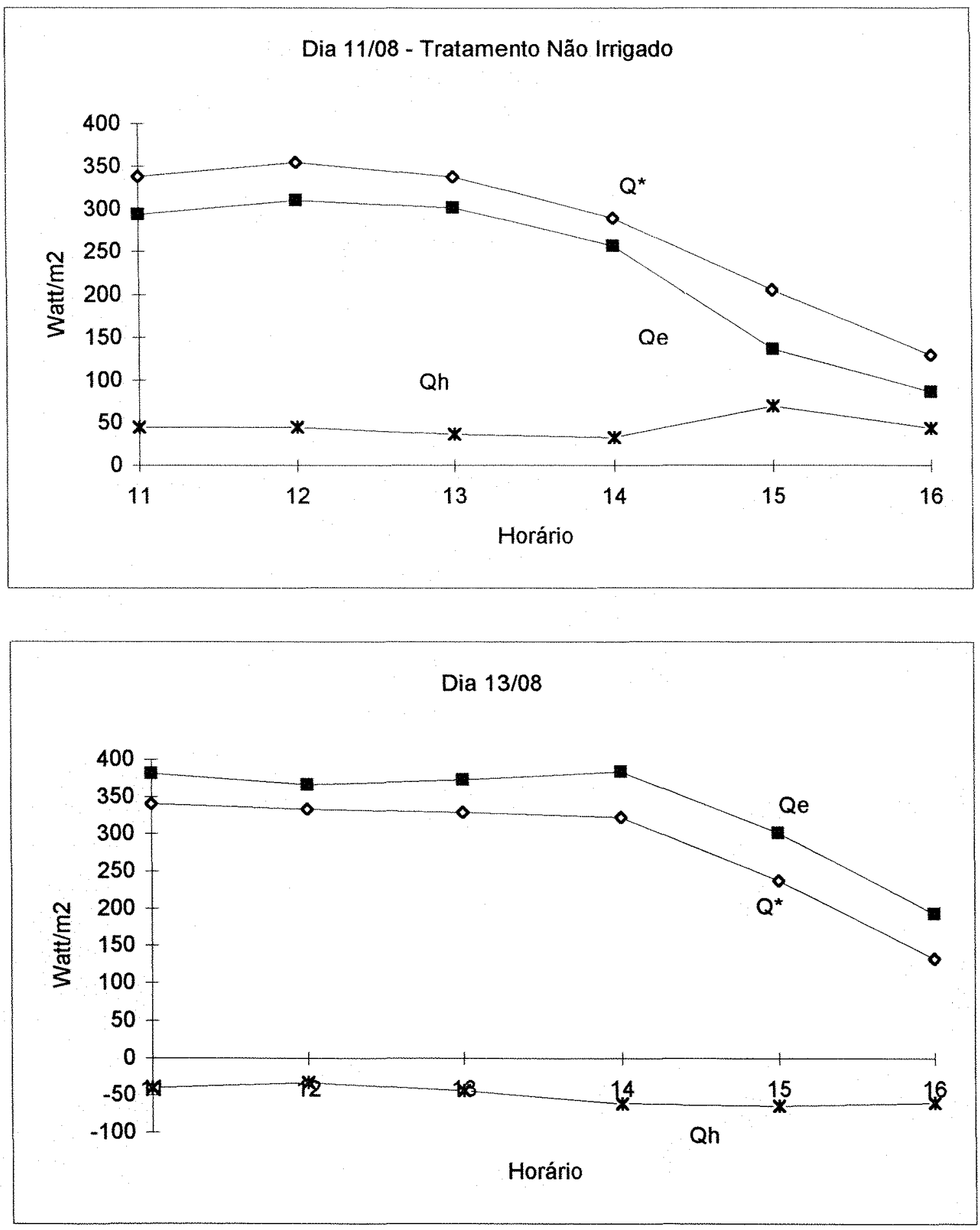

Figura 12 - Fluxos Horários de Saldo de Radiação $\left(Q^{\star}\right)$, Calor Latente $(Q e)$ e de Calor Sensivel ( $Q h$ ) 

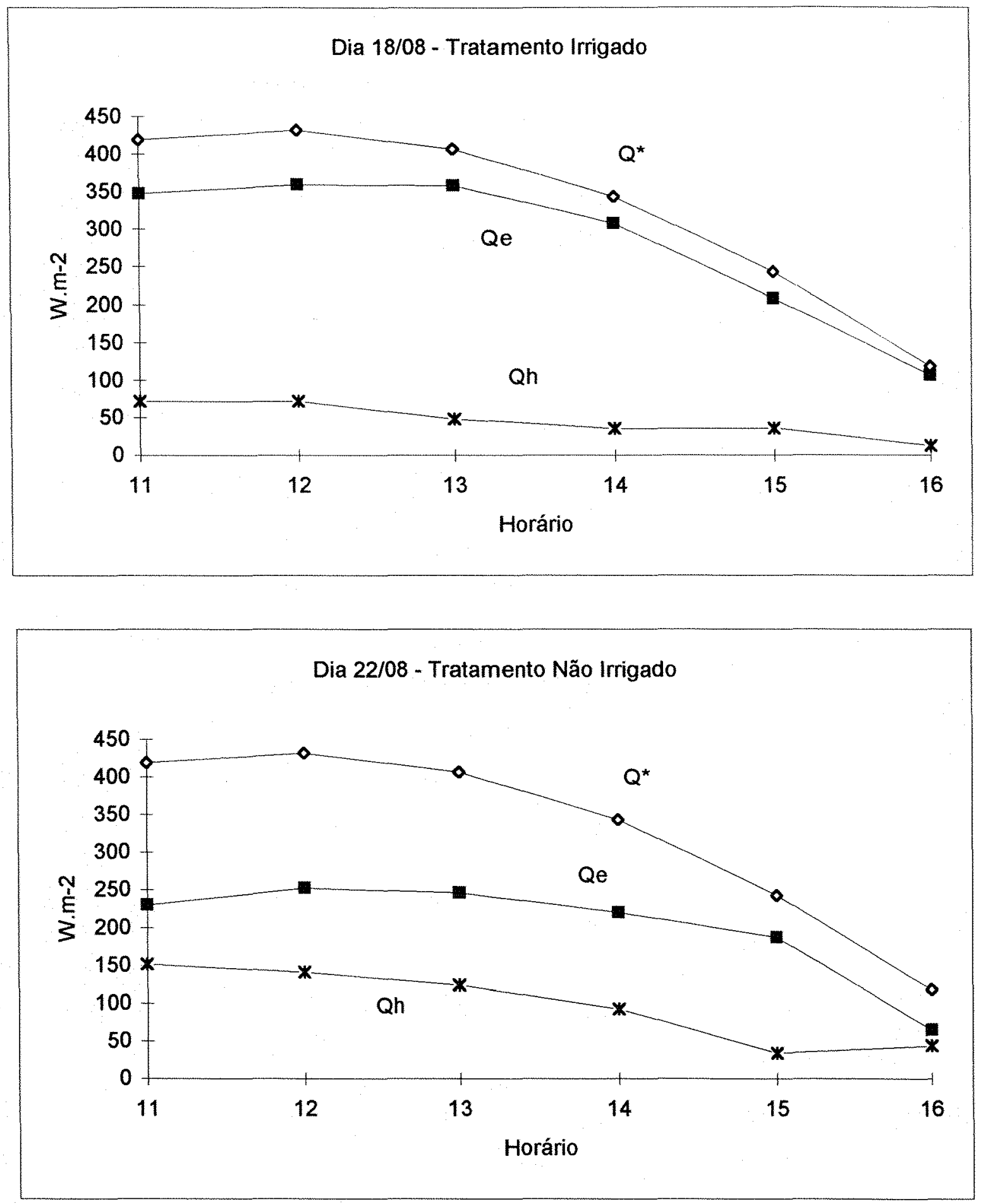

Figura 13 - Fluxos Horários de Saldo de Radiação (Q*), Calor Latente (Qe) e de Calor Sensivel (Qh) 
como fluxo lateral de calor, que determina um aumento nos valores dos fluxos de calor latente, como sendo responsável pela transmissão advectiva de calor.

Este comportamento foi igualmente observado por SUMAYO et al. (1980), que obteve valores de fluxos de calor latente superiores à radiação líquida, para condições de alta disponibilidade hídrica. Os autores salientaram que tal comportamento ocorreu sempre que a temperatura do ar ultrapassava valores limites de $33{ }^{\circ} \mathrm{C}$, quando se observou um fluxo adicional de calor adentro do sistema. Os valores do fluxo de calor sensível, nestes casos, foi sempre negativo, e a temperatura do ar superiores à temperatura da superfície, igualmente ao observado.

O comportamento dos fluxos nos dias em que se procedeu as amostragens no tratamento não irrigado podem ser considerados como incompativeis com o que a superfície na qual se obteve as estimativas demonstrava. Ocorre que, à medida em que o tratamento não irrigado era submetida à mais acentuados graus de severidade à deficiência hídrica, menor e menos importante a presença do fluxo de calor latente em relação ao fluxo de calor sensível estava sujeita a cultura. Observando-se as curvas obtidas para os dias $29 / 07,07 / 08,11 / 08,18 / 08$ e $22 / 08$, nota-se um progressivo aumento na presença do fluxo de calor sensível no balanço. Contudo, este aumento não refletiu com consistência as condições reais, uma vez que jamais superou os valores do fluxo de calor latente. Pelo contrário, o fluxo de calor sensível foi bastante inferior ao fluxo de calor latente, para a maioria dos dias amostrados.

Quanto aos valores do fluxo de calor latente, estes superaram a radiação líquida nos dias 29/07 e 07/08, indicando a presença de energia advectiva nestes dias. Nos demais dias foram inferiores à radiação líquida. Contudo, foram suficientemente grandes para indicar inconsistência em seus 
valores, incompatíveis com o estado de severidade à deficiência hídrica observada nestes dias. Apenas se observou um relativo decréscimo em seus valores e consequente aumento no fluxo de calor sensível no último dia de amostragem (22/08). Nesta situação, a cultura já havia deixado de receber adição de água há 46 dias.

\subsection{3 - Índices de Estresse Hídrico}

Foi estudado o comportamento do "Índice de Estresse Hídrico da Cultura" (CWSI), por duas formas de abordagem. IDSO et al. (1982) definiram o CWSI em termos da relação linear entre (Ts - Ta) e déficit de pressão de vapor do ar (es* - ea). JACKSON (1982), através deste índice proposto, obteve uma descrição analítica, onde se computa valores da resistência aerodinâmica e da cobertura, radiação líquida e déficit de pressão de vapor do ar. As duas abordagens foram descritas no ítem 2.2.3.

\subsubsection{1 - Relações Empíricas}

A relação entre $(T s$ - Ta) e (es* - ea) foi significativamente linear, como pode ser visualizado na figura 14 , com valor de 0,97 de coeficiente de correlação. 
A equação foi utilizada como descrito no item 3.2.5.9. Os valores que deram origem à reta de regressão são mostrados na tabela 29 do apêndice.

O comportamento comparativo diário dos índices podem ser vistos nas figuras 15, 16 e 17 . Nota-se que os valores do CWSI obtidos, para os dias analisados no tratamento não irrigado, foram diferentes. Na grande maioria dos dias e horários, os valores CWSI obtidos pela equação da reta de regressão foram superiores aos valores obtidos analiticamente. As exceções ocorreram no dia 29/07, às 11 e 12 horas; e nos dias 11,18 e 22, às 16 horas. Neste dias, observouse valores superiores do CWSI obtidos analiticamente, em comparação com os obtidos pela reta de regressão.

A partir do dia 29/07, nos demais dias houve uma tendência de os valores obtidos pela reta de regressão apresentarem maior uniformidade ao longo do dia. Quase sempre, o que pode ser notado nos dias 29/07, 11/08, 18/08 e 22/08, os valores obtidos pela reta de regressão decairam no horário das 16 horas. Contrariamente, neste horário, para todos os dias, com exceção do dia 29/07, os valores obtidos analiticamente sofreram um aumento acentuado. Tal comportamento leva a estabelecer visualmente uma tendência de resposta do CWSI obtido analiticamente com a resistência da cobertura. Ocorre que, notadamente, os valores da resistência da cobertura acusaram os maiores valores sempre no horário das 16 horas.

Pode-se afirmar empiricamente que os maiores valores do CWSI foram obtidos às 13 horas, para o caso da determinação pela reta de regressão. Para os valores obtidos analiticamente, foram encontrados mais frequentemente valores mais expressivos às 16 horas.

Com objetivo de melhor avaliar o comportamento dos índices ao longo do tempo, e à medida em que a severidade de estresse hídrico aumentava, 


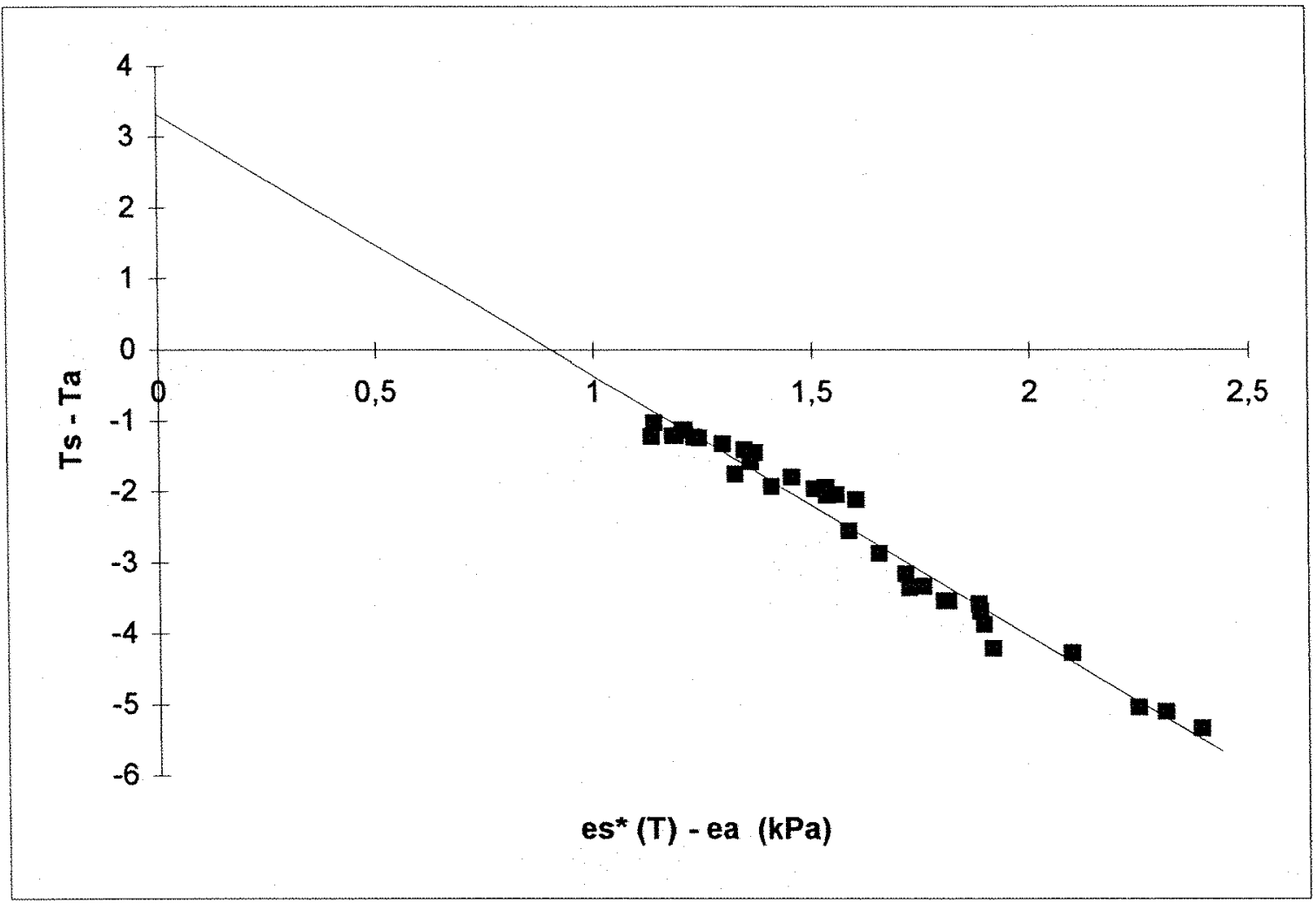

Figura 14 - Relação observada entre Ts - Ta e es* $(T)$ - ea para condições de boa disponibilidade hídrica (tratamento Irrigado) 

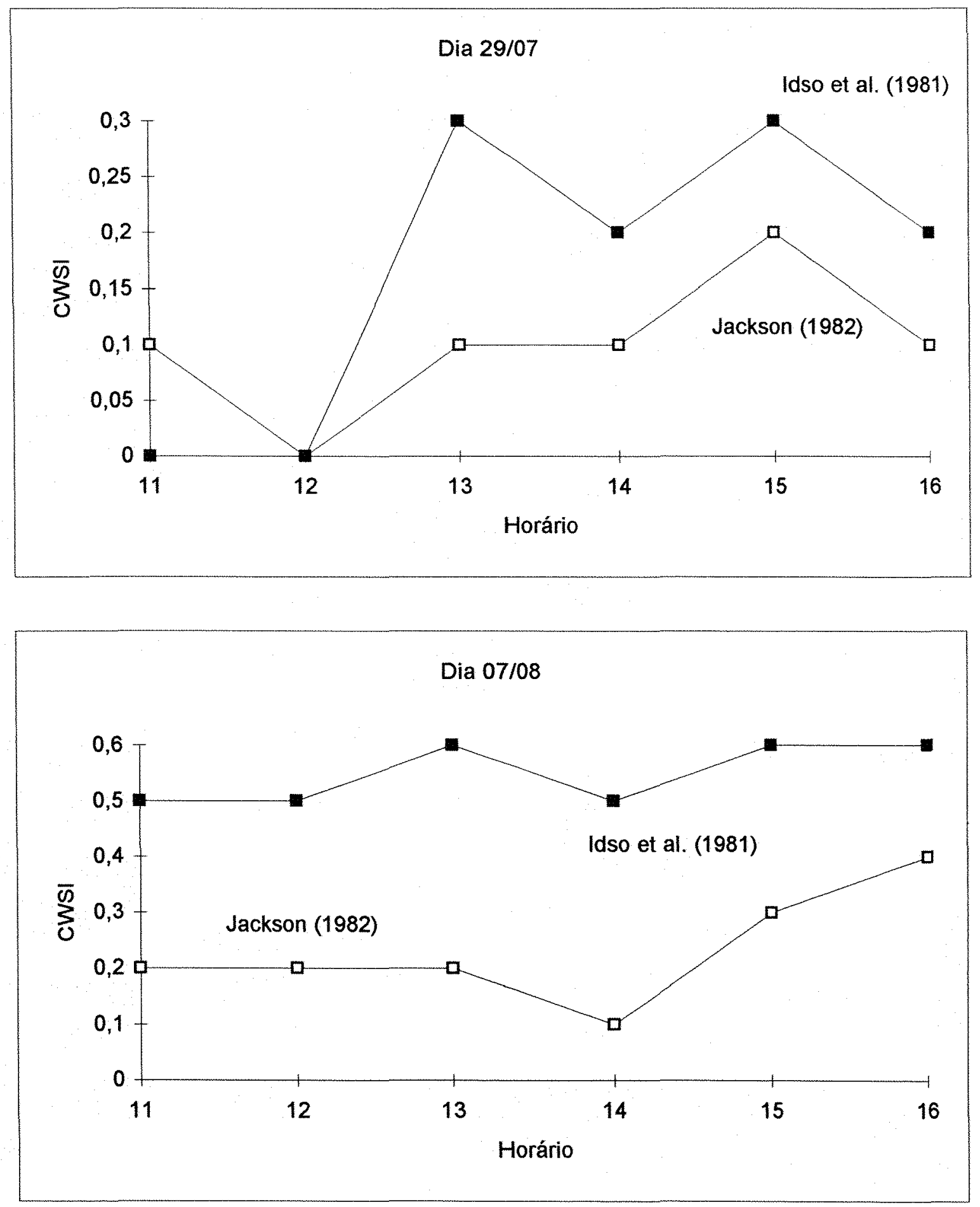

Figura 15 - Valores Horários do CWSI obtidos no Tratamento Não Irrigado através das duas formas de cálculo, nos dias 29/07/91 e 07/08/91 

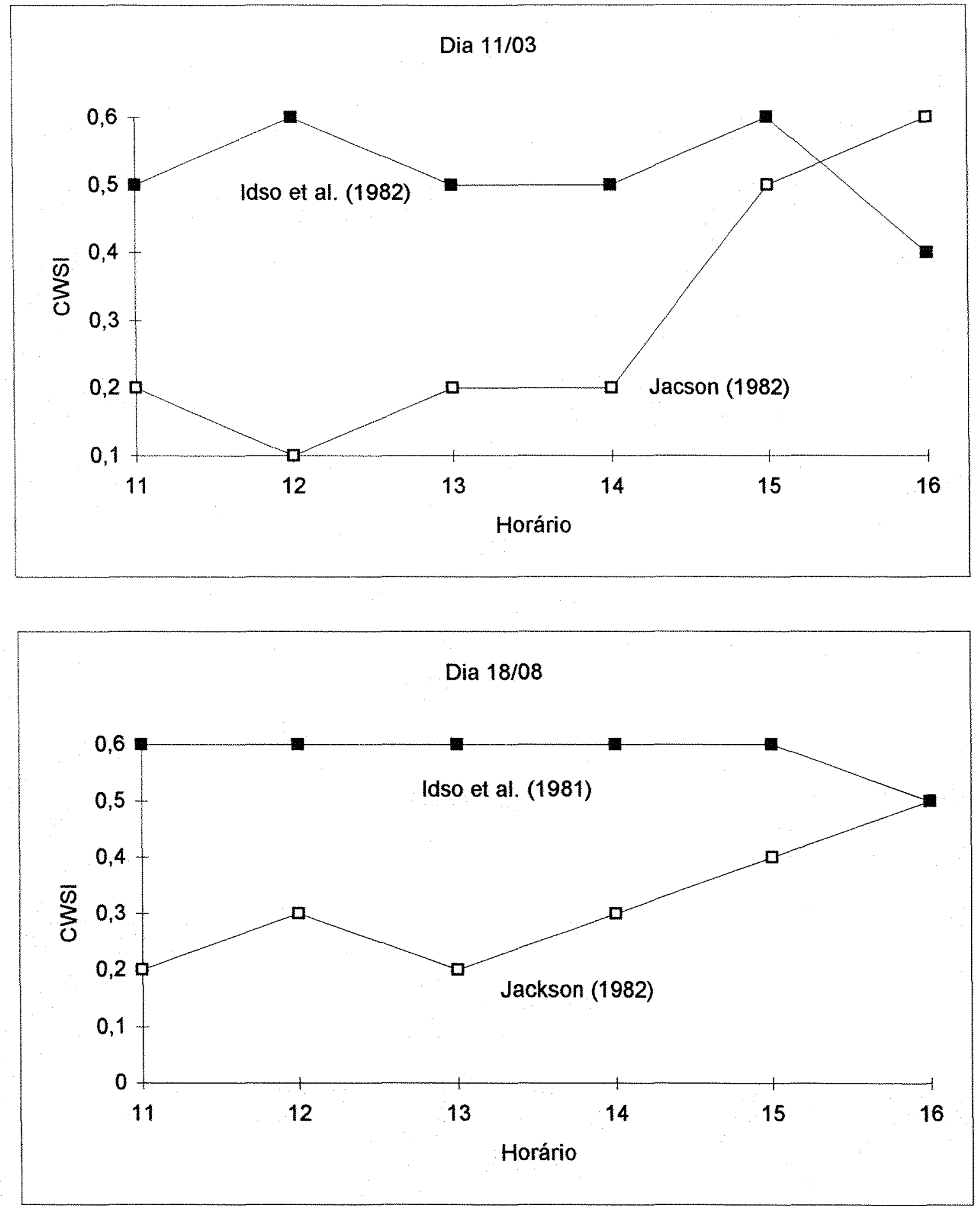

Figura 16 - Valores Horários do CWSI obtidos no Tratamento Não Irrigado através das duas formas de cálculo, nos dias 11/07/91 e 18/08/91 


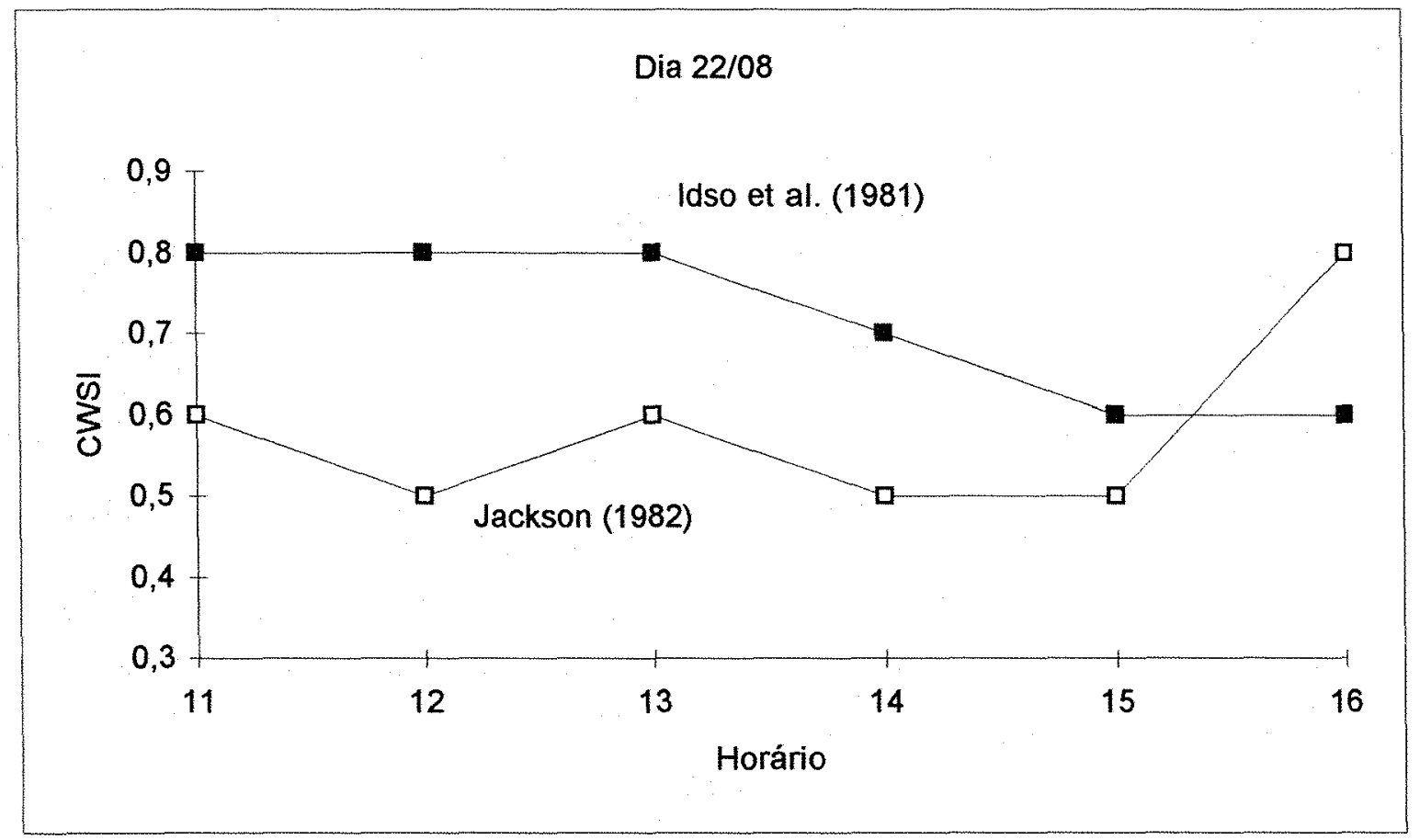

Figura 17 - Valores Horários do CWSI obtidos no Tratamento Não Irrigado através das duas formas de cálculo, nos dias 22/07/91 
elaborou-se as figuras 18, 19 e 20. Neste consta, para cada horário observado, os valores do CWSI obtidos pelas duas formas de abordagens, ao longo dos dias em que se procedeu as amostragens.

Observa-se que os valores do CWSI obtidos pela reta de regressão foram quase sempre superiores aos obtidos analiticamente. Os comportamentos foram semelhantes, ainda que com valores diferentes. Houve, neste sentido, um comportamento crescente dos valores obtidos pela reta de regressão, o que denota sua melhor adequação ao teorizado até aqui. Percebe-se que, com a evolução da severidade do estresse hídrico, houve uma tendência de aumento nos valores do CWSI obtidos pela reta de regressão. Isto se observa em todos os horários, com exceção das 15 horas, que manteve um valor constante à partir do segundo dia de amostragem.

O CWSI obtido pela reta de regressão atingiu um valor máximo de 0,8, para o último dia de amostragem, nos horários das $11,12,13$ e 16 horas. Para os valores obtidos analiticamente obteve-se um valor máximo de 0,6 , nos horários das 11,13 e 16 horas.

JACKSON (1982), analisando um ensaio com a cultura do trigo onde se observou relações entre o desenvolvimento da cultura, o uso de água e o CWSI, ponderou que os níveis considerados limites do CWSI se situam entre 0,3 e 0,5 , para efeito de se considera-lo como um indicador de estresse hídrico, bem como para sua utilização no monitoramento de água a ser aplicada por irrigação. Tais considerações são reforçadas por NIELSEN (1989), que não observou diferenças significativas no uso da água e na produção final da cultura da soja, quando se utilizou valores de 0,4 e 0,6 do CWSI para se proceder a irrigação. SAHA et al. (1986) obteve valores de 0,87 do CWSI para condições de restrições hídricas, bastante superiores aos encontrados sob regime hídrico sem restrições. O CWSI 

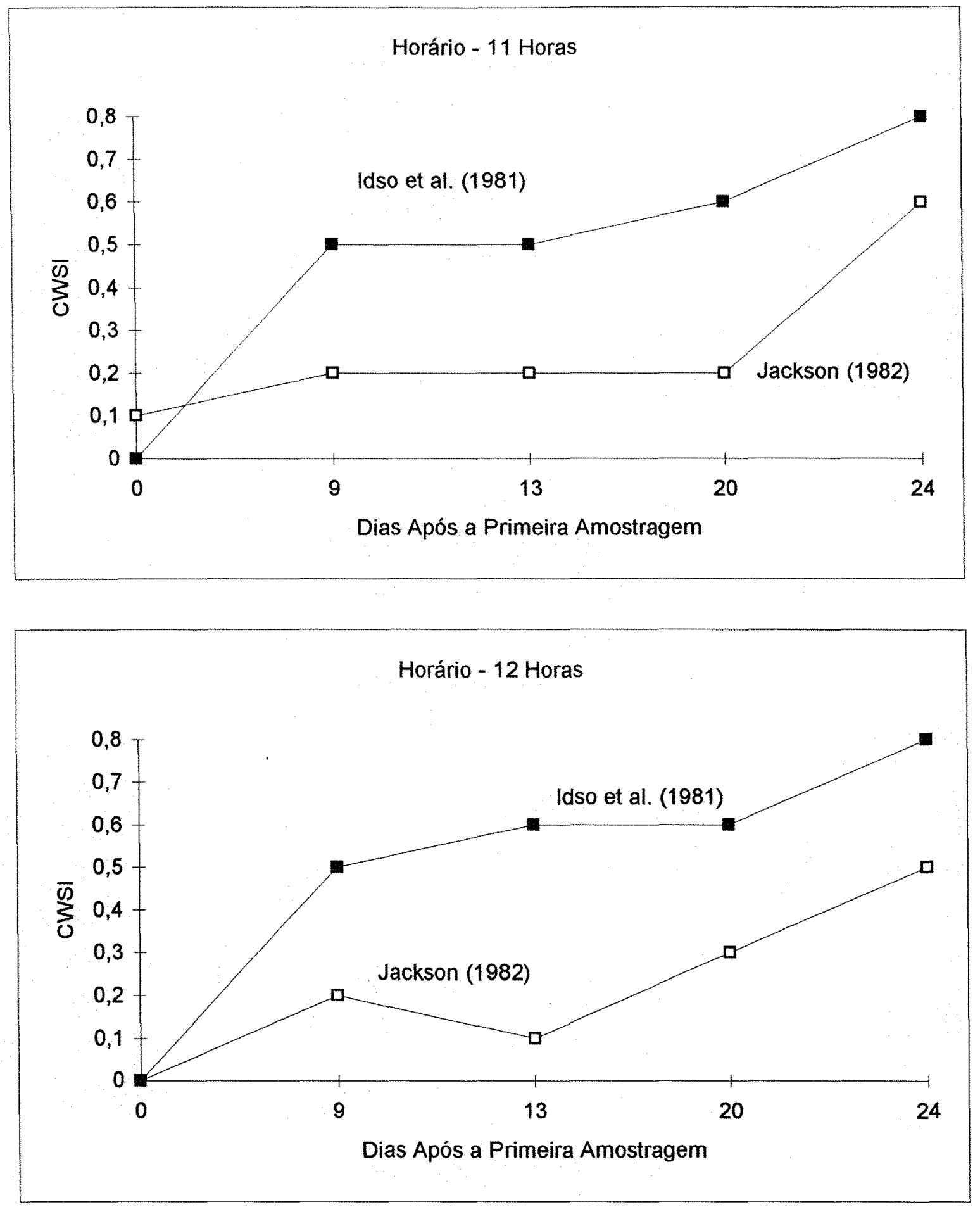

Figura 18 - Evolução do Valores do CWSI a partir do primeiro dia de amostragem 

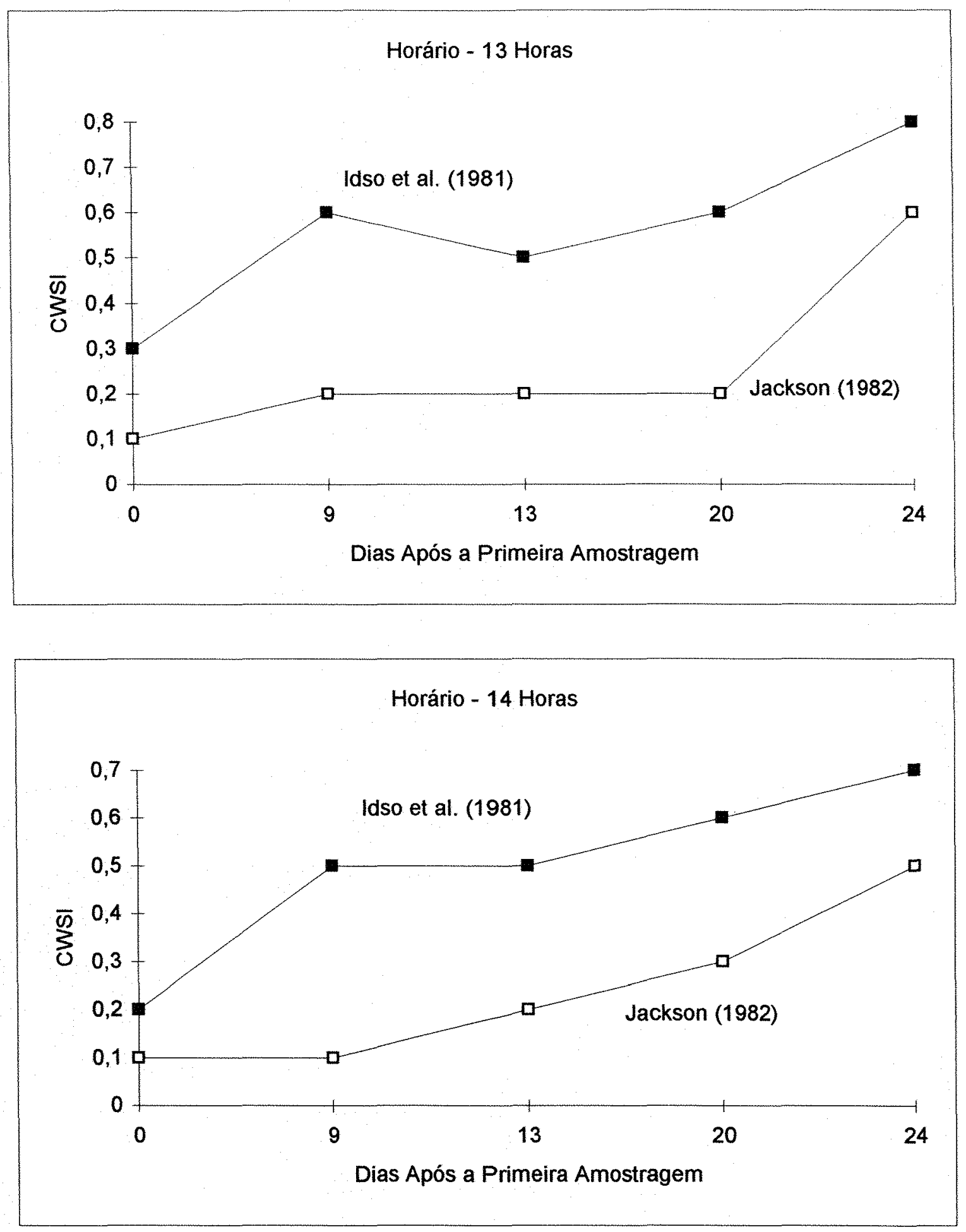

Figura 19 - Evolução do Valores do CWSI a partir do primeiro dia de amostragem 

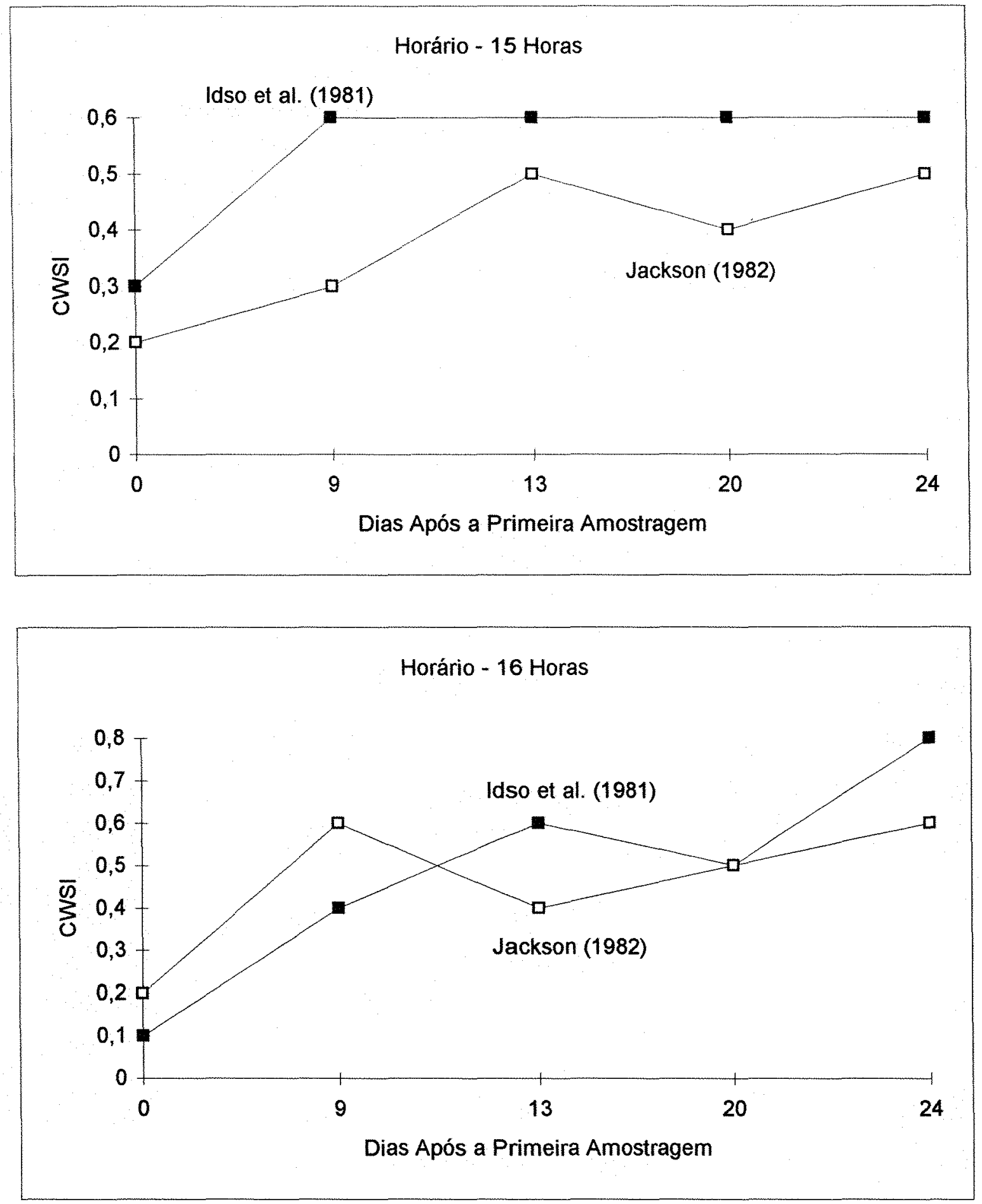

Figura 20 - Evolução do Valores do CWSI a partir do primeiro dia de amostragem 
aumentou com o passar do período, e decaiu quando ocorria precipitações no campo esperimental.

Estas considerações, aliadas à própria definição do índice, mostrada na equação, mostra que os valores do CWSI obtidos analiticamente se encontraram abaixo do esperado.

Analizando-se a figura 21 , que relaciona os índices obtidos analiticamente à resistência da cobertura nos respectivos dias e horários, pode-se verificar a grande correlação entre os parâmetros. Isto pode explicar satisfatoriamente os valores baixos obtidos do CWSI. A partir do momento em que os valores da resistência da cobertura mostraram valores modestos, para o grau de estresse em que se observou, modestos são os valores do CWSI, já que a relação entre ambos é linear e diretamente proporcional, pelo menos na faixa de valores de rc/ra entre 0 e 6 , e na faixa de valores de rc entre 0 e $300 \mathrm{~s} / \mathrm{m}$.

Da mesma forma, os valores do CWSI foram grandemente correlacionados com a razão rc/ra, como se observa na figura 21 . Tal comportamento era esperado, uma vez que, conforme teorizado no ítem 2.2 .3 , os parâmetros são diretamente diretamente proporcionais.

As relações obtidas entre o CWSI tanto para a resistência da cobertura quanto para a razão rc/ra, podem esclarecer o comportamento do índice, tanto nos dias e horários em que se obteve valores mais baixos quanto em relação aos valores máximos.

Analisando as curvas das figuras 18,19 e 20 , para todos os horários, os máximos valores foram obtidos no último dia de amostragem. Neste dia (22/08) os valores da resistência da cobertura atingiram os maiores valores, notadamente às 16 horas. Igualmente, o horário que apresentou maiores valores 

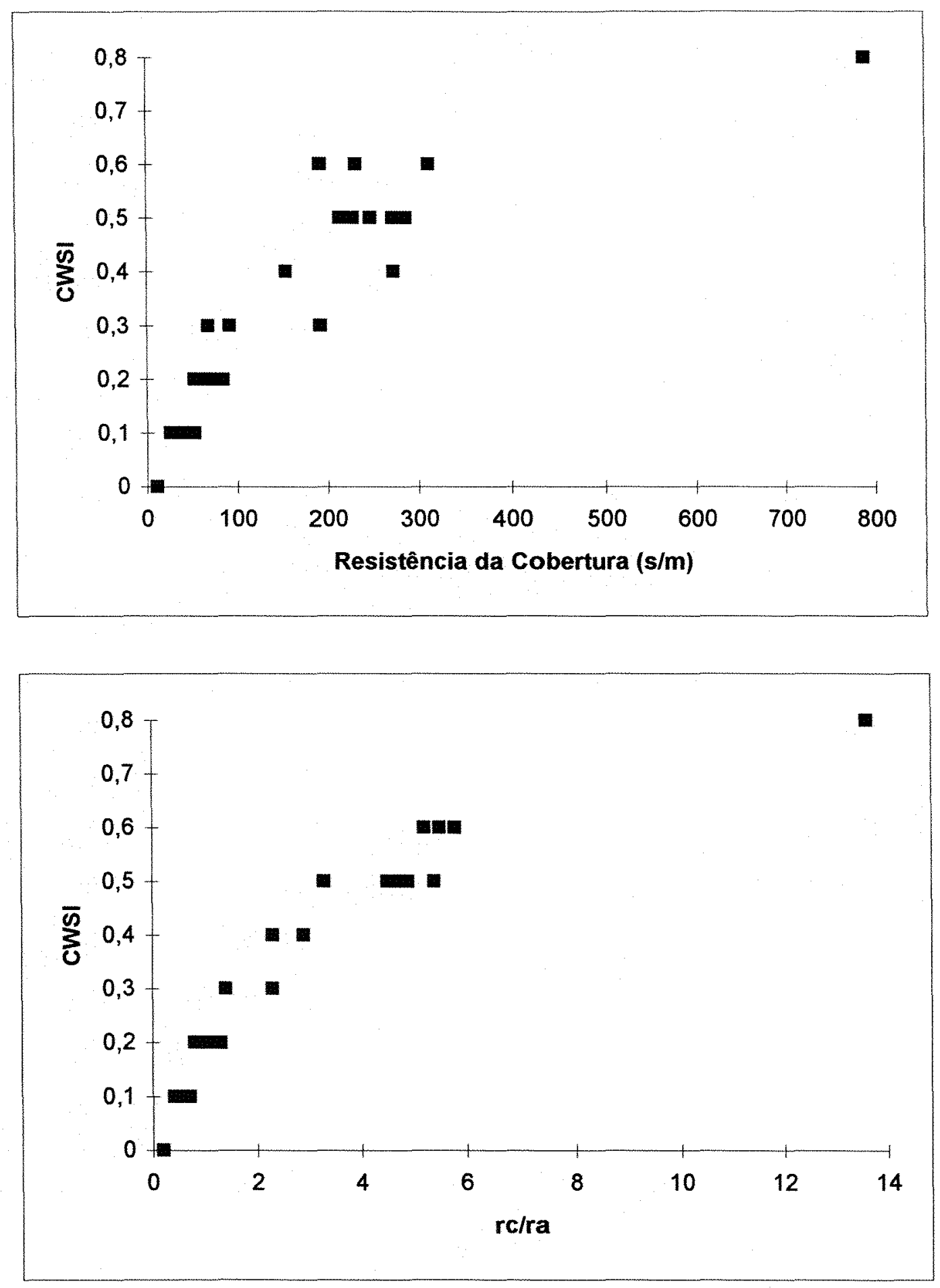

Figura 21 - Comportamento do CWSI em relação à Resistência da Cobertura e da Razão rc/ra 
do CWSI foi o das 16 horas. Neste horário, com exceção do dia 29/07, foram observados os maiores valores da resistência da cobertura.

De forma análoga, os valores do CWSI dos horários das $11,12,13 \mathrm{e}$ 14 horas não superaram o valor de 0,3 até o quarto dia de amostragem (18/08). Estes valores, baixos para a crescente deficiência hídrica à qual se submeteu a cultura, são relativos à valores inferiores a $100 \mathrm{~s} / \mathrm{m}$ da resistência da cobertura. Os valores do CWSI superiores à 0,3 foram obtidos sempre no último dia de amostragem (22/08), para todos os horários, e nos dias 11, 18 e 22/08 para os horários das 15 e 16 horas. Nestes dias e horários os valores da resistência da cobertura foram sempre superiores à $150 \mathrm{~s} / \mathrm{m}$, atingindo o valores máximo de $788,4 \mathrm{~s} / \mathrm{m}$, com correspondente valor de 0,8 do CWSI.

Analisando as curvas constantes nas figuras, observa-se que o CWSI aumente gradativamente com o aumento da resistência da cobertura e da razão rc/ra. As curvas tendem a ser menos acentuadas quando se aproximam os valores máximos, sugerindo limites máximos, a partir dos quais a curva se caminharia paralelamente ao eixo da abscissa.

Tais observações indicam a importância de se obter valores o mais acurados possíveis, tanto da resistência da cobertura quanto da resistência aerodinâmica. É importante notar que, como a resistência aerodinâmica é uma função da velocidade do vento, o comportamento obtido aqui se refere à velocidades máximas de $1,1 \mathrm{~m} / \mathrm{s}$, ou seja, ventos calmos. 


\section{CONCLUSÕES}

Pelos resultados obtidos, considerando os aspectos discutidos, permite-se evidenciar as seguintes conclusões :

De acordo com a metodologia aplicada e devido à ausência de precipitação no período em que houve a sejeição ao estresse hídrico, houve um diferenciamento claro entre os tratamentos aplicados. Pode-se afirmar que o tratamento não irrigado foi submetido a um grau severo de estresse hídrico. Em contrapartida, evidenciou-se uma situação oposta no tratamento irrigado, que não apresentou restrições hídricas.

A temperatura da superfície, ao longo dos dias e horários observados, foi sempre superior quando obtida no tratamento não irrigado. Houve diferenciação clara de seus valores devido ao regime hídrico diferenciado pelos tratamentos impostos. Observou-se diferenças entre cada tratamento da ordem de $6,7^{\circ} \mathrm{C}$. Tais diferenças aumentaram conforme a severidade do estresse hídrico se acentuou. 
Os valores da resistência da cobertura obtidos sob o tratamento não irrigado foram sempre superiores aos obtidos no tratamento irrigado. Evidenciouse uma tendência de aumento de seus valores ao final do dia, para ambos os tratamentos. Os valores observados no tratamento irrigado variaram consideravelmente de um dia para o outro. Este comportamento foi mais evidente no dia $06 / 08$, que atingiu $40,3 \mathrm{~s} / \mathrm{m}$, considerado alto por ter sido obtido no tratamento irrigado, e considerando outros valores obtidos sob condições semelhantes. No tratamento não irrigado os valores da resistência da cobertura foram crescentes, atingindo $788,4 \mathrm{~s} / \mathrm{m}$ no último dia de amostragem.

O comportamento dos fluxos de calor latente e sensível, na maioria dos dias e horas amostradas, permitiram identificar a presença de energia advectiva. Observou-se, neste sentido, uma presença superior do fluxo de calor latente em relação à radiação líquida. Tal fato ocorreu tanto nos dias em que se procedeu a coleta dos dados no tratamento irrigado, quanto nos dias em que foram obtidos dados no tratamento não irrigado.

Os valores do déficit de pressão de vapor do ar foram linearmente correlacionados com os valores da diferença Ts - Ta, com 0,97 de coeficiente de correlação.

$\mathrm{O}$ índice estudado, sob as duas formas de cálculo, acusou valores crescentes ao longo do tempo em que se acentuou a severidade do estresse hídrico, para todos os dias e horários. O CWSI segundo IDSO et al. (1981) apresentou valores superiores ao CWSI segundo JACKSON (1982) em quase todos os dias e horários. Contudo não se observou valores superiores à 0,6 , com 
excessão ao observado no dia $22 / 08$, último dia de amostragem, que apontou valores de 0,8 . Foi identificada grande correlação entre o CWSI e a resistência da cobertura, indicando haver influência de um sobre o outro. 


\section{REFERÊNCIAS BIBLIOGRÁFICAS}

ANDRÉ, R.G.B. Um estudo dos transportes verticais de momentum, calor sensível e vapor d'água sobre a superfície vegetada nos trópicos. São José dos Campos, 1981. 112 p. (Doutorado - INPE/CNPq).

BARLEY, W.G. \& DAVIES, J.A. The effect of uncertainty in aerodinamic resistance on evaporation estimates from the combination model. Boundary-Layer Meteorology, 20 : 187-199.

BOISSARD, P.; GUYOT, G.; JACKSON, R.D. Factors affecting the radiative temperature of a vegetative canopy. In : Radiative temperature of canopies. "s.1.", "s.ed."[1990].

BRUNEL, J.P. Estimation of sensible heat flux from measurements of surface radiative temperature and air temperature at two meters : aplication to determine actual evaporation rate. Agricultural and Forest Meteorology, 46 : 179-191, 1989.

CHOUDHURY, B.J. An analysis of infrared temperature observations over 
wheat and calculation of latente heat flux. Agricultural and Forest Meteorology, 37 : 75-88, 1986.

DIAS, R.A.; MATTHIAS, A.D.; HANKS, R.J. Evapotranspiration and yield estimation of spring wheat from canopy temperature. Agronomy Journal, 75 : 805-810, 1983 .

DOORENBOS, J. \& KASSAM, A.H. Efectos del água sobre el rendimiento de los cultivos. Roma, FAO, 1979. 212p. (Riego y drenage, 33).

EHRLER, W.L.; IDSO, S.B.; JACKSON, R.D.; REGINATO, R.J. Wheat canopy temperature : relation to water plant potencial. Agronomy Journal, 70 : 251-256, 1978 .

EPIPHANIO, J.C.N. Sensoriamento remoto termal para avaliação de produtividade e deficiência hídrica de milho (Zea mays l.) na região dos cerrados. São José dos Campos, 1983. (Mestrado - Instituto Nacional de Pesquisas Espaciais).

GARDNER, B.R.; BLAD, B.L.; GARRITY, D.P.; WATTS, D.G. Relationships between crop temperature, grain yield, evapotranspiration and phenological development in two hybrids of moisture stressed sorghum Irrigation Science, 2: 213-224, 1981 .

GATES, D.M. Leaf temperature an energy exchange. Archiv.Meteor.Geoph. Bioclimatol., 12 : 321-336, 1963. 
GATES, D.M. Biofisical ecology. New York, Springer, 1980. 661p.

GUYOT, G. \& CHASSERAY, E. Analyse de la signification physique et biologique de la température radiative d'un couvert de céréales. In : Signatures spectrales d'objects en télédétection. INRA, n.5, Avignos, France, 1981.

GUYOT, G. Variabilité angulaire et spatiale des donnees spectrales dans le visible et le proche infra-rouge. In : Signatures spectrales d'objets en télédétection. INRA, n. 23, Bordeaux, France, 1983.

HALIM, R.A.; BUXTON, D.R.; HATTENDORF, M.J.; CARLSON, R.E. Crop water stress index and forage quality relationships in alfalfa. Agronomy Journal, 82: 906-909, 1990.

HATFIELD, J.L.; PERRIER, A.; JACKSON, R.D. Estimation of evapotranspiration at one time-of-day using remotely sensed surface temperatures. Agricultural Water Management, 7: 341-350, 1983.

HATFIELD, J.L. Wheat canopy resistance determined by energy balance techniques. Agronomy Journal, 77: 279-283, 1985.

HEILMAN, J.L.; HEILMAN, W.E.; MOORE, D.G. Remote sensing of canopy temperature at incomplete cover. Agronomy Journal, 73: 403-406, 1981.

IDSO, S.B.; JACKSON, R.D.; REGINATO, R.J. Remote sensing of crop yields. 
Science, 196: 19-25, 1977.

IDSO, S.B.; REGINATO, R.J.; REICOSKY, D.C.; HATFIELD, J.L. Determining soil-induced plant water potencial depressions in alfalfa by means of infrared thermometry. Agronomy Jounal, 73: 826-830, 1981.

IDSO, S.B. \& REGINATO, R.J. Leaf diffusion resistence and photosynthesis in cotton as related to a foliage temperature based plant water stress index. Agricultural Meteorology, 27: 27-34, 1982.

IDSO, S.B.; REGINATO, R.J.; CLAWSON, K.L.; ANDERSON, M.G. On the stability of non-water-stressed baselines.Agricultural and Forest Meteorology, 32: $177-182,1984$.

IDSO, S.B.; PINTER Jr, P.J.; REGINATO, R. J. Non-water-stressed baselines : the importance of site selection for air temperature and air vapour pressure deficit measurements. Agricultural and Forest Meteorology, 53: 73-79, 1990.

JAKSON, R.D.Canopy temperature and crop water stress. Advances in Irrigation, 1: $43-83,1982$.

JACKSON, R.D.; IDSO, S.B.; REGINATO, R.J.; PINTER Jr., P.J. Canopy temperature as a crop water stress indicator. Water Resour. Res., 17 : 1133-1138, 1981. 
KIMES, D.S. Effect of vegetation canopy structure on remotely sensed canopy temperatures. Remote Sensing of Environment, 10: 165-174, 1980.

LORENZ, D. Canopy temperature and crop water stress. Advances in Irrigation, 1: 43-83, 1968.

MILLARD, J.P.; GOETTELMAN, R.C.; LE ROY, M. J. Infrared temperature variability in a large agricultural field.Internationa Journal of Remote Sensing 2: 201-211, 1981 .

MONTEITH, J.L. Environmental physics. Great Britain, 1990. 291 p.

NAKAYAMA, F.S. \& BUCKS, D.A. Crop water stress index, soil water, and rubber yield relations for guayule plant. Agronomy Journal, 76 : 791-794, 1984.

NIELSEN, D.C. Scheduling irrigations of soybeans with the crop water stress index (CWSI). "s.n.t."

NIELSEN, D.C.; CLAWSON, K.L.; BLAD, B.L. Effect of solar azimuth and infrared thermometer view direction of soybean canopy temperature. Agronomy Journal, 76: 607-610, 1984.

O'TOOLE, J.C. \& REAL, J.G. Estimation of Aerodinamic and crop resistances from canopy temperature. Agronomy Journal, 78: 305-310, 1986. 
PENNINGTON, D.A. \& HEATHERLY, L. Effects of changing solar radiation on canopy-air temperatures of cotton and soybean. Agricultural and Forest Meteorology, 46: 1-14, 1989.

SAHA, S.K.; GOPALAN, A.K.S.; KAMAT, D.S. Relations between remotely sensed canopy temperature, crop water stress, air vapour pressure deficit and evapotranspiration in chickpea. Agricultural and Forest Meteorology, 38: $17-26,1986$.

SMITH, R.C.G.; BARRS, H.D.; MEYER, W.S. Evaporation from irrigated wheat estimated using radiative surface temperature : an operational approach. Agricultural and Forest Meteorology, 48: 331-344, 1989.

SMITH, R.C.G.; BARRS, H.D.; FISCHER, R.A. Inferring stomatal resistance of sparse crops from infrared measurements of foliage temperature. Agricultural and Forest Meteorology, 42: 183-198, 1988.

SMITH, S.C.G.; BARRS, H.D.; STEINER, J.L.; STAPPER, M. Relationship between wheat yield and foliage temperature : theory and its aplication to infrared measurements. Agricultural and Forest Meteorology, 36: 129-143, 1985.

SOARES, A.M. La temperature de surface des couverts vegetaux en liason avec le microclimat et l'etat hidrique du sol. Languedoc, 1987. (DoutoradoUniversite des Sciences et Techniques du Languedoc). 
STEINMETZ, S.; LAGOUARDE, J.P.; DELECOLLE, R.; GUERIF, M.; SEGUIN, B. Evapotranspiration and water stress using thermal infrared measurements. A general review and a case study on winter durum wheat in souther france in : INTERNATIONAL SIMPOSIUM ON : PHYSIOLOGY/BREEDING OF WINTER CEREALS FOR STRESSED MEDITERRANEUM ENVIRONMENTS, 3-6 July, 1989, Monpellier, France.

SUMAYO, C.R.; KANEMASU, E.T.; BRAKKE, T.W. Using leaf temperature to assess evapotranspiration and advection. Agricultural Meteorology, 22 : 153-166, 1980.

WALKER, G.K. \& HATFIELD, J.L. Stress measurement using foliage temperatures. Agronomy Journal, 75: 623-629, 1983.

WALKER, G.K. \& HATFIELD, J.L. Test of stress-degree-day concept using multiples planting dates of red kidney beans. Agronomy Journal, 71: 967-971, 1979. 
APÊNDICE 
Tabela 3 - Valores Diários da Evapotranspiração de Referência (ETo), Evapotranspiração Máxima (ETM), Precipitações, Irrigações, do Potencial da Água do Solo, no Tratamento Irrigado

\begin{tabular}{|c|c|c|c|c|c|c|c|}
\hline DIAS & $\begin{array}{c}\text { E.T.C.A } \\
(\mathrm{mm})\end{array}$ & $\begin{array}{l}\text { ETo } \\
(\mathrm{mm}) \\
\end{array}$ & $\mathrm{kc}$ & $\begin{array}{l}\text { ETM } \\
(\mathrm{mm}) \\
\end{array}$ & $\begin{array}{l}\text { Precipit. } \\
\text { (mm) }\end{array}$ & $\begin{array}{l}\text { Irrigação } \\
\text { (mm) }\end{array}$ & $\begin{array}{c}\text { Tensiôm. } \\
\text { (atm) }\end{array}$ \\
\hline $20 / 05$ & 0 & 0 & 0,3 & 0 & 13 & 0 & - \\
\hline 21 & 4,6 & 3,45 & 0,3 & 1,04 & 0 & 0 & - \\
\hline 22 & 5 & 3,75 & 0,3 & 1,13 & 0 & 0 & \\
\hline 23 & 5 & 3,75 & 0,3 & 1,13 & 0 & 0 & -....... \\
\hline 24 & 4,6 & 3,45 & 0,3 & 1,04 & 0 & 23 & -..- \\
\hline 25 & 4,8 & 3,6 & 0,3 & 1,08 & 0 & 0 & ........ \\
\hline 26 & 4,6 & 3,45 & 0,3 & 1,04 & 0 & 0 & - \\
\hline 27 & 4,8 & 3,6 & 0,3 & 1,08 & 0 & 0 & \\
\hline 28 & 5 & 3,75 & 0,3 & 1,13 & 0 & 0 & \\
\hline 29 & 5 & 3,75 & 0,3 & 1,13 & 0 & 0 & -..- \\
\hline 30 & 4,8 & 3,6 & 0,3 & 1,08 & 0 & 0 & \\
\hline 31 & 4,5 & 3,38 & 0,3 & 1,01 & 0 & 0 & \\
\hline $01 / 06$ & 4,6 & 3,45 & 0,3 & 1,04 & 0 & 10 & \\
\hline 02 & 4,8 & 3,6 & 0,4 & 1,44 & 0 & 0 & - \\
\hline 03 & 5,2 & 3,9 & 0,4 & 1,56 & 0 & 0 & -..- \\
\hline 04 & 3,2 & 2,4 & 0,4 & 0,96 & 0 & 0 & \\
\hline 05 & 6,4 & 4,8 & 0,4 & 1,92 & 0 & 0 & $\cdots$ \\
\hline 06 & 6 & 4,5 & 0,4 & 1,8 & 0 & 0 & \\
\hline 07 & 3,9 & 2,93 & 0,4 & 1,17 & 0 & 0 & \\
\hline 08 & 3,9 & 2,93 & 0,4 & 1,17 & 0 & 0 & - \\
\hline 09 & 3 & 2,25 & 0,4 & 0,9 & 0 & 0 & - \\
\hline 10 & 3,2 & 2,4 & 0,4 & 0,96 & 0 & 0 & \\
\hline 11 & 5,2 & 3,9 & 0,4 & 1,56 & 0 & 0 & \\
\hline 12 & 5,4 & 4,05 & 0,4 & 1,62 & 0 & 0 & - \\
\hline 13 & 4 & 3 & 0,4 & 1,2 & 0 & 0 & - \\
\hline 14 & 4,1 & 3,08 & 0,4 & 1,23 & 0 & 0 & - \\
\hline 15 & 4 & 3 & 0,4 & 1,2 & 0 & 0 & - \\
\hline 16 & 4,2 & 3,15 & 0,7 & 2,21 & 0 & 0 & - \\
\hline 17 & 4,1 & 3,08 & 0,7 & 2,15 & 0 & 0 & -...- \\
\hline 18 & 4,5 & 3,38 & 0,7 & 2,36 & 0 & 0 & - \\
\hline 19 & 2,8 & 2,1 & 0,7 & 1,47 & 0 & 0 & -... \\
\hline 20 & 3,8 & 2,85 & 0,7 & 2 & 0 & 0 & - \\
\hline 21 & 2,3 & 1,73 & 0,7 & 1,21 & 1,2 & 0 & -..-- \\
\hline
\end{tabular}


Tabela 3 - Valores Diários da Evapotranspiração de Referência (ETo), Evapotranspiração Máxima (ETM), Precipitações, Irrigações, do Potencial da Água do Solo, no Tratamento Irrigado

\begin{tabular}{|c|c|c|c|c|c|c|c|}
\hline DIAS & $\begin{array}{c}\text { E.T.C.A } \\
\text { (mm) }\end{array}$ & $\begin{array}{l}\text { ETo } \\
(\mathrm{mm})\end{array}$ & $\mathrm{kc}$ & $\begin{array}{l}\text { ETM } \\
(\mathrm{mm})\end{array}$ & $\begin{array}{l}\text { Precipit. } \\
\text { (mm) }\end{array}$ & $\begin{array}{l}\text { Irrigação } \\
\text { (mm) }\end{array}$ & $\begin{array}{c}\text { Tensiôm } \\
\text { (atm) }\end{array}$ \\
\hline 22 & 0 & 0 & 0,7 & 0 & 2 & 0 & - \\
\hline 23 & 0 & 0 & 0,7 & 0 & 0 & 0 & - \\
\hline 24 & 0 & 0 & 0,7 & 0 & 0 & 0 & - \\
\hline 25 & 0 & 0 & 0,7 & 0 & 10 & 0 & - \\
\hline 26 & 3 & 2,25 & 0,7 & 1,58 & 19 & 0 & $\ldots$ \\
\hline 27 & 4,6 & 3,45 & 0,7 & 2,41 & 0 & 0 & $\ldots$ \\
\hline 28 & 4,4 & 3,3 & 0,7 & 2,31 & 0 & 0 & - \\
\hline 29 & 0 & 0 & 0,7 & 0 & 0 & 0 & -..- \\
\hline 30 & 3,2 & 2,4 & 0,7 & 1,68 & 0 & 0 & -..- \\
\hline $01 / 07$ & 3,9 & 2,93 & 0,8 & 2,34 & 0 & 0 & 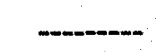 \\
\hline 02 & 2,9 & 2,18 & 0,8 & 1,74 & 0 & 0 & \\
\hline 03 & 3,2 & 2,4 & 0,8 & 1,92 & 0 & 0 & \\
\hline 04 & 5,2 & 3,9 & 0,8 & 3,12 & 0 & 0 & 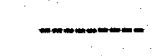 \\
\hline 05 & 5,4 & 4,05 & 0,8 & 3,24 & 0 & 0 & - \\
\hline 06 & 4,2 & 3,15 & 0,8 & 2,52 & 0 & 0 & 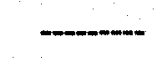 \\
\hline 07 & 4 & 3 & 0,8 & 2,4 & 0 & 25,2 & - \\
\hline 08 & 4,1 & 3,08 & 0,8 & 2,46 & 0 & 0 & \\
\hline 09 & 5,2 & 3,9 & 1,05 & 4,1 & 0 & 0 & 0.07 \\
\hline 10 & 4,5 & 3,38 & 1,05 & 3,54 & 0 & 0 & 0,1 \\
\hline 11 & 0 & 0 & 1,05 & 0 & 13,8 & 0 & 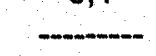 \\
\hline 12 & 3,6 & 2,7 & 1,05 & 2,84 & 0 & 0 & 0,05 \\
\hline 13 & 0 & 0 & 1,05 & 0 & 0 & 0 & - \\
\hline 14 & 2 & 1,5 & 1,05 & 1,58 & 0 & 0 & - \\
\hline 15 & 3 & 2,25 & 1,05 & 2,36 & 0 & 0 & 0,1 \\
\hline 16 & 3,6 & 2,7 & 1,05 & 2,84 & 0 & 0 & - \\
\hline 17 & 2,5 & 1,88 & 1,05 & 1,97 & 0 & 0 & 0,14 \\
\hline 18 & 4,6 & 3,45 & 1,05 & 3,62 & 0 & 0 & 0,24 \\
\hline 19 & 5,6 & 4,2 & 1,05 & 4,41 & 0 & 0 & 0,36 \\
\hline 20 & 5 & 3,75 & 1,2 & 4,5 & 0 & 0 & 0,5 \\
\hline 21 & 4,8 & 3,6 & 1,2 & 4,32 & 0 & 0 & - \\
\hline 22 & 4,8 & 3,6 & 1,2 & 4,32 & 0 & 25 & 0,55 \\
\hline 23 & 4,9 & 3,68 & 1,2 & 4,41 & 0 & 0 & - \\
\hline
\end{tabular}


Tabela 3 - Valores Diários da Evapotranspiração de Referência (ETo), Evapotranspiração Máxima (ETM), Precipitações, Irrigações, do Potencial da Água do Solo, no Tratamento Irrigado

\begin{tabular}{|c|c|c|c|c|c|c|c|}
\hline DIAS & $\begin{array}{c}\text { E.T.C.A } \\
(\mathrm{mm})\end{array}$ & $\begin{array}{l}\text { ETo } \\
\text { (mm) }\end{array}$ & $\mathrm{kc}$ & $\begin{array}{l}\text { ETM } \\
(\mathrm{mm})\end{array}$ & $\begin{array}{l}\text { Precipit. } \\
\text { (mm) }\end{array}$ & $\begin{array}{l}\text { Irrigação } \\
\text { (mm) }\end{array}$ & $\begin{array}{l}\text { Tensiôm. } \\
\text { (atm) }\end{array}$ \\
\hline 24 & 2,9 & 2,18 & 1,2 & 2,61 & 0 & 0 & 0,07 \\
\hline 25 & 4,6 & 3,45 & 1,2 & 4,14 & 0 & 0 & \\
\hline 26 & 5,3 & 3,98 & 1,2 & 4,77 & 0 & 0 & \\
\hline 27 & 4,8 & 3,6 & 1,2 & 4,32 & 0 & 0 & 0,42 \\
\hline 28 & 4,4 & 3,3 & 1,2 & 3,96 & 0 & 0 & 0,49 \\
\hline 29 & 6,6 & 4,95 & 1,2 & 5,94 & 0 & 26 & 0,5 \\
\hline 30 & 4,9 & 3,68 & 1,2 & 4,41 & 0 & 0 & 0,1 \\
\hline 31 & 4,5 & 3,38 & 1,2 & 4,05 & 0 & 0 & \\
\hline $01 / 08$ & 5,4 & 4,05 & 1,2 & 4,86 & 0 & 0 & 0,32 \\
\hline 02 & 6,9 & 5,18 & 1,2 & 6,21 & 0 & 0 & \\
\hline 03 & 4,2 & 3,15 & 1,2 & 3,78 & 0 & 25 & 0,46 \\
\hline 04 & 4,6 & 3,45 & 1,2 & 4,14 & 0 & 0 & \\
\hline 05 & 5 & 3,75 & 1,2 & 4,5 & 0 & 0 & 0,12 \\
\hline 06 & 5,3 & 3,98 & 1,2 & 4,77 & 0 & 0 & 0,23 \\
\hline 07 & 6,8 & 5,1 & 1,2 & 6,12 & 0 & 0 & 0,38 \\
\hline 08 & 0 & 0 & 1,2 & 0 & 9,2 & 0 & 0,53 \\
\hline 09 & 1,6 & 1,2 & 1,2 & 1,44 & 0 & 15 & \\
\hline 10 & 5,3 & 3,98 & 1,2 & 4,77 & 0 & 0 & \\
\hline 11 & 5,5 & 4,13 & 1,2 & 4,95 & 0 & 0 & 0,14 \\
\hline 12 & 5,6 & 4,2 & 1,2 & 5,04 & 0 & 0 & \\
\hline 13 & 5,1 & 3,83 & 1,2 & 4,59 & 0 & 0 & 0,33 \\
\hline 14 & 5,6 & 4,2 & 1,2 & 5,04 & 0 & 24 & 0,48 \\
\hline 15 & 5,2 & 3,9 & 1,2 & 4,68 & 0 & 0 & \\
\hline 16 & 6,7 & 5,03 & 0,75 & 3,77 & 0 & 0 & 0,09 \\
\hline 17 & 6,6 & 4,95 & 0,75 & 3,71 & 0 & 0 & 0,23 \\
\hline 18 & 6,8 & 5,1 & 0,75 & 3,83 & 0 & 0 & \\
\hline 19 & 6 & 4,5 & 0,75 & 3,38 & 0 & 0 & 0,31 \\
\hline 20 & 6,2 & 4,65 & 0,75 & 3,49 & 0 & 0 & \\
\hline 21 & 7,1 & 5,33 & 0,75 & 3,99 & 0 & 0 & 0,56 \\
\hline 22 & 6,7 & 5,03 & 0,75 & 3,77 & 0 & 10,5 & \\
\hline 23 & 8,6 & 6,45 & 0,75 & 1,29 & 0 & 0 & \\
\hline 24 & 8,4 & 6,3 & 0,2 & 1,26 & 0 & 0 & \\
\hline 25 & 8,6 & 6,45 & 0,2 & 1,29 & 0 & 0 & \\
\hline
\end{tabular}


Tabela 4 - Valores Diários da Evapotranspiração de Referência (ETo), Evapotranspiração Máxima (ETM), Precipitações, Irrigações, do Potencial da Água do Solo, no Tratamento Não Irrigado

\begin{tabular}{|c|c|c|c|c|c|c|c|}
\hline DIAS & $\begin{array}{c}\begin{array}{c}\text { E.T.C.A } \\
(\mathrm{mm})\end{array} \\
\end{array}$ & $\begin{array}{l}\text { ETo } \\
\text { (mm) }\end{array}$ & $\mathrm{kc}$ & $\begin{array}{l}\text { ETM } \\
(\mathrm{mm})\end{array}$ & $\begin{array}{c}\text { Precipit. } \\
\text { (mm) }\end{array}$ & $\begin{array}{c}\text { Irrigação } \\
(\mathrm{mm})\end{array}$ & $\begin{array}{r}\text { Tensiôm. } \\
\text { (atm) }\end{array}$ \\
\hline $20 / 05$ & 0 & 0 & 0,3 & 0 & 13 & 0 & 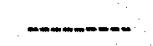 \\
\hline 21 & 4,6 & 3,45 & 0,3 & 1,04 & 0 & 0 & -..- \\
\hline 22 & 5 & 3,75 & 0,3 & 1,13 & 0 & 0 & \\
\hline 23 & 5 & 3,75 & 0,3 & 1,13 & 0 & 0 & - \\
\hline 24 & 4,6 & 3,45 & 0,3 & 1,04 & 0 & 23 & - \\
\hline 25 & 4,8 & 3,6 & 0,3 & 1,08 & 0 & 0 & --.-- \\
\hline 26 & 4,6 & 3,45 & 0,3 & 1,04 & 0 & 0 & - \\
\hline 27 & 4,8 & 3,6 & 0,3 & 1,08 & 0 & 0 & 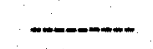 \\
\hline 28 & 5 & 3,75 & 0,3 & 1,13 & 0 & 0 & - \\
\hline 29 & 5 & 3,75 & 0,3 & 1,13 & 0 & 0 & \\
\hline 30 & 4,8 & 3,6 & 0,3 & 1,08 & 0 & 0 & - \\
\hline 31 & 4,5 & 3,38 & 0,3 & 1,01 & 0 & 0 & 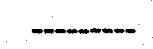 \\
\hline $01 / 06$ & 4,6 & 3,45 & 0,3 & 1,04 & 0 & 10 & -..... \\
\hline 02 & 4,8 & 3,6 & 0,4 & 1,44 & 0 & 0 & -..-- \\
\hline 03 & 5,2 & 3,9 & 0,4 & 1,56 & 0 & 0 & - \\
\hline 04 & 3,2 & 2,4 & 0,4 & 0,96 & 0 & 0 & - \\
\hline 05 & 6,4 & 4,8 & 0,4 & 1,92 & 0 & 0 & \\
\hline 06 & 6 & 4,5 & 0,4 & 1,8 & 0 & 0 & - \\
\hline 07 & 3,9 & 2,93 & 0,4 & 1,17 & 0 & 0 & - \\
\hline 08 & 3,9 & 2,93 & 0,4 & 1,17 & 0 & 0 & - \\
\hline 09 & 3 & 2,25 & 0,4 & 0,9 & 0 & 0 & $\cdots$ \\
\hline 10 & 3,2 & 2,4 & 0,4 & 0,96 & 0 & 0 & $\ldots$ \\
\hline 11 & 5,2 & 3,9 & 0,4 & 1,56 & 0 & 0 & 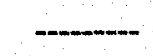 \\
\hline 12 & 5,4 & 4,05 & 0,4 & 1,62 & 0 & 0 & -יב- \\
\hline 13 & 4 & 3 & 0,4 & 1,2 & 0 & 0 & - \\
\hline 14 & 4,1 & 3,08 & 0,4 & 1,23 & 0 & 0 & \\
\hline 15 & 4 & 3 & 0,4 & 1,2 & 0 & 0 & \\
\hline 16 & 4,2 & 3,15 & 0,7 & 2,21 & 0 & 0 & - \\
\hline 17 & 4,1 & 3,08 & 0,7 & 2,15 & 0 & 0 & -..-- \\
\hline 18 & 4,5 & 3,38 & 0,7 & 2,36 & 0 & 0 & - \\
\hline 19 & 2,8 & 2,1 & 0,7 & 1,47 & 0 & 0 & - \\
\hline 20 & 3,8 & 2,85 & 0,7 & 2 & 0 & 0 & -..-..- \\
\hline 21 & 2,3 & 1,73 & 0,7 & 1,21 & 1,2 & 0 & - \\
\hline
\end{tabular}


Tabela 4 - Valores Diários da Evapotranspiração de Referência (ETo), Evapotranspiração Máxima (ETM), Precipitações, Irrigações, do Potencial da Água do Solo, no Tratamento Não Irrigado

\begin{tabular}{|c|c|c|c|c|c|c|c|}
\hline DIAS & $\begin{array}{c}\text { E.T.C.A } \\
(\mathrm{mm})\end{array}$ & $\begin{array}{l}\text { ETo } \\
\text { (mm) }\end{array}$ & $\mathrm{kc}$ & $\begin{array}{l}\text { ETM } \\
(\mathrm{mm})\end{array}$ & $\begin{array}{c}\text { Precipit. } \\
(\mathrm{mm})\end{array}$ & $\begin{array}{c}\text { Irrigação } \\
\text { (mm) }\end{array}$ & $\begin{array}{c}\text { Tensiôm } \\
\text { (atm) }\end{array}$ \\
\hline 22 & 0 & 0 & 0,7 & 0 & 2 & 0 & - \\
\hline 23 & 0 & 0 & 0,7 & 0 & 0 & 0 & - \\
\hline 24 & 0 & 0 & 0,7 & 0 & 0 & 0 & - \\
\hline 25 & 0 & 0 & 0,7 & 0 & 10 & 0 & - \\
\hline 26 & 3 & 2,25 & 0,7 & 1,58 & 19 & 0 & - \\
\hline 27 & 4,6 & 3,45 & 0,7 & 2,41 & 0 & 0 & 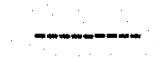 \\
\hline 28 & 4,4 & 3,3 & 0,7 & 2,31 & 0 & 0 & - \\
\hline 29 & 0 & 0 & 0,7 & 0 & 0 & 0 & - \\
\hline 30 & 3,2 & 2,4 & 0,7 & 1,68 & 0 & 0 & - \\
\hline $01 / 07$ & 3,9 & 2,93 & 0,8 & 2,34 & 0 & 0 & - \\
\hline 02 & 2,9 & 2,18 & 0,8 & 1,74 & 0 & 0 & - \\
\hline 03 & 3,2 & 2,4 & 0,8 & 1,92 & 0 & 0 & - \\
\hline 04 & 5,2 & 3,9 & 0,8 & 3,12 & 0 & 0 & -ביביב-י- \\
\hline 05 & 5,4 & 4,05 & 0,8 & 3,24 & 0 & 0 & 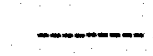 \\
\hline 06 & 4,2 & 3,15 & 0,8 & 2,52 & 0 & 0 & --י-ריב- \\
\hline 07 & 4 & 3 & 0,8 & 2,4 & 0 & 25,2 & - \\
\hline 08 & 4,1 & 3,08 & 0,8 & 2,46 & 0 & 0 & - \\
\hline 09 & 5,2 & 3,9 & 1,05 & 4,1 & 0 & 0 & 0.07 \\
\hline 10 & 4,5 & 3,38 & 1,05 & 3,54 & 0 & 0 & 0,1 \\
\hline 11 & 0 & 0 & 1,05 & 0 & 13,8 & 0 & 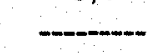 \\
\hline 12 & 3,6 & 2,7 & 1,05 & 2,84 & 0 & 0 & 0,05 \\
\hline 13 & 0 & 0 & 1,05 & 0 & 0 & 0 & 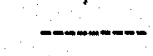 \\
\hline 14 & 2 & 1,5 & 1,05 & 1,58 & 0 & 0 & - \\
\hline 15 & 3 & 2,25 & 1,05 & 2,36 & 0 & 0 & 0,1 \\
\hline 16 & 3,6 & 2,7 & 1,05 & 2,84 & 0 & 0 & - \\
\hline 17 & 2,5 & 1,88 & 1,05 & 1,97 & 0 & 0 & 0,14 \\
\hline 18 & 4,6 & 3,45 & 1,05 & 3,62 & 0 & 0 & 0,24 \\
\hline 19 & 5,6 & 4,2 & 1,05 & 4,41 & 0 & 0 & 0,36 \\
\hline 20 & 5 & 3,75 & 1,2 & 4,5 & 0 & 0 & 0,5 \\
\hline 21 & 4,8 & 3,6 & 1,2 & 4,32 & 0 & 0 & - \\
\hline 22 & 4,8 & 3,6 & 1,2 & 4,32 & 0 & 0 & 0,55 \\
\hline 23 & 4,9 & 3,68 & 1,2 & 4,41 & 0 & 0 & - \\
\hline
\end{tabular}


Tabela 4 - Valores Diários da Evapotranspiração de Referência (ETo), Evapotranspiração Máxima (ETM), Precipitações, Irrigações, do Potencial da Água do Solo, no Tratamento Não Irrigado

\begin{tabular}{|c|c|c|c|c|c|c|c|}
\hline DIAS & $\begin{array}{c}\text { E.T.C.A } \\
(\mathrm{mm})\end{array}$ & $\begin{array}{l}\text { ETo } \\
(\mathrm{mm})\end{array}$ & $\mathrm{kc}$ & $\begin{array}{l}\text { ETM } \\
(\mathrm{mm})\end{array}$ & $\begin{array}{c}\text { Precipit. } \\
\text { (mm) }\end{array}$ & $\begin{array}{l}\text { Irrigação } \\
\text { (mm) }\end{array}$ & $\begin{array}{c}\text { Tensiôm. } \\
\text { (atm) }\end{array}$ \\
\hline 24 & 2,9 & 2,18 & 1,2 & 2,61 & 0 & 0 & -1 \\
\hline 25 & 4,6 & 3,45 & 1,2 & 4,14 & 0 & 0 & - \\
\hline 26 & 5,3 & 3,98 & 1,2 & 4,77 & 0 & 0 & - \\
\hline 27 & 4,8 & 3,6 & 1,2 & 4,32 & 0 & 0 & \\
\hline 28 & 4,4 & 3,3 & 1,2 & 3,96 & 0 & 0 & \\
\hline 29 & 6,6 & 4,95 & 1,2 & 5,94 & 0 & 0 & \\
\hline 30 & 4,9 & 3,68 & 1,2 & 4,41 & 0 & 0 & ב-ב- \\
\hline 31 & 4,5 & 3,38 & 1,2 & 4,05 & 0 & 0 & 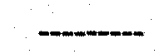 \\
\hline $01 / 08$ & 5,4 & 4,05 & 1,2 & 4,86 & 0 & 0 & \\
\hline 02 & 6,9 & 5,18 & 1,2 & 6,21 & 0 & 0 & \\
\hline 03 & 4,2 & 3,15 & 1,2 & 3,78 & 0 & 0 & \\
\hline 04 & 4,6 & 3,45 & 1,2 & 4,14 & 0 & 0 & \\
\hline 05 & 5 & 3,75 & 1,2 & 4,5 & 0 & 0 & \\
\hline 06 & 5,3 & 3,98 & 1,2 & 4,77 & 0 & 0 & \\
\hline 07 & 6,8 & 5,1 & 1,2 & 6,12 & 0 & 0 & \\
\hline 08 & 0 & 0 & 1,2 & 0 & 9,2 & 0 & - \\
\hline 09 & 1,6 & 1,2 & 1,2 & 1,44 & 0 & 0 & - \\
\hline 10 & 5,3 & 3,98 & 1,2 & 4,77 & 0 & 0 & $\ldots$ \\
\hline 11 & 5,5 & 4,13 & 1,2 & 4,95 & 0 & 0 & $\cdots$ \\
\hline 12 & 5,6 & 4,2 & 1,2 & 5,04 & 0 & 0 & \\
\hline 13 & 5,1 & 3,83 & 1,2 & 4,59 & 0 & 0 & \\
\hline 14 & 5,6 & 4,2 & 1,2 & 5,04 & 0 & 0 & \\
\hline 15 & 5,2 & 3,9 & 1,2 & 4,68 & 0 & 0 & -...... \\
\hline 16 & 6,7 & 5,03 & 0,75 & 3,77 & 0 & 0 & - \\
\hline 17 & 6,6 & 4,95 & 0,75 & 3,71 & 0 & 0 & - \\
\hline 18 & 6,8 & 5,1 & 0,75 & 3,83 & 0 & 0 & - \\
\hline 19 & 6 & 4,5 & 0,75 & 3,38 & 0 & 0 & מיב-יב- \\
\hline 20 & 6,2 & 4,65 & 0,75 & 3,49 & 0 & 0 & \\
\hline 21 & 7,1 & 5,33 & 0,75 & 3,99 & 0 & 0 & \\
\hline 22 & 6,7 & 5,03 & 0,75 & 3,77 & 0 & 0 & - \\
\hline 23 & 8,6 & 6,45 & 0,75 & 1,29 & 0 & 0 & -...- \\
\hline 24 & 8,4 & 6,3 & 0,2 & 1,26 & 0 & 0 & - \\
\hline 25 & 8,6 & 6,45 & 0,2 & 1,29 & 0 & 0 & - \\
\hline
\end{tabular}


Tabela 5 - Valores dasTemperaturas Horárias do Dossel (C) obtidas no dia 27/07

\begin{tabular}{|c|c|c|c|c|c|c|}
\hline HORA & 11 & 12 & 13 & 14 & 15 & 16 \\
\hline \multicolumn{7}{|c|}{ LADO IRRIGADO } \\
\hline 1 & 22,2 & 23,9 & 23 & 22,2 & 22,1 & 20,3 \\
\hline 2 & 22,1 & 24,2 & 22 & 22,7 & 20,9 & 21,8 \\
\hline 3 & 22,1 & 21,8 & 22,1 & 22,3 & 20,8 & 21,8 \\
\hline 4 & 21,3 & 21,6 & 21,6 & 22,7 & 21,1 & 22,8 \\
\hline 5 & 23 & 22,9 & 22,8 & 22,1 & 21,3 & 22 \\
\hline 6 & 21,4 & 23,5 & 21,8 & 22,7 & 21,2 & 22,4 \\
\hline 7 & 22,6 & 22,8 & 20,5 & 22,5 & 21,5 & 22 \\
\hline 8 & 22,6 & 22,3 & 22,4 & 23,3 & 21,8 & 21,7 \\
\hline 9 & 23,5 & 24,1 & 21,6 & 22,2 & 21,4 & 21,1 \\
\hline 10 & 24 & 22,9 & 20,8 & 23,1 & 22,6 & 22,5 \\
\hline MÉDIA & 22,6 & 23 & 21.8 & 22.6 & 21.5 & 21.8 \\
\hline \multicolumn{7}{|c|}{ LADO NÁO IRRIGADO } \\
\hline 1 & 20,4 & 21,9 & 22 & 24,8 & 20,3 & 21,9 \\
\hline 2 & 22,1 & 23,7 & 22 & 24 & 21,5 & 22,32 \\
\hline 3 & 23,6 & 23,8 & 23,9 & 23,2 & 21,8 & 23,3 \\
\hline 4 & 24,6 & 24,9 & 25 & 22,7 & 21 & 22 \\
\hline 5 & 24,5 & 25,5 & 24,8 & 22,9 & 21,7 & 22,6 \\
\hline 6 & 24,7 & 25,4 & 24,5 & 24 & 22,8 & 23 \\
\hline 7 & 24 & 26,1 & 25,8 & 24 & 22,6 & 22,2 \\
\hline 8 & 24,3 & 26,4 & 24,5 & 23,4 & 22,4 & 21,9 \\
\hline 9 & 24,3 & 26,6 & 24,9 & 22,7 & 22,8 & 22,6 \\
\hline 10 & 25,7 & 26,7 & 24,1 & 22,9 & 22,8 & 22,8 \\
\hline MEDIA & 23.8 & 25.1 & 24.2 & 23.5 & 22.0 & 22,5 \\
\hline
\end{tabular}


Tabela 6 - Valores das Temperaturas dos Bulbos Úmido e Sêco $\left({ }^{\circ} \mathrm{C}\right)$, Pressões Parciais (ea) e de Saturação do Vapor (es(T)) - kPa, da Radiação Líquida $(R n)$ e das Velocidades do Vento $(V)-\mathrm{m} / \mathrm{s}$, obtidos no dia $27 / 07$ - Lado Irrigado

\begin{tabular}{|l|rrrrrrr|}
\hline HORA & 11 & \multicolumn{1}{c}{12} & \multicolumn{1}{c}{13} & 14 & 15 & \multicolumn{1}{c|}{16} \\
\hline TU1 $(1,5 \mathrm{M})$ & 19,3 & 19,1 & 19,2 & 18,9 & 17,9 & 17,9 \\
Tu2 $(2,3 \mathrm{M})$ & 17,4 & 17,5 & 17,4 & 17,7 & 16,5 & 16,7 \\
\hline TUM $(1,85 \mathrm{M})$ & 18,3 & 18,3 & 18,3 & 18,3 & 17,2 & 17,3 \\
\hline T1 $(1,5 \mathrm{M})$ & 24 & 25,1 & 25,8 & 26,2 & 25,5 & 24,8 \\
T2 $(2,3 \mathrm{M})$ & 23,4 & 24,8 & 25,7 & 26,1 & 25,8 & 25,2 \\
\hline TM $(1,85)$ & 23,7 & 25 & 25,8 & 26,1 & 25,7 & 25 \\
\hline
\end{tabular}

\begin{tabular}{|l|rrrrrr|}
\hline es (Tu) & 2,113 & 2,107 & 2,103 & 2,109 & 1,961 & 1,977 \\
ea & 1,757 & 1,664 & 1,604 & 1,588 & 1,393 & 1,463 \\
es(T) & 2,936 & 3,168 & 3,324 & 3,399 & 3,307 & 3,176 \\
es(Ts) & 2,728 & 2,815 & 2,619 & 2,744 & 2,565 & 2,623 \\
es(T)-ea & 1,18 & 1,505 & 1,721 & 1,811 & 1,914 & 1,713 \\
es(Ts)-ea & 0,971 & 1,151 & 1,015 & 1,156 & 1,171 & 1,16 \\
\hline
\end{tabular}

\begin{tabular}{|r|rrrrrr|}
\hline$Q^{*}(\mathrm{~W} / \mathrm{m} 2)$ & 284,9 & 314,8 & 341,1 & 350,2 & 300,51 & 195,9 \\
& & & & & & \\
V2 $(1,85 \mathrm{M})$ & 1 & 0,8 & 1 & 1,1 & 1 & 0,7 \\
$\mathrm{~V} 1(1,10 \mathrm{M})$ & 0,2 & 0,3 & 0,4 & 0,4 & 0,5 & 0,3 \\
\hline
\end{tabular}


Tabela 7 - Valores Horários dos Parâmetros: Ri, $u^{*}$, ra, rc, Qe, Qh e CWSI, obtidos no dia 27/07 - Tratamento Irrigado

\begin{tabular}{|l|rrrrrrr|}
\hline HORA & 11 & 12 & 13 & 14 & 15 & 16 \\
\hline Ri & & & & & & \\
FIM & 0,1 & 0,2 & 0,4 & 0,2 & 0,7 & 0,8 \\
$\mathrm{u}^{*}(\mathrm{~m} / \mathrm{s})$ & 0,8 & 0,4 & 0,3 & 0,5 & 0,2 & 0,2 \\
DELTA & 0,4 & 0,5 & 0,7 & 0,6 & 0,8 & 0,8 \\
Ts - Ta & 170,7 & 179 & 177,2 & 182,6 & 175,2 & 173,7 \\
ram (S/M) & $-1,2$ & -2 & -4 & $-3,6$ & $-4,2$ & $-3,2$ \\
ra (s/m) & 49,7 & 52 & 39 & 37,7 & 35,1 & 47,5 \\
rc (s/m) & 60,6 & 62,2 & 46,9 & 46,1 & 42,1 & 55 \\
rc/ra & 0,4 & 1 & 0,7 & 4 & 11 & 28,7 \\
CWSI (1) & 0 & 0 & 0 & 0,1 & 0,3 & 0,5 \\
CWSI (2) & 0 & 0 & 0 & 0 & 0,1 & 0,1 \\
Qh (W.m-2) & 0 & 0 & 0 & 0 & 0 & 0 \\
Qe (W.m-2) & $-26,1$ & $-41,1$ & $-109,8$ & $-100,6$ & $-130,1$ & $-74,8$ \\
\hline
\end{tabular}

(1)* VALORES OBTIDOS CONFORME JACKSON (1982)

(2) ${ }^{\star \star}$ VALORES OBTIDOS CONFORME IDSO et al (1981) 
Tabela 8 - Valores das Temperatuas Horárias do Dossel $\left({ }^{\circ} \mathrm{C}\right)$, obtidas no dia 29/07

\begin{tabular}{|c|c|c|c|c|c|c|}
\hline HORA & 11 & 12 & 13 & 14 & 15 & 16 \\
\hline \multicolumn{7}{|c|}{ LADO IRRIGADO } \\
\hline 1 & 22,4 & 23,8 & 24,5 & 23,5 & 22,4 & 22,4 \\
\hline 2 & 22,5 & 23,2 & 24 & 23,3 & 22,3 & 20,9 \\
\hline 3 & 22,9 & 24 & 24 & 23 & 20,3 & 20,4 \\
\hline 4 & 23 & 22,6 & 23,3 & 22,5 & 20,1 & 20,3 \\
\hline 5 & 23,6 & 24 & 23,9 & 22,7 & 21,4 & 21,1 \\
\hline 6 & 23,6 & 24,2 & 23,6 & 23,1 & 22,3 & 22,1 \\
\hline 7 & 23,9 & 24,5 & 24,6 & 23,9 & 23,2 & 22,2 \\
\hline 8 & 24 & 24,2 & 24,7 & 23,6 & 21,4 & 21,5 \\
\hline 9 & 24,6 & 24,1 & 24,4 & 24 & 21,8 & 21,3 \\
\hline 10 & 24 & 23,6 & 24 & 24,2 & 23,1 & 22,8 \\
\hline Média & 23.5 & 23.8 & 24.1 & 23.4 & 21.8 & 21.5 \\
\hline \multicolumn{7}{|c|}{ LADO NÁ IRRIGADO } \\
\hline 1 & 24,8 & 25,2 & 26,4 & 24,4 & 24,4 & 25,6 \\
\hline 2 & 24 & 25,5 & 27,3 & 25,1 & 25,4 & 25 \\
\hline 3 & 24,8 & 25,4 & 27,1 & 25,3 & 25,8 & 25,8 \\
\hline 4 & 24,4 & 25,2 & 26,8 & 25,3 & 26,2 & 25,7 \\
\hline 5 & 25,4 & 24,6 & 26,2 & 25,4 & 25,1 & 25,7 \\
\hline 6 & 25 & 24,6 & 26,1 & 25,5 & 25,8 & 25,1 \\
\hline 7 & 24,7 & 26,3 & 26,5 & 25,8 & 25 & 25,2 \\
\hline 8 & 25,1 & 26,1 & 26,7 & 26,8 & 25,9 & 24,8 \\
\hline 9 & 24,9 & 26,1 & 27,8 & 24,9 & 25,9 & 24,4 \\
\hline 10 & 25,5 & 26 & 27,3 & 25,9 & 26,4 & 25,9 \\
\hline Média & 24.9 & 25.5 & 26.8 & 25.4 & 25.6 & 25.3 \\
\hline
\end{tabular}


Tabela 9 - Valores das Temperaturas dos Bulbos Úmido e Sêco $\left({ }^{\circ} \mathrm{C}\right)$, Pressões Parciais (ea) e de Saturação do Vapor $(e s(T))$ - kPa, da Radiação Líquida $\left(Q^{*}\right)$ e das Velocidades do Vento $(M)$ - m/s, obtidos no dia 29/07 - Lado não Irrigado

\begin{tabular}{|l|rrrrrrr|}
\hline HORA & 11 & 12 & 13 & 14 & 15 & 16 \\
\hline TU1 $(1,5 \mathrm{M})$ & 18,3 & 20 & 21,4 & 21,5 & 20,3 & 20,8 \\
Tu2 $(2,3 \mathrm{M})$ & 17,1 & 19,6 & 18,4 & 18,3 & 18,5 & 19,6 \\
\hline Tu M $(1,85 \mathrm{M})$ & 17,7 & 19,8 & 19,7 & 19,9 & 19,4 & 20,2 \\
\hline T1 $(1,5 \mathrm{M})$ & 26,6 & 28,1 & 28,2 & 27,6 & 27,7 & 27,6 \\
T2 $(2,3 \mathrm{M})$ & 25,6 & 27,5 & 27,5 & 27,3 & 27,7 & 27,9 \\
\hline TM $(1,85)$ & 26,1 & 27,8 & 27,8 & 27,4 & 27,7 & 27,7 \\
\hline
\end{tabular}

\begin{tabular}{|l|rrrrrr|}
\hline es (Tu) & 2,031 & 2,312 & 2,299 & 2,322 & 2,25 & 2,364 \\
ea & 1,477 & 1,781 & 1,758 & 1,818 & 1,694 & 1,86 \\
es(T) & 3,38 & 3,74 & 3,754 & 3,667 & 3,725 & 3,732 \\
es(Ts) & 3,148 & 3,271 & 3,536 & 3,259 & 3,288 & 3,236 \\
es(T)-ea & 1,903 & 1,958 & 1,996 & 1,849 & 2,031 & 1,872 \\
es(Ts)-ea & 1,671 & 1,489 & 1,778 & 1,441 & 1,594 & 1,376 \\
\hline
\end{tabular}

\begin{tabular}{|r|rrrrrr|}
\hline$Q^{*}(\mathrm{~W} \cdot \mathrm{m}-2)$ & 343,1 & 378,8 & 334,7 & 270,8 & 217,6 & 189,2 \\
& & & & & & \\
$\mathrm{~V} 2(1,85 \mathrm{M})$ & 0,8 & 0,8 & 0,8 & 0,8 & 0,7 & 0,5 \\
$\mathrm{~V} 1(1,10 \mathrm{M})$ & 0,4 & 0,4 & 0,4 & 0,4 & 0,3 & 0,2 \\
\hline
\end{tabular}


Tabela 10 - Valores Horários dos Parâmetros : Ri, $\phi \mathrm{m}, \mathrm{u}^{*}$, ra, rc, Qh, Qe e CWSI obtidos no dia 29/07 - Lado não Irrigado

\begin{tabular}{|l|rrrrrr|}
\hline \multicolumn{1}{|c|}{ HORA } & 11 & 12 & 13 & 14 & 15 & 16 \\
\hline $\mathrm{Ri}$ & 0,3 & 0,5 & 0,3 & 0,6 & 1,1 & 0,8 \\
$\phi \mathrm{m}$ & 0,4 & 0,3 & 0,4 & 0,3 & 0,2 & 0,2 \\
$\mathrm{u}^{\star}(\mathrm{m} / \mathrm{s})$ & 0,4 & 0,6 & 0,3 & 0,5 & 0,6 & 0,7 \\
$\Delta$ & 193,4 & 205,6 & 213,1 & 203,5 & 205,7 & 204,4 \\
Ts - Ta & $-1,2$ & $-2,3$ & -1 & -2 & $-2,1$ & $-2,4$ \\
ram (s/m) & 51,7 & 47,5 & 53 & 45,9 & 52,8 & 65,4 \\
ra (s/m) & 63,5 & 56,8 & 65,8 & 55,4 & 61,9 & 73,2 \\
rc (s/m) & 25,3 & 10,7 & 32,1 & 33,2 & 56,9 & 42,6 \\
rc/ra & 0,4 & 0,2 & 0,5 & 0,6 & 0,9 & 0,6 \\
CWSI (1) & 0,1 & 0 & 0,1 & 0,1 & 0,2 & 0,1 \\
CWSI (1) & 0 & 0 & 0,3 & 0,2 & 0,3 & 0,2 \\
Qh (W.m-2) & $-2,4$ & -52 & $-20,1$ & $-46,9$ & $-44,5$ & $-42,9$ \\
Qe (W.m-2) & 367,5 & 430,8 & 354,8 & 317,6 & 262,1 & 232,1 \\
\hline
\end{tabular}

(1)* VALORES OBTIDOS CONFORME JACKSON (1982)

(2) ${ }^{\star \star}$ VALORES OBTIDOS CONFORME IDSO el al. (1981) 
Tabela 11 - Valores das Temperaturas Horárias do Dossel $\left({ }^{\circ} \mathrm{C}\right)$, obtidas no dia 06/08

\begin{tabular}{|c|c|c|c|c|c|c|}
\hline HORA & 11 & 12 & 13 & 14 & 15 & 16 \\
\hline \multicolumn{7}{|c|}{ LADO IRRIGADO } \\
\hline 1 & 22,2 & 21,8 & 21,1 & 22,1 & 23,3 & 22,1 \\
\hline 2 & 22,7 & 21,6 & 22,2 & 22,2 & 23,1 & 22,5 \\
\hline 3 & 23,1 & 23,2 & 23,2 & 23,2 & 23,4 & 22,4 \\
\hline 4 & 22,5 & 22,8 & 21,4 & 23 & 23,9 & 21,4 \\
\hline 5 & 23 & 21,8 & 22,9 & 23,3 & 24,7 & 22 \\
\hline 6 & 21,6 & 22,1 & 21,6 & 22,4 & 23,5 & 20,8 \\
\hline 7 & 22,7 & 21,1 & 23,4 & 23,2 & 22,5 & 22,2 \\
\hline 8 & 21,8 & 21,8 & 22,7 & 23,1 & 23,1 & 21,3 \\
\hline 9 & 22,8 & 22 & 23 & 23,6 & 23,6 & 22,2 \\
\hline 10 & 21,8 & 22,5 & 23,1 & 23 & 23,3 & 21,5 \\
\hline Média & 22.4 & 22.1 & 22.5 & 22.9 & 23.4 & 21.8 \\
\hline \multicolumn{7}{|c|}{ LADO NÁO IRRIGADO } \\
\hline 1 & 23,9 & 24,4 & 28 & 27,3 & 25 & $\overline{23,9}$ \\
\hline 2 & 24 & 26,9 & 28 & 26,4 & 25,5 & 24,2 \\
\hline 3 & 23 & 26,6 & 26,5 & 26,2 & 24,6 & 23,9 \\
\hline 4 & 23,4 & 26,2 & 25,7 & 25,9 & 24,9 & 23,6 \\
\hline 5 & 23,6 & 26,4 & 27,2 & 26,4 & 25,5 & 23,5 \\
\hline 6 & 23,8 & 26,4 & 27,6 & 27 & 26,2 & 23,7 \\
\hline 7 & 24,4 & 26,9 & 28 & 27 & 26,2 & 24,9 \\
\hline 8 & 23,9 & 27,4 & 28 & 26,4 & 25 & 22,8 \\
\hline 9 & 24,5 & 28,2 & 28,4 & 27,3 & 25,2 & 23,8 \\
\hline 10 & 24,2 & 26,6 & 28,1 & 28,2 & 26,9 & 24 \\
\hline Média & 23.9 & 26.7 & 27.6 & 26.8 & 25.5 & 23.8 \\
\hline
\end{tabular}


Tabela 12 - Valores Horários das Temperaturas dos Bulbos Úmido e Sêco ( $\left.{ }^{\circ} \mathrm{C}\right)$, Pressões Parciais (e: e de Saturação do Vapor (es(T)) - kPa, da Radiação Líquida $\left(Q^{*}\right)$ e das Velocidades do Vento (V) - m/s, obtidos no dia 06/08 - Lado Irrigado

\begin{tabular}{|l|rrrrrrr|}
\hline HORA & 11 & 12 & 13 & 14 & 15 & 16 \\
\hline Tu1 $(1,5 \mathrm{M})$ & 18 & 18,4 & 18,8 & 19,2 & 20,1 & 17,2 \\
Tu2 $(2,3 \mathrm{M})$ & 16,8 & 16,8 & 17,2 & 17,2 & 18 & 16,4 \\
\hline TuM $(1,85 \mathrm{M})$ & 17,4 & 17,6 & 18 & 18,4 & 19,1 & 16,8 \\
\hline T1 $(1,5 \mathrm{M})$ & 24,5 & 25,5 & 27,5 & 28,3 & 27,6 & 26,8 \\
T2 $(2,3 \mathrm{M})$ & 24,4 & 25,4 & 27,5 & 27,8 & 27,9 & 27,6 \\
\hline TM $(1,85)$ & 24,5 & 25,4 & 27,5 & 28 & 27,7 & 27,2 \\
\hline
\end{tabular}

\begin{tabular}{|l|rrrrrr|}
\hline \multicolumn{1}{|c|}{ HORA } & \multicolumn{1}{c}{11} & \multicolumn{1}{c}{13} & \multicolumn{1}{c|}{14} & 15 & \multicolumn{1}{c|}{16} \\
\hline es (Tu) & 1,992 & 2,018 & 2,065 & 2,2121 & 2,209 & 1,914 \\
ea & 1,523 & 1,5 & 1,432 & 1,482 & 1,633 & 1,222 \\
es(T) & 3,076 & 3,253 & 3,68 & 3,792 & 3,727 & 3,613 \\
es(Ts) & 2,718 & 2,661 & 2,725 & 2,8 & 2,891 & 2,623 \\
es(T)-ea & 1,553 & 1,753 & 2,248 & 2,31 & 2,094 & 2,391 \\
es(Ts)-ea & 1,195 & 1,16 & 1,293 & 1,318 & 1,258 & 1,401 \\
\hline
\end{tabular}

\begin{tabular}{|c|c|c|c|c|c|c|}
\hline HORA & 11 & 12 & 13 & 14 & 15 & 16 \\
\hline$Q^{*}(W \cdot m-2)$ & 317,8 & 417,7 & 412,9 & 381 & 223,5 & 104,1 \\
\hline $\mathrm{V} 2(1,85 \mathrm{M})$ & 0,8 & 0,9 & 1 & 0,7 & 0,5 & 0,6 \\
\hline $\mathrm{V} 1(1,10 \mathrm{M})$ & 0,5 & 0,5 & 0,6 & 0,5 & 0,3 & 0,3 \\
\hline
\end{tabular}


Tabela 13 - Valores Horários dos Parâmetros : Ri, $\phi m, u^{*}$, ra, rc, Qh, Qe e CWSI obtidos no dia 06/08 - Lado Irrigado

\begin{tabular}{|c|c|c|c|c|c|c|}
\hline HORA & 11 & 12 & 13 & 14 & 15 & 16 \\
\hline $\mathbf{R} \mathbf{i}$ & 0,8 & 0,8 & 1 & 2,8 & 2,6 & 3,9 \\
\hline$\phi \mathrm{m}$ & 0,2 & 0,2 & 0,2 & 0,1 & 0,1 & 0 \\
\hline$u^{*}(M / S)$ & 0,6 & 0,8 & 1 & 1,5 & 1,4 & 1,8 \\
\hline$\Delta$ & 173,9 & 176,7 & 188,6 & 193,4 & 194,6 & 184 \\
\hline Ts - Ta & $-2,1$ & $-3,3$ & -5 & $-5,1$ & $-4,3$ & $-5,3$ \\
\hline $\mathrm{ram}(\mathrm{s} / \mathrm{m})$ & 43,1 & 38,1 & 33 & 40,3 & 57,5 & 51,7 \\
\hline $\mathrm{ra}(\mathrm{s} / \mathrm{m})$ & 51,8 & 45,6 & 39,2 & 45 & 62,6 & 55,9 \\
\hline $\mathrm{rc}(\mathrm{s} / \mathrm{m})$ & 11,4 & 5 & 4,4 & 3,7 & 8,3 & 40,3 \\
\hline $\mathrm{rc} / \mathrm{ra}$ & 0,2 & 0,1 & 0,1 & 0,1 & 0,1 & 0,7 \\
\hline CWSI (1)* & 0,1 & 0 & 0 & 0 & 0 & 0,2 \\
\hline CWSI (2) ${ }^{\star \star}$ & 0 & 0 & 0 & 0 & 0 & 0 \\
\hline Qh (W.m-2) & $-51,4$ & $-95,2$ & $-167,1$ & $-147,3$ & $-88,8$ & $-124,2$ \\
\hline Qe (W.m-2) & 369,3 & 448,7 & 580 & 528,3 & 346,7 & 284,3 \\
\hline
\end{tabular}

(1)* VALORES OBTIDOS CONFORME JACKSON (1982)

$(2)^{\star *}$ VALORES OBTIDOS CONFORME IDSO (1981) 
Tabela 14 - Valores dasTemperaturas Horárias do Dossel (C) obtidas no dia 07/08

\begin{tabular}{|c|ccccccc|}
\hline HORA & 11 & 12 & 13 & 14 & 15 & 16 \\
\hline \multicolumn{7}{|c}{} & \multicolumn{7}{c|}{10} \\
\hline 1 & 23.9 & 24.4 & 24.6 & 25.8 & 26.1 & 25 \\
2 & 25.6 & 25 & 25 & 26.4 & 24.6 & 24.8 \\
3 & 24.8 & 25.5 & 25.5 & 26 & 25.9 & 24.4 \\
4 & 26 & 25.7 & 26.5 & 26.8 & 25.4 & 25 \\
5 & 24.2 & 25.1 & 26.1 & 26.3 & 24.5 & 25 \\
6 & 24.2 & 24.8 & 25.9 & 26.8 & 25.4 & 24.2 \\
7 & 24.6 & 25.3 & 25.6 & 26.5 & 25.4 & 24.1 \\
8 & 26 & 27.2 & 25.5 & 26.6 & 25.9 & 25 \\
9 & 25.2 & 26.4 & 27.8 & 26.9 & 25 & 26.2 \\
10 & 24.7 & 25.4 & 27.7 & 26.3 & 25 & 24.7 \\
\hline MEDIA & 24.9 & 25.5 & 26 & 26.4 & 25.3 & 24.8 \\
\hline & & & LADO NAOOIRRIGADO & & \\
\hline 1 & 26.9 & 28.5 & 30.9 & 29.1 & 29.2 & 28.9 \\
2 & 27 & 28.7 & 31.3 & 29.9 & 28.9 & 27.9 \\
3 & 27.2 & 28.9 & 30.7 & 28.4 & 28.8 & 28.3 \\
4 & 27.3 & 28.8 & 30.4 & 28.3 & 27.8 & 27.4 \\
5 & 27.7 & 28.6 & 30.9 & 28.8 & 28.9 & 28.4 \\
6 & 27.6 & 29.6 & 31.3 & 29.5 & 28.9 & 28.4 \\
7 & 28.4 & 29.1 & 31.9 & 29.7 & 30.1 & 29 \\
8 & 28.2 & 28.9 & 31.3 & 28.9 & 28.3 & 28.1 \\
9 & 28.2 & 29.3 & 30.5 & 29.1 & 29.2 & 28.2 \\
10 & 28.5 & 29.3 & 30.7 & 29 & 29.3 & 28.4 \\
\hline MEDIA & 27.7 & 29 & 31 & 29.1 & 28.9 & 28.3 \\
\hline
\end{tabular}


Tabela 15 - Valores das Temperaturas dos Bulbos Ümido e Sêco $\left({ }^{\circ} \mathrm{C}\right)$, Pressões Parciais (ea) e de Saturação do Vapor (es $(T))$ - $k P a$, da Radiação Líquida $\left(Q^{*}\right)$ e das Velocidades do Vento $(\mathrm{V})$ - $\mathrm{m} / \mathrm{s}$, obtidos no dia $07 / 08$ - Lado Não Irrigado

\begin{tabular}{|l|rrrrrrr|}
\hline HORA & 11 & 12 & 13 & 14 & 15 & 16 \\
\hline Tu1 $(1,5 \mathrm{M})$ & 19.1 & 19.5 & 20.4 & 18.8 & 19.4 & 18.1 \\
TU2 $(2,3 \mathrm{M})$ & 17.9 & 18.2 & 18.7 & 18.1 & 18.3 & 17.3 \\
\hline Tu M $(1,85 \mathrm{M})$ & 18.5 & 18.8 & 19.6 & 18.5 & 18.8 & 17.7 \\
\hline T1 $(1,5 \mathrm{M})$ & 26.6 & 28.1 & 29.7 & 28 & 26.9 & 26.7 \\
T2 $(2,3 \mathrm{M})$ & 25.6 & 27.8 & 29.2 & 28.2 & 27.3 & 26.6 \\
\hline TM $(1,85)$ & 26.1 & 27.9 & 29.4 & 28.1 & 27.1 & 26.6 \\
\hline
\end{tabular}

\begin{tabular}{|l|llllll|}
\hline es (Tu) & 2.136 & 2.179 & 2.279 & 2.131 & 2.179 & 2.029 \\
ea & 1.632 & 1.574 & 1.621 & 1.491 & 1.629 & 1.435 \\
es(T) & 3.387 & 3.775 & 4.119 & 3.811 & 3.597 & 3.497 \\
es(Ts) & 3.723 & 4.008 & 4.501 & 4.032 & 4.002 & 3.856 \\
es(T)-ea & 1.755 & 2.201 & 2.498 & 2.320 & 1.968 & 2.061 \\
es(Ts)-ea & 2.091 & 2.434 & 2.880 & 2.541 & 2.372 & 2.420 \\
\hline
\end{tabular}

\begin{tabular}{|r|rrrrrr|}
\hline$Q^{*}(\mathrm{~W} / \mathrm{m} 2)$ & 312.6 & 330.0 & 318.7 & 133.1 & 32.5 & 38 \\
$\mathrm{~V} 2(1,85 \mathrm{~m})$ & & & & & & \\
$\mathrm{V} 1(1,10 \mathrm{~m})$ & 0.7 & 0.8 & 0.8 & 0.7 & 0.7 & 0.6 \\
\hline
\end{tabular}


Tabela 16 - Valores Horários dos Parâmetros : Ri, $u^{*}$, ra, rc, $\phi m$ Qh, Qe e CWSI, obtidos 07/08 - Tratamento Não Irrigado

\begin{tabular}{|c|c|c|c|c|c|c|}
\hline HORA & 11 & 12 & 13 & 14 & 15 & 16 \\
\hline$R i$ & $\wedge-0.9$ & ${ }^{\wedge}-0.3$ & $\wedge-0.5$ & $\wedge-0.4$ & $\wedge-0.3$ & $\wedge_{-0.4}$ \\
\hline$\phi m$ & 0.5 & 0.6 & 0.6 & 0.6 & 0.7 & 0.6 \\
\hline$u^{*}(\mathrm{~m} / \mathrm{s})$ & 0.2 & 0.2 & 0.2 & 0.2 & 0.3 & 0.2 \\
\hline$\Delta$ & 208.3 & 225.7 & 246.7 & 277.2 & 220.8 & 214.5 \\
\hline $\mathrm{Ts}-\mathrm{Ta}$ & 1.6 & 1 & 1.5 & 1 & 1.8 & 1.7 \\
\hline $\operatorname{ram}(\mathrm{S} / \mathrm{M})$ & 43.9 & 57.6 & 60.2 & 64.1 & 70.8 & 78.0 \\
\hline $\mathrm{ra}(\mathrm{s} / \mathrm{m})$ & 62.3 & 75.4 & 76.8 & 83 & 84.9 & 93.9 \\
\hline $\mathrm{rc}(\mathrm{s} / \mathrm{m})$ & 84 & 76.8 & 68.1 & 46.2 & 192.3 & 272.5 \\
\hline $\mathrm{rc} / \mathrm{ra}$ & 1.3 & 1 & 0.9 & 0.6 & 2.3 & 2.9 \\
\hline CWSI (1) * & 0.2 & 0.2 & 0.2 & 0.1 & 0.3 & 0.4 \\
\hline CWSI (2) & 0.5 & 0.5 & 0.6 & 0.5 & 0.6 & 0.6 \\
\hline Qh (W.m-2) & 33.5 & 17.8 & 26.2 & 15.2 & 27.9 & 23.1 \\
\hline$Q_{e}(W . m-2)$ & 279.1 & 312.2 & 388.1 & 384.0 & 167.1 & 129.0 \\
\hline
\end{tabular}

(1)* VALORES OBTIDOS CONFORME JACKSON (1982)

$(2)^{\star \star}$ VALORES OBTIDOS CONFORME IDSO et al. (1981) 
Tabela 17 - Valores das Temperaturas Horárias do Dossel $\left({ }^{\circ} \mathrm{C}\right)$, obtidos no dia 11/08

\begin{tabular}{|c|c|c|c|c|c|c|}
\hline HORA & 11 & 12 & 13 & 14 & 15 & 16 \\
\hline \multicolumn{7}{|c|}{ LADO IRRIGADO } \\
\hline 1 & 24 & 25,1 & 26,3 & 24,8 & 28,2 & 25,1 \\
\hline 2 & 24,6 & 24,7 & 26,7 & 26,4 & 27,9 & 25 \\
\hline 3 & 25 & 26,4 & 27,2 & 27,9 & 28,3 & 25,3 \\
\hline 4 & 25,6 & 27 & 26,9 & 27,5 & 27,9 & 25 \\
\hline 5 & 26,2 & 28,1 & 27,9 & 27,5 & 27,6 & 25 \\
\hline 6 & 25,3 & 26 & 28,6 & 28,8 & 28 & 25,2 \\
\hline 7 & 25,6 & 26,4 & 27,2 & 27,5 & 27,8 & 24,6 \\
\hline 8 & 25,9 & 26,8 & 26,9 & 27,4 & 27,7 & 24,9 \\
\hline 9 & 25,6 & 25,5 & 27,7 & 27,6 & 27,5 & 24,9 \\
\hline 10 & 25,5 & 25,4 & 27,5 & 28 & 27,2 & 25 \\
\hline Média & 25.3 & 26.1 & 27.3 & 27.4 & 27.8 & 25 \\
\hline \multicolumn{7}{|c|}{ LADO NÁO IRRIGADO } \\
\hline 1 & 26,5 & 27,7 & 29,2 & 26,9 & 29,2 & 26,4 \\
\hline 2 & 27,9 & 29,3 & 28,9 & 28,9 & 29,8 & 27,2 \\
\hline 3 & 28,1 & 29,6 & 29,3 & 29,2 & 30,4 & 27,6 \\
\hline 4 & 27,8 & 29,4 & 28,9 & 29,1 & 30 & 27,1 \\
\hline 5 & 29,1 & 29,9 & 28,6 & 29,9 & 30,3 & 27,3 \\
\hline 6 & 29 & 29,9 & 29 & 30,5 & 30,6 & 27,9 \\
\hline 7 & 29,9 & 30,9 & 28,8 & 31,2 & 30,6 & 27,8 \\
\hline 8 & 29,4 & 31 & 28,7 & 30,2 & 30,2 & 27,3 \\
\hline 9 & 28,7 & 30,4 & 28,5 & 30,6 & 29,8 & 27,3 \\
\hline 10 & 28,7 & 30,1 & 28,2 & 30,3 & 30,2 & 27,7 \\
\hline Média & 28.5 & 29.8 & 28.8 & 29.7 & 30.1 & 27.4 \\
\hline
\end{tabular}


Tabela 18 - Valores Horários das Temperaturas dos Bulbos Úmido e Sêco $\left({ }^{\circ} \mathrm{C}\right)$, Pressões Parciais e de Saturação do Vapor (es(T)) - kPa, da Radiação Líquida $\left(Q^{*}\right)$ e das Velocidades do Vento $(V)-\mathrm{m} / \mathrm{s}$, obtidos no dia 11/08 - Lado Não Irrigado

\begin{tabular}{|l|rrrrrr|}
\hline HORA & 11 & 12 & 13 & 14 & 15 & 16 \\
\hline Tu1 $(1,5 \mathrm{M})$ & 22,2 & 22,7 & 22,2 & 23 & 21,8 & 20,8 \\
Tu2 $(2,3 \mathrm{M})$ & 19,4 & 20,1 & 20 & 20,4 & 19,2 & 19,4 \\
\hline Tu M $(1,85 \mathrm{M})$ & 20,8 & 21,4 & 21,1 & 21,7 & 20,5 & 20,1 \\
\hline T1 $(1,5 \mathrm{M})$ & 26,8 & 27,6 & 27,8 & 28,2 & 27,7 & 25,6 \\
T2 $(2,3 \mathrm{M})$ & 25,5 & 26,7 & 26,3 & 27,3 & 26,3 & 25,2 \\
\hline TM $(1,85)$ & 26,2 & 27,2 & 27,1 & 27,8 & 27 & 25,4 \\
\hline
\end{tabular}

\begin{tabular}{|l|rrrrrr|}
\hline HORA & \multicolumn{1}{c}{11} & 12 & 13 & 14 & 15 & \multicolumn{1}{c|}{16} \\
\hline es (Tu) & 2,465 & 2,551 & 2,515 & 2,597 & 2,417 & 2,363 \\
ea & 2,109 & 2,165 & 2,12 & 2,191 & 1,984 & 2,015 \\
es(T) & 3,406 & 3,613 & 3,591 & 3,739 & 3,576 & 3,246 \\
es (Ts) & 3,903 & 4,21 & 3,972 & 4,176 & 4,281 & 3,65 \\
es(T)-ea & 1,297 & 1,448 & 1,47 & 1,548 & 1,592 & 1,231 \\
es(Ts)-ea & 1,794 & 2,045 & 1,851 & 1,985 & 2,297 & 1,635 \\
\hline
\end{tabular}

\begin{tabular}{|c|rrrrrr|}
\hline HORA & 11 & 12 & 13 & 14 & 15 & 16 \\
\hline$Q^{*}$ (W.m-2) & 337,7 & 354,3 & 337,2 & 288,9 & 204,9 & 128,9 \\
V2 $(1,85 \mathrm{~m})$ & & & & & & 1 \\
V1 $(1,10 \mathrm{~m})$ & 0,9 & 0,7 & 0,7 & 0,7 & 1 & 1 \\
& 0,5 & 0,4 & 0,8 & 0,4 & 0,8 & 0,6 \\
\hline
\end{tabular}


Tabela 19 -Valores Horários dos Parâmetros : Ri, $\phi \mathrm{m}, \mathbf{u}^{*}, \mathrm{ra}, \mathrm{rc}, \mathrm{Qh}, \mathrm{Qe}$ e CWSI obtidos no dia 11/08 - Lado Não Irrigado

\begin{tabular}{|c|c|c|c|c|c|c|}
\hline HORA & 11 & 12 & 13 & 14 & 15 & 16 \\
\hline Ri & $-0,5$ & $-0,9$ & $-2,5$ & $-0,6$ & $-4,6$ & $-0,3$ \\
\hline$\phi m$ & 0,6 & 0,5 & 0,4 & 0,6 & 0,3 & 0,6 \\
\hline$u^{*}(\mathrm{~m} / \mathrm{s})$ & 0,3 & 0,3 & 0,2 & 0,2 & 0,2 & 0,3 \\
\hline$\Delta$ & 196,4 & 205,9 & 211,5 & 215,8 & 213,9 & 190,6 \\
\hline Ts - Ta & 2,3 & 2,6 & 1,7 & 1,9 & 3,1 & 2 \\
\hline $\operatorname{ram}(\mathrm{s} / \mathrm{m})$ & 53,1 & 61,7 & 40,4 & 60,8 & 38,7 & 45,9 \\
\hline $\mathrm{ra}(\mathrm{s} / \mathrm{m})$ & 67,8 & 77,1 & 61,8 & 76,7 & 58,2 & 59,9 \\
\hline $\mathrm{rc}(\mathrm{s} / \mathrm{m})$ & 51,7 & 51,8 & 58,4 & 74,4 & 272,2 & 312 \\
\hline $\mathrm{rc} / \mathrm{ra}$ & 0,8 & 0,7 & 0,9 & 1 & 4,7 & 5,2 \\
\hline CWSI (1)* & 0,2 & 0,1 & 0,2 & 0,2 & 0,5 & 0,6 \\
\hline CWSI (2) & 0,5 & 0,6 & 0,5 & 0,5 & 0,6 & 0,4 \\
\hline Qh (W.m-2) & 44,6 & 44,4 & 36,3 & 32,3 & 69,2 & 43 \\
\hline$Q e(W \cdot m-2)$ & 293,1 & 309,9 & 300,8 & 256,5 & 135,8 & 85,8 \\
\hline
\end{tabular}

* (1) VALORES OBTIDOS CONFORME JACKSON (1982)

**(2) VALORES OBTIDOS CONFORME IDSO et al. (1981) 
Tabela 20 - Valores das Temperaturas Horárias do Dossel $\left({ }^{\circ} \mathrm{C}\right)$, obtidos no dia 13/08

\begin{tabular}{|c|c|c|c|c|c|c|}
\hline HORA & 11 & 12 & 13 & 14 & 15 & 16 \\
\hline \multicolumn{7}{|c|}{ LADO IRRIGADO } \\
\hline 1 & 21,7 & 24,8 & 25,3 & 24,5 & 24,4 & 24,4 \\
\hline 2 & 21,8 & 24,2 & 24,8 & 24,3 & 24,3 & 22,9 \\
\hline 3 & 22,2 & 25 & 24,8 & 24 & 22,3 & 22,4 \\
\hline 4 & 22,3 & 23,6 & 24,1 & 23,5 & 22,1 & 22,3 \\
\hline 5 & 22,9 & 25 & 24,7 & 23,7 & 23,4 & 23,1 \\
\hline 6 & 22,9 & 25,2 & 24,4 & 24,1 & 24,3 & 24,1 \\
\hline 7 & 23,2 & 25,5 & 25,4 & 24,9 & 25,2 & 24,2 \\
\hline 8 & 23,3 & 25,2 & 25,5 & 24,6 & 23,4 & 23,5 \\
\hline 9 & 23,9 & 25,1 & 25,2 & 25 & 23,8 & 23,3 \\
\hline 10 & 23,3 & 24,6 & 24,8 & 25,2 & 25,1 & 24,8 \\
\hline Média & 22.8 & 24.8 & 24.9 & 24.4 & 23.8 & 23.5 \\
\hline \multicolumn{7}{|c|}{ LADO NÁO IRRIGADO } \\
\hline 1 & 22,8 & 25,2 & 25,9 & 24,9 & 23,9 & 25,1 \\
\hline 2 & 22 & 25,5 & 26,8 & 25,6 & 24,9 & 24,5 \\
\hline 3 & 22,8 & 25,4 & 26,6 & 25,8 & 25,3 & 25,3 \\
\hline 4 & 22,4 & 25,2 & 26,3 & 25,8 & 25,7 & 25,2 \\
\hline 5 & 23,4 & 24,6 & 25,7 & 25,9 & 24,6 & 25,2 \\
\hline 6 & 23 & 24,3 & 25,6 & 26 & 25,3 & 24,6 \\
\hline 7 & 22,7 & 26,3 & 26 & 26,3 & 24,5 & 24,7 \\
\hline 8 & 23,1 & 26,1 & 27,3 & 27,3 & 25,4 & 24,3 \\
\hline 9 & 22,9 & 26,1 & 26,8 & 25,4 & 25,4 & 23,9 \\
\hline 10 & 23,5 & 26 & 26 & 26,4 & 25,9 & 25,4 \\
\hline Média & 22.9 & 25.5 & 26.3 & 25.9 & 25.1 & 24,8 \\
\hline
\end{tabular}


Tabela 21 - Valores das Temperaturas dos Bulbos Úmido e Sêco $\left({ }^{\circ} \mathrm{C}\right)$, Pressões Parciais (ea) e de Saturação do Vapor (es(T)) - kPa, da Radiação Liquida $\left(Q^{*}\right)$ e das Velocidades do Vento $(\mathrm{V})$ - $\mathrm{m} / \mathrm{s}$, obtidos no dia 13/08 - Lado Irrigado

\begin{tabular}{|l|rrrrrrr|}
\hline HORA & 11 & 12 & 13 & 14 & 15 & 16 \\
\hline Tu1 $(1,5 \mathrm{M})$ & 18,6 & 21 & 21,4 & 21,5 & 20,3 & 22,2 \\
Tu2 $(2,3 \mathrm{M})$ & 17,5 & 20,3 & 19,7 & 19,5 & 19,4 & 20,2 \\
\hline Tu M $(1,85 \mathrm{M})$ & 18 & 20,6 & 20,6 & 20,5 & 19,8 & 21,2 \\
\hline T1 $(1,5 \mathrm{M})$ & 25,1 & 26,6 & 27,7 & 27,1 & 26,7 & 27,2 \\
T2 $(2,3 \mathrm{M})$ & 24,1 & 26 & 25,9 & 26,7 & 26,7 & 26,4 \\
\hline TM $(1,85)$ & 24,6 & 26,3 & 26,8 & 26,9 & 26,7 & 26,8 \\
\hline
\end{tabular}

\begin{tabular}{|l|rrrrrr|}
\hline \multicolumn{1}{|c|}{ HORA } & \multicolumn{1}{c}{11} & \multicolumn{1}{c}{12} & 13 & 14 & 15 & \multicolumn{1}{c|}{16} \\
\hline es (Tu) & 2,073 & 2,434 & 2,427 & 2,41 & 2,319 & 2,516 \\
ea & 1,64 & 2,058 & 2,01 & 1,979 & 1,862 & 2,144 \\
es(T) & 3,091 & 3,424 & 3,54 & 3,561 & 3,513 & 3,521 \\
es(Ts) & 2,773 & 3,141 & 3,156 & 3,059 & 2,96 & 2,902 \\
es(T) - ea & 1,452 & 1,366 & 1,53 & 1,582 & 1,652 & 1,378 \\
es(Ts)-ea & 1,133 & 1,083 & 1,146 & 1,08 & 1,098 & 0,758 \\
\hline
\end{tabular}

\begin{tabular}{|c|rrrrrrr|}
\hline HORA & 11 & 12 & 13 & 14 & 15 & 16 \\
\hline $\mathrm{Q}^{*}(\mathrm{~W} \cdot \mathrm{m}-2)$ & 340,4 & 332,7 & 328,7 & 322,3 & 236,9 & 123 \\
$\mathrm{~V} 2(1,85 \mathrm{~m})$ & & & & & & \\
$\mathrm{V} 1(1,10 \mathrm{~m})$ & 0,8 & 1 & 0,7 & 0,7 & 0,7 & 0,5 \\
& 0,4 & 0,4 & 0,4 & 0,4 & 0,3 & 0,2 \\
\hline
\end{tabular}


Tabela 22 - Valores Horários dos Parâmetros : Ri, фm, u*, ra, rc, Qh, Qe e CWSI obtidos no dia $13 / 08$

\begin{tabular}{|c|c|c|c|c|c|c|}
\hline HORA & 11 & 12 & 13 & 14 & 15 & 16 \\
\hline Ri & 0,5 & 0,1 & 0,7 & 0,9 & 0,8 & 1,5 \\
\hline$\phi \mathrm{m}$ & 0,3 & 0,6 & 0,2 & 0,2 & 0,2 & 0,1 \\
\hline$u^{*}(\mathrm{~m} / \mathrm{s})$ & 0,5 & 0,4 & 0,6 & 0,7 & 0,7 & 0,9 \\
\hline$\Delta$ & 175,9 & 194,3 & 197,6 & 195,4 & 191,5 & 190 \\
\hline Ts - Ta & $-1,8$ & $-1,5$ & $-1,9$ & $-2,6$ & $-2,9$ & $-3,3$ \\
\hline $\operatorname{ram}(\mathrm{s} / \mathrm{m})$ & 47,9 & 45,6 & 48,1 & 46,3 & 50,4 & 63,4 \\
\hline $\mathrm{ra}(\mathrm{s} / \mathrm{m})$ & 57,8 & 56,9 & 57,3 & 54,2 & 58,1 & 69,9 \\
\hline $\mathrm{rc}(\mathrm{s} / \mathrm{m})$ & 0,3 & 0,9 & 2,7 & 0,7 & 13 & 7 \\
\hline $\mathrm{ra} / \mathrm{ra}$ & 0 & 0 & 0 & 0 & 0,2 & 0,1 \\
\hline CWSI $(1)^{\star}$ & 0 & 0 & 0 & 0 & 0,1 & 0 \\
\hline CWSI (2) ${ }^{\star *}$ & 0 & 0 & 0 & 0 & 0 & 0 \\
\hline Qh (W.m-2) & $-40,6$ & $-33,2$ & $-43,9$ & $-61,3$ & $-64,3$ & $-60,3$ \\
\hline Qe (W.m-2) & 381 & 365.9 & 372,7 & 383,6 & 301,2 & 192,3 \\
\hline
\end{tabular}

(1) * VALORES OBTIDOS CONFORME JACKSON (1982)

$(2)^{\star \star}$ VALORES OBTIDOS CONFORME IDSO et al. (1981) 
Tabela 23 -Valores das Temperaturas Horárias do Dossel $\left({ }^{\circ} \mathrm{C}\right)$, obtidos no dia $18 / 08$

\begin{tabular}{|c|c|c|c|c|c|c|}
\hline HORA & 11 & 12 & 13 & 14 & 15 & 16 \\
\hline \multicolumn{7}{|c|}{ LADO IRRIGADO } \\
\hline 1 & 19,3 & 19,6 & 20,3 & 21 & 20,6 & 21 \\
\hline 2 & 20,9 & 20,1 & 21,4 & 21,2 & 20,5 & 19,6 \\
\hline 3 & 21,1 & 20,9 & 22,1 & 21,9 & 21,6 & 20,5 \\
\hline 4 & 22,4 & 22,4 & 23 & 21,1 & 21,5 & 21,4 \\
\hline 5 & 22,2 & 22,4 & 23,7 & 23,8 & 22 & 21,2 \\
\hline 6 & 22,6 & 22,5 & 26,3 & 23,8 & 23,7 & 20,9 \\
\hline 7 & 23,2 & 22,8 & 24,4 & 22,3 & 22,7 & 20,6 \\
\hline 8 & 22,1 & 22,5 & 23,9 & 22,4 & 22,9 & 20,5 \\
\hline 9 & 22 & 23,2 & 24,6 & 24,2 & 23,2 & 21,4 \\
\hline 10 & 22,2 & 22,4 & 24,5 & 23,7 & 23,2 & 20,3 \\
\hline Média & 21.8 & 21.8 & 3.4 & 22.5 & 22.2 & 20.7 \\
\hline \multicolumn{7}{|c|}{ LADO NÁO IRRIGADO } \\
\hline 1 & 24,5 & 25,7 & 26,5 & 28,5 & 28,4 & 26,9 \\
\hline 2 & 25,7 & 24,4 & 26,6 & 27,9 & 28,2 & 27,3 \\
\hline 3 & 25,3 & 24,9 & 27,3 & 28,2 & 27,9 & 26,3 \\
\hline 4 & 24,8 & 26 & 27,6 & 27 & 26,7 & 25,3 \\
\hline 5 & 24,7 & 26,9 & 27,9 & 26,3 & 26,6 & 26,1 \\
\hline 6 & 24,7 & 26,9 & 28,4 & 28,3 & 27,2 & 25,8 \\
\hline 7 & 26,1 & 26,6 & 26,5 & 28 & 27,6 & 26,5 \\
\hline 8 & 25,4 & 27 & 28,6 & 29 & 27,9 & 25,7 \\
\hline 9 & 25,1 & 26,8 & 26,7 & 27,2 & 26 & 26,4 \\
\hline 10 & 25,2 & 27,5 & 28 & 28,8 & 26,8 & 26,5 \\
\hline Média & 25.2 & 26.3 & 27.4 & 27.9 & 27.3 & 26.3 \\
\hline
\end{tabular}


Tabela 24 - Valores das Temperaturas dos Bulbos Úmido e Sêco $\left({ }^{\circ} \mathrm{C}\right)$, Pressões Parciais (ea) e de Saturação do Vapor (es(T)) - kPa, da Radiação Líquida ( $\left.Q^{*}\right)$ e das Velocidades do Vento $(V)$ - $\mathrm{m} / \mathrm{s}$, obtidos no dia $18 / 08$ - Lado não Irrigado

\begin{tabular}{|l|rrrrrrr|}
\hline HORA & \multicolumn{1}{|c}{11} & \multicolumn{1}{c}{12} & 13 & 14 & 15 & 16 \\
\hline Tu1 $(1,5 \mathrm{M})$ & 15,9 & 16,3 & 17,3 & 16,5 & 16,7 & 16,6 \\
Tu2 $(2,3 \mathrm{M})$ & 15 & 15,5 & 16,5 & 17,4 & 16,5 & 17,5 \\
\hline Tu M $(1,85 \mathrm{M})$ & 15,5 & 15,9 & 16,9 & 16,9 & 16,6 & 17,1 \\
\hline T1 $(1,5 \mathrm{M})$ & 22,8 & 23,9 & 25,8 & 26,8 & 25,5 & 25,8 \\
T2 $(2,3 \mathrm{M})$ & 22 & 23,3 & 24,5 & 25,5 & 25,5 & 25,1 \\
\hline TM $(1,85)$ & 22,4 & 23,6 & 25,1 & 26,2 & 25,5 & 25,5 \\
\hline
\end{tabular}

\begin{tabular}{|l|rrrrrr|}
\hline \multicolumn{1}{|c|}{ HORA } & \multicolumn{1}{c}{11} & 12 & 13 & 14 & 15 & 16 \\
\hline es(Tu) & 1,762 & 1,81 & 1,929 & 1,932 & 1,894 & 1,952 \\
ea & 1,303 & 1,297 & 1,382 & 1,317 & 1,302 & 1,396 \\
es(T) & 2,71 & 2,922 & 3,202 & 3,406 & 3,275 & 3,261 \\
es(Ts) & 3,203 & 3,423 & 3,661 & 3,771 & 3,643 & 3,425 \\
es(T)-ea & 1,407 & 1,625 & 1,82 & 2,088 & 1,973 & 1,865 \\
es(Ts)-ea & 1,9 & 2,126 & 2,279 & 2,454 & 2,341 & 2,029 \\
\hline
\end{tabular}

\begin{tabular}{|c|c|c|c|c|c|c|}
\hline HORA & 11 & 12 & 13 & 14 & 15 & 16 \\
\hline $\mathrm{Q}^{*}(\mathrm{~W} \cdot \mathrm{m}-2)$ & 418,9 & 431,5 & 406,3 & 342,9 & 242,8 & 118,4 \\
\hline V2 $(1,85 \mathrm{~m})$ & 1,4 & 1,5 & 1,1 & 1 & 1 & 0,8 \\
\hline $\mathrm{V} 1(1,10 \mathrm{~m})$ & 0,6 & 0,6 & 0,5 & 0,5 & 0,4 & 0,3 \\
\hline
\end{tabular}


Tabela 25 -Valores Horários dos Parâmetros : Ri, $\phi \mathrm{m}, \mathrm{u}^{*}$, ra, rc, Qh, Qe e CWSI obtidos no dia $18 / 08$

\begin{tabular}{|c|c|c|c|c|c|c|}
\hline HORA & 11 & 12 & 13 & 14 & 15 & 16 \\
\hline $\mathrm{Ri}$ & $-0,2$ & $-0,1$ & $-0,2$ & $-0,2$ & $-0,2$ & $-0,2$ \\
\hline$\phi \mathrm{m}$ & 0,8 & 0,8 & 0,7 & 0,8 & 0,8 & 0,8 \\
\hline$u^{*}(m / s)$ & 0,4 & 0,4 & 0,3 & 0,3 & 0,3 & 0,2 \\
\hline$\Delta$ & 176,9 & 188,2 & 201,8 & 210 & 203,3 & 197,5 \\
\hline Ts - Ta & 2,8 & 2,7 & 2,3 & 1,7 & 1,8 & 0,8 \\
\hline $\mathrm{ram}(\mathrm{s} / \mathrm{m})$ & 38,2 & 36,4 & 47,8 & 49,9 & 52,1 & 70,2 \\
\hline $\mathrm{ra}(\mathrm{s} / \mathrm{m})$ & 50,1 & 47,8 & 61,2 & 63,9 & 66 & 87,2 \\
\hline $\mathrm{rc}(\mathrm{s} / \mathrm{m})$ & 56,8 & 67,7 & 63 & 91,9 & 154,5 & 286,3 \\
\hline $\mathrm{rc} / \mathrm{ra}$ & 1,1 & 1,4 & 1 & 1,4 & 2,3 & 3,3 \\
\hline CWSI (1)* & 0,2 & 0,3 & 0,2 & 0,3 & 0,4 & 0,5 \\
\hline CWSI (2) & 0,6 & 0,6 & 0,6 & 0,6 & 0,6 & 0,5 \\
\hline Qh (W.m-2) & 71,9 & 72 & 48 & 35,3 & 35,5 & 12,4 \\
\hline$Q e(W . m-2)$ & 347 & 359,5 & 358,2 & 307,6 & 207,3 & 106,1 \\
\hline
\end{tabular}

(1)* VALORES OBTIDOS CONFORME JACKSON (1982)

$(2)^{* *}$ VALORES OBTIDOS CONFORME IDSO et al. (1981) 
Tabela 26 - Valores das Temperaturas Horárias do Dossel $\left({ }^{\circ} \mathrm{C}\right)$, obtidos no dia 22/08

\begin{tabular}{|c|c|c|c|c|c|c|}
\hline HORA & 11 & 12 & 13 & 14 & 15 & 16 \\
\hline \multicolumn{7}{|c|}{ LADO IRRIGADO } \\
\hline 1 & 25,6 & 23,4 & 23,5 & 22,7 & 23,2 & 22 \\
\hline 2 & 26,1 & 25 & 25 & 22,2 & 23,9 & 21,5 \\
\hline 3 & 25,4 & 25,7 & 25,5 & 22,6 & 23,9 & 22,3 \\
\hline 4 & 25,7 & 27,3 & 25,2 & 22,9 & 23,8 & 24,2 \\
\hline 5 & 25,2 & 28,3 & 26 & 25,1 & 23,7 & 24,1 \\
\hline 6 & 25,8 & 27,1 & 26,2 & 24,7 & 22,5 & 22,7 \\
\hline 7 & 26,3 & 27,3 & 26,9 & 25,1 & 23,6 & 22,3 \\
\hline 8 & 26,1 & 26,7 & 26 & 24,9 & 21,4 & 23,7 \\
\hline 9 & 25,4 & 26,3 & 26,1 & 25,7 & 22,2 & 23,6 \\
\hline 10 & 24,8 & 27,2 & $\quad 26,9$ & 23,6 & 23,1 & 23 \\
\hline Média & 25.6 & 26.4 & 25.7 & & & 22.9 \\
\hline \multicolumn{7}{|c|}{ LADO NÁO IRRIGADO } \\
\hline 1 & 27,6 & 30,7 & 31,6 & 31,3 & 30,3 & 26,6 \\
\hline 2 & 28,9 & 31,6 & 31,2 & 31,1 & 30,4 & 29,7 \\
\hline 3 & 28,5 & 30,9 & 31 & 31,1 & 30,1 & 29,4 \\
\hline 4 & 28,9 & 30,4 & 30,1 & 30,1 & 29,1 & 28,1 \\
\hline 5 & 30,1 & 31,7 & 32 & 31,1 & 29,7 & 29,3 \\
\hline 6 & 30,1 & 31 & 31,8 & 31,3 & 30,1 & 29,5 \\
\hline 7 & 30,2 & 31,9 & 32,5 & 31,4 & 30,3 & 29,4 \\
\hline 8 & 30,7 & 32,5 & 32,8 & 31,2 & 30,5 & 29,4 \\
\hline 9 & 30,3 & 31 & 31,5 & 30 & 29,3 & 28,7 \\
\hline 10 & 28,6 & 311 & 30.5 & 29,8 & 28,3 & 297 \\
\hline Média & 29.4 & 31.3 & 31.5 & 30.8 & 29.8 & 29 \\
\hline
\end{tabular}


Tabela 27 - Valores das Temperaturas dos Bulbos Úmido e Sêco $\left({ }^{\circ} \mathrm{C}\right)$, Pressões Parciais (ea) e de Saturação do Vapor (es(T)) - kPa, da Radiação Líquida $\left(Q^{*}\right)$ e das Velocidades do Vento $(V)$ - $\mathrm{m} / \mathrm{s}$, obtidos no dia $22 / 08$ - Lado não Irrigado

\begin{tabular}{|l|rrrrrr|}
\hline HORA & 11 & 12 & 13 & 14 & 15 & 16 \\
\hline Tu1 $(1,5 \mathrm{M})$ & 17,6 & 17,1 & 17,2 & 17,5 & 17,8 & 16,9 \\
Tu2 $(2,3 \mathrm{M})$ & 16,9 & 17,2 & 16,6 & 17,7 & 17,5 & 16,5 \\
\hline Tu M $(1,85 \mathrm{M})$ & 17,2 & 17,2 & 16,9 & 17,6 & 17,7 & 16,7 \\
\hline T1 $(1,5 \mathrm{M})$ & 26 & 27,4 & 27,6 & 28,2 & 28,7 & 27,2 \\
T2 $(2,3 \mathrm{M})$ & 24,7 & 26,6 & 27,8 & 26,9 & 28,1 & 26,9 \\
\hline TM $(1,85)$ & 25,3 & 27 & 27,7 & 27,5 & 28,4 & 27,1 \\
\hline
\end{tabular}

\begin{tabular}{|l|rrrrrrr|}
\hline \multicolumn{1}{|c|}{ HORA } & \multicolumn{1}{c}{11} & 12 & 13 & 14 & 15 & \multicolumn{1}{c|}{16} \\
\hline es (Tu) & 1,97 & 1,963 & 1,931 & 2,015 & 2,023 & 1,904 \\
ea & 1,432 & 1,307 & 1,215 & 1,355 & 1,31 & 1,216 \\
es(T) & 3,238 & 3,582 & 3,721 & 3,684 & 3,873 & 3,584 \\
es(Ts) & 4,107 & 4,576 & 4,637 & 4,463 & 4,207 & 4,011 \\
es(T)-ea & 1,806 & 2,274 & 2,506 & 2,328 & 2,564 & 2,369 \\
es(Ts)-ea & 2,675 & 3,269 & 3,422 & 3,108 & 2,898 & 2,795 \\
\hline
\end{tabular}

\begin{tabular}{|c|rrrrrrr|}
\hline HORA & 11 & 12 & 13 & 14 & 15 & 16 \\
\hline$Q^{*}$ (W.m-2) & 418,9 & 431,5 & 406,3 & 342,9 & 242,8 & 118,4 \\
V2 $(1,85 \mathrm{~m})$ & & & 1,7 & 1,7 & 1,4 & 1,2 & 1,1 \\
V1 $(1,10 \mathrm{~m})$ & 1,2 & 1 & 0,8 & 0,6 & 0,4 & 0,4 \\
& & & & & & & \\
\hline
\end{tabular}


Tabela 28 - Valores Horários dos Parâmetros : Ri, $\phi \mathrm{m}, \mathrm{u}^{\star}, \mathrm{ra}, \mathrm{rc}$, Qh, Qe e CWSI obtidos no dia $22 / 08$

\begin{tabular}{|c|c|c|c|c|c|c|}
\hline HORA & 11 & 12 & 13 & 14 & 15 & 16 \\
\hline $\mathbf{R i}$ & $-0,2$ & $-0,3$ & $-0,2$ & $-0,2$ & $-0,1$ & $-0,1$ \\
\hline$\phi \mathrm{m}$ & 0,7 & 0,6 & 0,7 & 0,7 & 0,8 & 0,7 \\
\hline$u^{\star}(m / s)$ & 0,5 & 0,4 & 0,5 & 0,4 & 0,4 & 0,4 \\
\hline$\Delta$ & 213,4 & 233,9 & 239,2 & 234,1 & 233,1 & 220,7 \\
\hline Ts - Ta & 4,1 & 4,2 & 3,8 & 3,3 & 1,4 & $\quad 1,9$ \\
\hline $\mathrm{ram}(\mathrm{m} / \mathrm{s})$ & 24,3 & 28,3 & 29,8 & 36,3 & 43,4 & 45,7 \\
\hline $\mathrm{ra}(\mathrm{s} / \mathrm{m})$ & 34,9 & 39,3 & 40,1 & 47 & 55 & 57,8 \\
\hline $\mathrm{rc}(\mathrm{s} / \mathrm{m})$ & 192,1 & 213,6 & 231,5 & 228,6 & 247,4 & 788,4 \\
\hline $\mathrm{rc} / \mathrm{ra}$ & 5,5 & 5,4 & 5,8 & 4,9 & 4,5 & 13,6 \\
\hline CWSI $(1)^{\star}$ & 0,6 & 0,5 & 0,6 & 0,5 & 0,5 & 0,8 \\
\hline CWSI (2) & 0,8 & 0,8 & 0,8 & 0,7 & 0,6 & 0,6 \\
\hline Qh $(W \cdot m-2)$ & 151,1 & 140,3 & 123,7 & 91,8 & 33,8 & 43,3 \\
\hline Qe (W.m-2) & 230,1 & 252,4 & 246 & 220,2 & 187,1 & 64,5 \\
\hline
\end{tabular}

(1)* VALORES OBTIDOS CONFORME JACKSON (1982)

(2)** VALORES OBTIDOS CONFORME IDSO et al. (1981) 
Tabela 29 - Valores referentes à diferença (Ts - Ta) e es* $(T)$ - ea que orirginaram a equação de regressão para a obtenção do CWSI

\begin{tabular}{|c|c|c|c|c|c|}
\hline Ts-Ta & $\mathrm{es}^{*}(\mathrm{~T})-\mathrm{ea}$ & $\mathrm{Ts}-\mathrm{Ta}^{*}$ & $\mathrm{es}^{*}(\mathrm{~T})-\mathrm{ea}$ & $\mathrm{Ts}-\mathrm{Ta}$ & $\mathrm{es}^{*}(\mathrm{~T})-\mathrm{ea}$ \\
\hline$\wedge-2,1$ & 1.553 & $\wedge-3.2$ & 1.713 & $\wedge-3.9$ & 1.892 \\
$\wedge-3.3$ & 1.753 & $\wedge-1.8$ & 1.452 & $\wedge-1.6$ & 1.356 \\
$\wedge-5.0$ & 2.248 & $\wedge-1.5$ & 1.366 & $\wedge-1.4$ & 1.341 \\
$\wedge-5.1$ & 2.310 & $\wedge-1.9$ & 1.530 & $\wedge-1.9$ & 1.405 \\
$\wedge-4.3$ & 2.094 & $\wedge-2.6$ & 1.582 & $\wedge-1.3$ & 1.235 \\
$\wedge-5.3$ & 2.391 & $\wedge-2.9$ & 1.652 & $\wedge-1.1$ & 1.201 \\
$\wedge-1.2$ & 1.180 & $\wedge-1.3$ & 1.291 & $\wedge-1.0$ & 1.138 \\
$\wedge-2.0$ & 1.505 & $\wedge-2.1$ & 1.532 & $\wedge-1.8$ & 1.320 \\
$\wedge-3.4$ & 1.721 & $\wedge-3.5$ & 1.801 & $\wedge-1.2$ & 1.132 \\
$\wedge-3.5$ & 1.811 & $\wedge-3.6$ & 1.881 & $\wedge-1.2$ & 1.223 \\
$\wedge-4.2$ & 1.914 & $\wedge-3.7$ & 1.885 & $\wedge-2.1$ & 1.599 \\
\hline
\end{tabular}

